\title{
The Ocular Surface
}

\section{Association of Dry Eye Disease and Sun Exposure in Geographically Diverse Adult (> 40 years) Populations of India: The SEED (Sun Exposure, Environment and Dry eye disease) Study - Second Report of the ICMR-EYE SEE Study Group --Manuscript Draft--}

\begin{tabular}{|c|c|}
\hline Manuscript Number: & THEOCULARSURFACE-D-20-00172R1 \\
\hline Article Type: & Research Paper \\
\hline Keywords: & $\begin{array}{l}\text { epidemiology; Dry eye; Risk Factors; Age; Sex; Sunlight exposure; Smoking; } \\
\text { Indoor smoke exposure; Environment air pollution and geographic location; Systemic } \\
\text { factors hypertension, diabetes, BMI. }\end{array}$ \\
\hline Corresponding Author: & $\begin{array}{l}\text { Radhika Tandon, MD, FRCOphth } \\
\text { Dr Rajendra Prasad Centre for Ophthalmic Sciences, All India Institute of Medical } \\
\text { Sciences } \\
\text { New Delhi, Delhi INDIA }\end{array}$ \\
\hline First Author: & Radhika Tandon, MD, FRCOphth \\
\hline \multirow[t]{9}{*}{ Order of Authors: } & Radhika Tandon, MD, FRCOphth \\
\hline & Praveen Vashist, MD \\
\hline & Noopur Gupta, MS \\
\hline & Vivek Gupta, MD \\
\hline & Pranita Sahay, MD \\
\hline & Dipali Deka, MS \\
\hline & Sachchidanand Singh, PhD \\
\hline & K Vishwanath, MS \\
\hline & GVS Murthy, MD \\
\hline Abstract: & 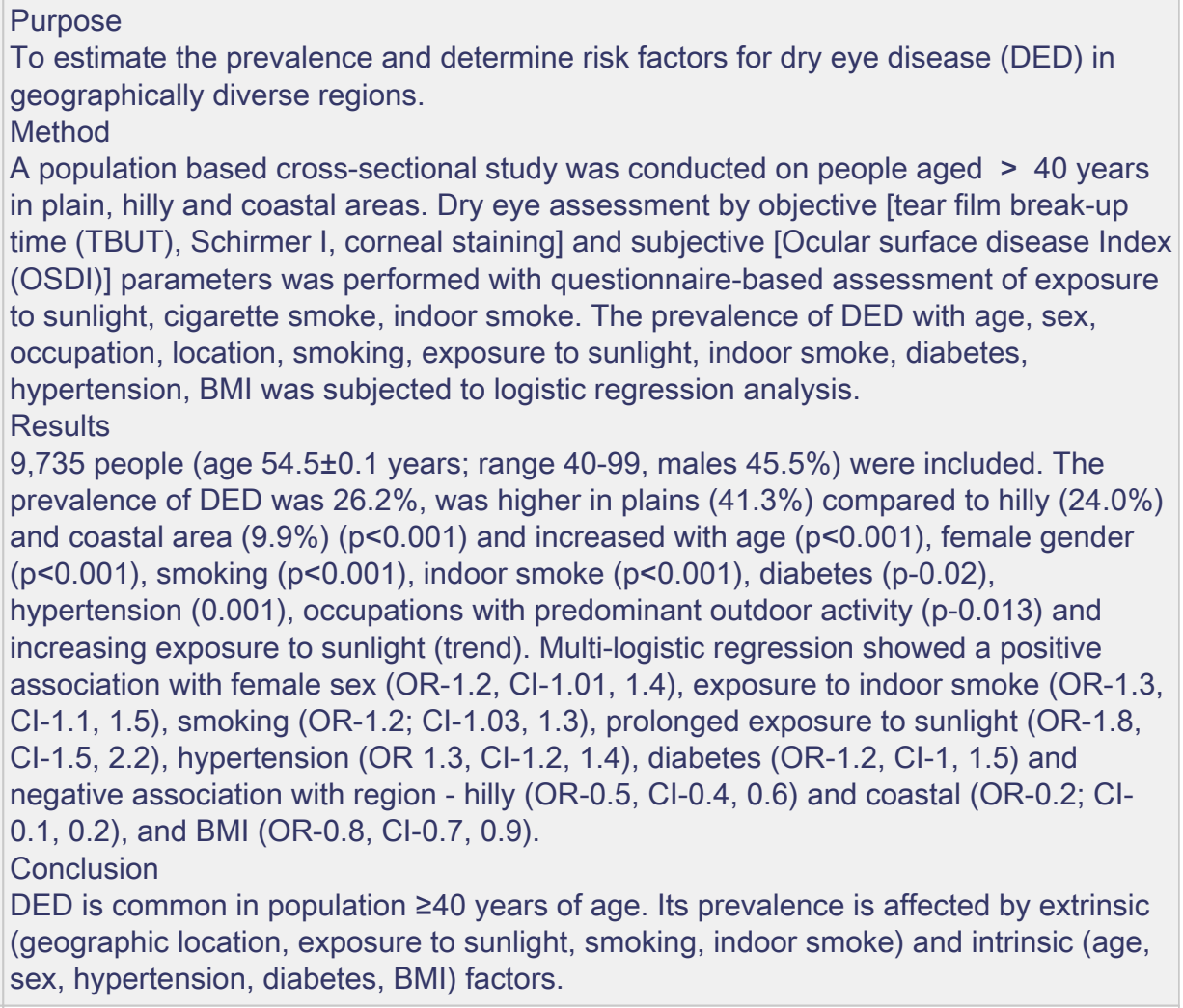 \\
\hline Suggested Reviewers: & James Chodosh, MD, MPH \\
\hline
\end{tabular}


Professor, Massachusetts Eye and Ear Infirmary

james_chodosh@meei.harvard.edu

Prof Chodosh is a renowned ophthalmologist and corneal surgeon. He has a public health background and a global perspective of Ophthalmology.

Madan Deshpande, MS

Director, H V Desai Eye Hospital, Eye Hospital, Pune, India

col.md@hvdeh.org

Senior Ophthalmologist, Teacher, Academician with special interest and extensive experience in public health, preventive ophthalmology and health promotive policies.

Opposed Reviewers:

Response to Reviewers: 
12 July 2020

To

The Editor-in-Chief

The Ocular Surface.

Subject: Submission of Revision of Manuscript of Original Research for Publication in the Journal The Ocular Surface

Dear Dr Djalilian,

I am submitting a revised version of our manuscript titled 'Association of Dry Eye Disease

and Sun Exposure in Geographically Diverse Populations of India: The SEED (Sun Exposure, Environment and Dry eye disease) Study -Second Report of the ICMR-EYE SEE Study

Group' in response to your kind consideration for publication in your esteemed journal.

The work is original and has not been submitted to any other journal. The manuscript was been prepared in accordance with the instructions to authors and all authors have contributed substantially to the work for publication and approved the final manuscript and its revised version. We have attended to the comments and suggestion provided by the Editor and Reviewers and are indeed grateful for the opportunity to improve the quality of the work.

On behalf of all the co-authors, I do hope you find the revised manuscript worthy for publication.

With regards,

Dr Radhika Tandon, MD, DNB, FRCOphth, FRCSEd

Professor of Ophthalmology, 
Dr Rajendra Prasad Centre for Ophthalmic Sciences, All India Institute of Medical Sciences, New Delhi. 


\section{Detailed Point by Point Summary of Revisions and Responses by the Authors}

\section{Editor's letter}

\section{Manuscript Number: THEOCULARSURFACE-D-20-00172}

Association of Dry Eye Disease and Sun Exposure in Geographically Diverse Populations of India: The SEED (Sun Exposure, Environment and Dry eye disease) Study - Second Report of the ICMR-EYE SEE Study Group

Dear DrTandon,

Thank you for submitting your manuscript to The Ocular Surface.

I have completed my evaluation of your manuscript. The reviewers recommend reconsideration of your manuscript following major revisions and modifications. I invite you to resubmit your manuscript after addressing the comments below. Please resubmit your revised manuscript by Jul 16, 2020.

When revising your manuscript, please consider all issues mentioned in the reviewers' comments carefully: please outline every change made in response to their comments and provide suitable rebuttals for any comments not addressed. Please note that your revised submission may need to be re-reviewed.

To submit your revised manuscript, please log in as an author at https://www.editorialmanager.com/theocularsurface/, and navigate to the "Submissions Needing Revision" folder under the Author Main Menu.

The Ocular Surface values your contribution and I look forward to receiving your revised manuscript.

Kind regards,

Ali Djalilian, MD

Editor-in-Chief

The Ocular Surface 


\section{Authors' response}

Dear Dr Djalilian,

Thank you for giving us the opportunity to revise and resubmit our manuscript. We appreciate the considerable time and effort spent by the Editor and the Reviewers in evaluating our paper and providing valuable feedback for improvement. The detailed comments have been carefully processed and major revisions undertaken accordingly. The point by point explanation of the changes is indicated in the reply along with indications of how the manuscript has been corrected.

We sincerely hope the manuscript is now acceptable for publication in the prestigious journal The Ocular Surface.

With regards,

Dr Radhika Tandon

Corresponding author 


\section{AUTHORS REPLY}

We would like to thank the editor for giving us the opportunity to revise and resubmit our manuscript and our grateful to the editor and reviewers for the helpful feedback which we found very useful and constructive in improving the reporting of our work. We are indeed grateful for this kind consideration and have revised the manuscript accordingly. We hope you find all the aspects put forth have been covered satisfactorily.

We have tried to address all the issues raised and concerns expressed and our responses to each is summarized in a point to point reply as follows:

\section{Reviewer \#1:}

This is an interesting study conducted in India which looked into several associated factors of dry eye focusing on environmental variables. The sample size is large (close to 1000) and results are valuable. The magnitude of the dry eye problem is consistent with other studies.

1. The main study findings on the importance of UV exposure and smoking support the oxidative stress hypothesis in dry eye, which is not emphasized enough in the research in the dry eye field. Perhaps the authors can comment more on that in the discussion.

Authors: We thank the reviewer for the encouraging remarks and appreciation of our work. The observation to comment about the hypothesis and mechanisms of etio-pathogenesis in the discussion has been addressed by adding a brief note about it in the discussion. $A$ paragraph highlighting the oxidative stress hypothesis has been added to the discussion-

"Oxidative stress is known to result in ocular surface changes and DED.[31,32] Both smoking and ultraviolet radiation are risk factors for increased oxidative stress and as a corollary can be considered as contributory risk factors for DED; as observed in our study. The role of smoking in oxidative damage to ocular structures resulting in dry eye, lenticular changes and retinal pigment epithelial cell changes has been reported in few studies.[31-34] Ocular exposure with ultraviolet radiation resulting in oxidative stress has been extensively 
explored in relation to corneal collagen crosslinking.[35] However, its direct impact on the ocular surface is relatively unexplored. The rise of inflammatory mediators as a consequence of oxidative stress can result in goblet cell damage and DED. Future studies evaluating changes in tear film inflammatory markers with levels of UV radiation exposure and conjunctival impression cytology can be performed to quantitatively test this hypothesis." (Page 19-20; Line 439-450)

2. These are my comments, which mainly refer to clarifying some points.

Authors: The various comments referring to clarifying some points are indeed pertinent and were very interesting to consider. Most or all of the information has been provided and incorporated as best possible to add clarity and is shown point wise below.

\section{Results}

3. Since gender is a big factor, I suggest performing additional analysis for males and females separately for see the effects of the outdoor variables (and show as supplementary tables). It is also required for harmonizing study reporting as recommended by human studies involving both sexes.

Authors: We thank the reviewer for the suggestion and for emphasizing the requirement for harmonizing study reporting as recommended by human studies involving both sexes. A supplementary table has been added showing a gender-wise multivariate analysis. The association is the same for both for most of the risk factors except indoor smoke in males and diabetes in females. (Supplementary Table 2)

Supplementary Table 2: A gender wise multi-logistic regression analysis showing association of DED with various risk factors

The results section has also been updated to reflect the salient results

"On performing additional analysis for males and females separately, gender wise multilogistic regression analysis, smoking was non-significant for both males and females, indoor smoke had a positive association in males (OR 1.7; $\mathrm{Cl}-1.4,2.0)$ only, and diabetes showed a positive association in females (OR 1.3; $\mathrm{Cl}-1.0,1.6)$ only. (Supplementary Table 2). Additional 
sub-analysis of hypertension as systolic and diastolic showed that only systolic hypertension had association with DED on multiple-logistic regression analysis. (Supplementary Table 3)." (Page 15-16; Line 326-337)

4. Separately, since the prevalence of dry eye varies between the 3 centers, I think it is good to stratify the multivariate regression using each center (stratified by area) and show in supplementary tables and comment whether the relationships of sun exposure and smoking still hold.

Authors: The results of centre wise multivariate analysis are provided in Table 5. A positive correlation of DED with sun-exposure was observed in all the three centres; however, smoking showed a positive correlation with DED in the overall population and only in DelhiNCR when assessed separately for individual centres.

Table 5: Centre-wise and overall multiple logistic regression analyses showing association of dry eye disease with various risk factors (included as Table 5 in original submission)

5. The study is sampled from clusters of about $\mathbf{5 0 0}$. If the participation rate is $81 \%$ it is quite reasonable. Is it possible to show a table of comparison between participants and non-participants in terms of age, sex, and location of address? There is always the possibility that older and more morbid cases avoid participation, so under estimating the prevalence.

Authors: It is nice that the reviewer drew attention to this aspect. An additional table has been provided below to show the age and gender composition of the participant and nonparticipant population. Also a study site wise proportion of participant and nonparticipant population is included. As can be seen in the table, an adequate proportion of recruited population in $\geq 70$ years age group participated in the study and there is nothing to suggest that older and more morbid cases were left out; hence ruling out the possibility of an underestimated prevalence. Home visits were conducted in special situations like a bed bound or moribund patient and this could perhaps be partly responsible for the good response rate observed even in the elderly group. 
"Home visits were conducted in special situations like a bed bound or moribund patient." (Page 7; Line 125-126)

"The participation was similar across age groups. (Supplementary Table 1)"

(Page 10; Line 198)

Supplementary Table 1: Demographic profile of the participant and non-participant population of the study

6. In the multiple regression, did you explore potential interaction terms such as sun exposure and pollution, or age and sun exposure, instead of using them as purely separate variables?

Authors: This is an important and interesting line of investigation. In the multivariate regression analysis, the effect of sun exposure was evaluated after adjusting for age and a positive correlation was obtained between DED and sun-exposure in the overall population as well as the individual study centres. We agree with the reviewer that exploring the interaction of pollution variables with DED could have added valuable information; however, the pollution variables were not individual specific as the data was collected at the site level and hence could not be assessed in the multivariate analysis. This point has been added in the discussion.

"Exploring the interaction of pollution variables with DED in multi-logistic regression analysis could have added valuable information. However, the pollution variables were not individual specific as the data was collected at the city level and hence could not be assessed in multi-logistic regression analysis. For the sake of scientific rigor, further validation of this aspect may be considered in future studies with long term monitoring of indoor air quality parameters of the participants using portable devices." (Page 21-22; Line 477-481)

7. The humidity readings in the Table 2 did not have SD or confidence intervals. Are these only taken once in each location? If so is it taken during the morning, mid afternoon or evening? 
Authors: The table has now been revised to include standard deviations of the humidity data. The humidity data is generally recorded every 3 hours and the daily average value is then calculated. What has been reported in the table is the annual average value obtained from the monthly averaged data and the standard deviations represent those calculated from the monthly average values. (Refer revised Table 2)

\section{In the last table multivariate regression, please indicate the list of independent} variables in the model.

Authors: The list of independent variables in the last table (Table 5) have been added in the table footnote as advised.

\section{Methodology}

\section{Since OSDI is symptom based, I wonder if there is a questionnaire used that} monitored the frequency of use of artificial tears? If there is under-usage of such eyedrops, it will increase the severity levels obtained by OSDI

Authors: It is true that the assessment of artificial tear usage could have provided additional baseline information about the population and usage or under-usage of artificial tears would affect the severity levels obtained by OSDI which is a symptom based questionnaire. The idea of this study was to primarily assess the prevalence of dry eye disease in the population studied and it was not designed to estimate disease severity. OSDI was used as a screening tool and not applied as a diagnostic criterion. Recording of usage of lubricant eye drops and exact dosage etc. are not a part of the standard OSDI questionnaire nor has been mentioned as an essential criteria to be evaluated for diagnosis of DED by the TFOS study, hence, we did not formally capture these details. Based on the clinical noting in the records less than $10 \%$ participants were using artificial tears.

"Based on the clinical noting in the records, $<10 \%$ participants were using artificial tears."

(Page 13 ; Line 258-9) 
10. Are there features of meibomian gland dysfunction on slit lamp examination? This may be a confounding or contributing factor to symptoms.

Authors: We agree that meibomian gland dysfunction could be a contributing factor to symptoms and a confounding factor for etiology of dry eye disease. Features of Meibomian gland dysfunction on slit lamp examination were evaluated clinically but the nature, pattern and extent were not however assessed in this study. This has been mentioned as a short fall in the discussion.

"Similarly, the nature, pattern and extent of Meibomian gland dysfunction (MGD) which could be a contributing factor for symptoms of DED, though evaluated clinically on slit lamp examination, was not analysed. Also, hyperlipidaemia which has been reported to be associated with MGD and DED was not assessed as part of this study. These aspects have been included in the ongoing phase 2 of the study." (Page 23; Line 516-520)

11. What are the frequencies of allergies such as sinusitis, eczema and asthma in this study? Most of the symptoms of OSDI are not specific and can be contributed by other OSD. Please discuss this

Authors: Although specific questions were not asked for sinusitis, eczema and asthma; a separate question was asked for presence of any known systemic illness for which 51 participants reported a history of asthma, 3 participants reported having skin allergy and 1 reported for sinusitis. This has been added to the text as follows:

"Allergic conditions like asthma, skin allergy and sinusitis were observed in $0.56 \%$ of the participants $(n-55 / 9,735)$. Asthma was the most common condition noted in the participants with allergic conditions ( $n-51 / 55)$." (Page 11; Line 206-208)

We concur with the reviewer's concern regarding occurrence of OSDI symptoms from ocular surface disorders other than DED, hence we used both TBUT and OSDI for diagnosis of DED in the current study. As advised we have added this in the discussion.

“However, as symptoms of OSDI are non-specific and can occur due to any ocular surface disorder, it can be fallacious to rely on OSDI as a sole criterion for diagnosis of DED; hence 
the TFOS DEWS II criteria were applied that take into consideration clinical signs in addition to symptoms for DED diagnosis." (Page 16-17; Line 352-359)

12. Are there any questions related to sleep quality? This has been shown to be associated with symptoms of dry eye even after adjusting for hypertension, etc.

Authors: Regrettably there were no questions for sleep quality included in the study. The concept has recently come to the fore with few studies having shown an association between sleep disorder and dry eye disease. A proper assessment of sleep disorder would require use of validated sleep questionnaire like Pittsburgh Sleep Quality Index (27 questions) or the Epworth Sleepiness Scale (8 questions). As this was a large population based survey with 4 independent forms to be filled for each participant taking over one hour per participant for complete evaluation, hence its incorporation was not feasible as it was considerably increasing the time required for evaluation per participant. This has been added in the discussion for completeness.

“Recently, an association between sleep disorder, physical activity, stress factors and depression with DED has come to fore. Additional data on sleep parameters could have added to the study; however a proper assessment of sleep disorder requires use of validated sleep questionnaire like Pittsburgh Sleep Quality Index (27 questions) or the Epworth Sleepiness Scale (8 questions).[54,55] As this was a large population based survey with 4 independent forms to be filled requiring over one hour per participant for complete evaluation, hence its incorporation was not considered feasible."(Page 22-23; Line 495-505)

\section{Similarly are there data here on the use of CNS drugs like opioid drugs and antidepressants?}

Authors: We regret to inform, there is no detailed information available on the use of CNS drugs like opioid drugs and antidepressants. There were very few patients who had a positive history for CNS or neuropsychiatric disorders like stroke (n-9), seizure (n-4), and Parkinson's disease (n-3), anxiety disorder (n-2) and depression ( $n-1)$. 
The cases with Parkinson's disease were on treatment while the rest of them were not on any therapy at the time of examination, hence to make an inference from the above is difficult. This information has been added in results.

"A detailed individual drug history for central nervous system (CNS) drugs like opioids and anti-depressants was not obtained separately in this study. However, a positive history for CNS or neuropsychiatric disorders was obtained in participants as follows: stroke (n-9), seizure (n-4), Parkinson's disease (n-3), anxiety disorder (n-2) and depression (n-1) of whom only those with Parkinson's disease were on treatment at the time of examination." (Page 14-15; Line 296-301)

\section{Just to clarify:}

14. Lifetime Effective Sun Exposure $=\Sigma$ [Daily hours of sun exposure without head gear + (Daily 136 hours of sun exposure using head gear x protection factor)] x 365 x Number of years. Is the number of years referring to the age? If not how is the participant able to estimate the number of years?

Authors: The assessment was based on the Melbourne visual impairment project model. The number of years refers to the years after the person crossed the age of 15 till the time of examination (so effectively current age in years-15). The average hours of exposure per day was enquired about along with use of any sun protection. In case, there was a change of occupation or lifestyle resulting in an increase or decrease of sun exposure in the past, it was separately documented with the number of years and was summed up to calculate the lifetime effective sun exposure.

"The number of years refers to the duration from the time respondent crossed the age of 15 years and the time of examination (current age - 15)." (Page 9; Line 160, 163-4) This is the format in which the sun exposure details were obtained: 


\section{PRESENT ACTIVITY}

1. What type of work are you mainly involved in throughout the day? (Multiple responses possible)

आप की प्रत्येक दिन की दिनचर्या क्या है? (एक से अधिक उत्तर संभव)

1. Agricultural work ( खेती का कार्य)

2. Outdoor Non Agricultural Work (घर के बाहर अन्य कार्य)

3. Indoor work (घर के अन्दर का कार्य)

2. For how many years have you been doing this kind of work? आप यह कार्य कितने वर्षो से कर रहे हैं?

$$
\text { years (वर्ष) }
$$

3. How many hours do you usually spend outdoor after sunrise and before sunset? (9:00 AM to 5:00 PM) Record in decimal form (eg: 1:30hr $=1.5 \mathrm{hr}$ ) आप सूरज निक्लने से सूरज डूबने तक प्रायः कितने घंटे घर से बाहर बिताते हैं ? (सुबह 9:00 बजे से शाम 5:00 बजे तक) $0=\mathrm{Ni}$ (कुछ नही)

$$
\text { hours ( घटे) }
$$

4. For how many hours are you usually outdoors in the middle of the day? (From 11:00 AM to 3:00 PM)

आमतौर पर आप दोपहर में कितने घंटे घर से बाहर बिताते है? (सुबह 11:00 बजे से दोपहर $3: 00$ बजे तक)

$$
\text { hours ( घंटे) }
$$

5. What type of head gear or eye gear do you nomally wear when outside b/w 9 AM to 5 PM?

आमतौर पर आप जब धूप में जाते है तो सूबह $9: 00$ बजे से $5: 00$ बजे तक सिर व आँख ढ़कने के लिए क्या इस्तेमाल करते है ? Record in decimal form ( eg: $1: 30 \mathrm{hr}=1.5 \mathrm{hr}$ )

0. None ( कुछ नही )

घंटे प्रति दिन

1. Veil/ Dupatta/Saree pallu/Ghunghat(बूरका / दूषट्टा / साड़ी पल्लू / घूँघट) ..........

2. Pagdi/saroopa/ mundas /towel( पगड़ी / सरूपा / मुंडास / तौलीया )

3. Umbrella( छाता )

4. Cap ( टोपी)

5. Sunglasses/prescription glasses (धूप का चश्मा / नम्बर वाला चश्मा ) 66. Others अन्य (उल्लेख करें)

\section{PAST ACTIVITY}

6. Were you doing some other work in the past? Multiple responses possible क्या आप इसके पहले दूसरा काम करते थे?

(एक से अधिक उत्तर संभव)

0 . Not applicable ( लागू नही)

1. Agricultural work ( खेती का कार्य)

2. Outdoor Non Agricultural Work ( घर के बाहर अन्य कार्य)

3. Indoor work ( घर के अन्दर का कार्य)

7. For how many years did you follow this routine? आप ने यह कार्य कितने वर्षो तक किया था? - years ( वर्ष)

8. How many hours did you usually spend outdoor after sunrise and before sunset? (9.00am to 5.00PM) Record in decimal form ( eg: $1: 30 \mathrm{hr}=1.5 \mathrm{hr}$ ) आप सूरज निकलने से सूरज डूबने तक प्राय: कितने घंटे घर से बाहर बिताते थे? (सुबह 9:00 बजे से शाम 5:00 बजे तक) $0=\mathrm{Nil}$ (कुछ नही) hours ( घंटे)
9. For how many hours were you usually outdoors in the middle of the day. (From 11:00 AM to 3:00 PM) आमतौर पर आप दोपहर में कितने घंटे घर से बाहर बिताते थे? (सूबह 11:00 बजे से दोपहर 3:00 बजे तक) hours (घंटे)

10. What type of head gear or eye gear did you normally wear when outside b/w 9:00 AM to $5: 00 \mathrm{PM}$ ?

आमतौर पर आप जब धूप में जाते थे तो सूबह 9:00 बजे से शाम 5:00 बजे तक सिर व आँख ढ़कने के लिए क्या इस्तेमाल करते थे? Record in decimal form (eg: 1:30hr =1.5hr)

0. None ( कुछ नही ) घंटे प्रति दिन

1. Veil/ Dupatta/Saree pallu/ Ghunghat( बूरका / दूपट्टा / साड़ी पल्लू / घूँघट )

2. Pagdi/saroopa/ mundas /towel( पगड़ी / सरूपा / मुडास / तौलीया )

3. Umbrella ( छाता )

4. Cap ( टेपी)

5. Sunglasses/prescription glasses ( धूप का चश्मा / नम्बर वाला चश्मा ) 66. Others अन्य (उल्लेख करें)

\section{REMOTE PAST ACTIVITY}

11. Were you doing some other work in the past? (Multiple responses possible) क्या आप इसके पहले दूसरा काम करते थे? (एक से अधिक उत्तर संभव)

0 . Not applicable ( लागू नही)

1. Agricultural work ( खेती का कार्य)

2. Outdoor Non Agricultural Work ( घर के बाहर अन्य कार्य)

3. Indoor work ( घर के अन्दर का कार्य )

12. For how many years did you follow this routine? आप ने यह कार्य कितने वर्षो तक किया था ?

$$
\text { years ( वर्ष) }
$$

13. How many hours did you usually spend outdoor after sunrise and before sunset? (9.00AM to 5.00PM) Record in decimal form (eg: $1: 30 \mathrm{hr}=1.5 \mathrm{hr}$ ) आप सूरज निक्लने से सूरज डूबने तक प्रायः कितने घंटे घर से बाहर बिताते थे?

(सुबह 9:00 बजे से शाम 5:00 बजे तक) $0=\mathrm{Nil}$ (कुछ नहीं)

$$
\text { hours ( घंटे ) }
$$

4. For how many hours were you usually outdoors in the middle of the day. (From 11:00 AM to 3:00 PM) आमतौर पर आप दोपहर में कितने घंटे घर से बाहर बिताते थे? (सूबह 11:00 बजे से दोपहर $3: 00$ बजे तक)

$$
\text { hours ( घंटे) }
$$

15. What type of head gear or eye gear did you nomally wear when outside b/w $9 A M$ to5PM?

आमतौर पर आप जब धूप में जाते थे तो सुबह 9:00 बजे से शाम 5:00 बजे तक सिर व ऑँख ढ़कने के लिए क्या इस्तेमाल करते थे?

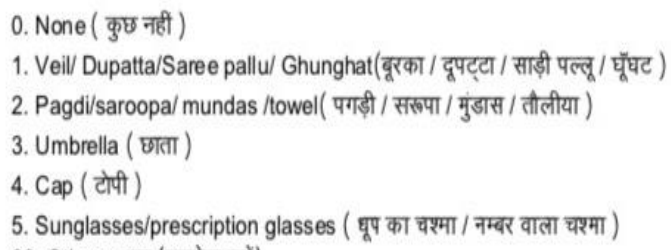

घंटे प्रति दिन

...............

..............

...............

...............

................ 
15. Is type of occupation one of the questions? (for example indoor factory workers vs indoor secretaries? Some exposure to chemical is possible in specific occupations.) Since 82.2\% of participants have outdoor occupations, it should be mentioned in the discussion that this study may not be optimal to evaluate indoor pollution and other similar factors Authors: Yes, type of occupation was part of the questionnaire. The following was the list of occupations into which the participants were classified-

1. House work

2. Cultivator

3. Agricultural labourer

4. Non Agricultural labourer

5. Skilled worker

6. Office Job (Class I)

7. Office Job(Class II/III)

8. Office Job(Class IV)

9. Business

10. Professional (Doctor, Engineer, Lawyer etc.)

11. Unemployed

12. Retired/ Not working because of old age

13. Not working because of handicap/ sickness

14. Student

15. Not applicable

16. Others (specify)

Further the activity was divided based on their responses into primarily indoor or outdoor. There was no obvious history of occupational exposure to chemicals reported by the participants though details were not specifically obtained.

"Occupation was classified as primarily indoors or outdoors" (Page 7; Line 115) 
"No definitive history of occupational exposure to chemicals was reported by any

of the participants." (Page 10; Line-201-202)

\section{Are ozone and hydrocarbon levels measured in the study locations?}

Authors: The ozone and hydrocarbon values were not measured at these locations during the study period.

17. Are there any measures of air flow rate? If there is a higher flow in coastal and hilly areas, may explain a reduced exposure of the ocular surface to some air pollutants.

Authors: Yes, measures of the air flow rates are available and have been mentioned as average wind speed in the table. The average wind speed is highest in the coastal region $(8.4 \mathrm{Km} / \mathrm{h})$ followed by the plain region in Delhi $(6.5 \mathrm{Km} / \mathrm{h})$ and minimum in hilly region Guwahati $(3.4 \mathrm{Km} / \mathrm{h})$. This may explain a reduced exposure of the ocular surface to some air pollutants and this has been added in the discussion.

"Also, the average wind speed was highest in Prakasam (Southern coastal). This may explain a reduced exposure of the ocular surface to some air pollutants and resultant low prevalence of DED. " (Page 21; Line 460-462)

18. Are there data on second hand smoke versus smoking, or current smokers vs past smokers, or heavy smokers vs lighter smokers?

Authors: Yes, the data for past and current smokers as well as light and heavy smokers is available. Participants with current smoking constituted $80.9 \%$ while $19.1 \%$ of the participants had history of smoking in the past.

In our study, smoking was defined as use of any smoked tobacco product like cigarette, bidi, hukkah etc. and hence classifying all of them into heavy and light smokers is difficult. However, among the participants using cigarettes, $59.5 \%$ of the participants were heavy smokers ( $>=5$ cigarettes per day) while $40.5 \%$ were light smokers ( $<5$ cigarettes per day). 
"Smoking was reported by $36.8 \%$ of the participants with $80.9 \%$ participants being

current smokers. Among the participants with history of cigarette smoking, 59.5\% participants were heavy smokers ( $\geq 5$ cigarettes/day)." (Page 11; Line - 208-210)

\section{Is cosmetic use or contact lens wear documented in the women?}

Authors: Since the study was planned for rural Indian population aged 040 years, contact lens use was not a part of our questionnaire as it is not routinely used in this section of the population. Based on the clinical records, none of the patients reported use of contact lenses. Use of cosmetics in women is again not common in rural populations above 40 though it was not specifically documented. This aspect has been listed as a short fall.

"In addition, data on usage of contact lens, eye cosmetics and visual display unit would have been of additional interest; however they are not commonly used in the rural Indian population aged $\geq 40$ years studied, hence could not be separately assessed as a part of this study" (page 23, line 496-499)

20. I agree it is useful to know the type of anti-hypertensive medications in those with and without dry eye.

Authors: We thank the reviewer for understanding our concern.

\section{The study is conducted in three different regions from 2010 to 2016 . Are the three} regions performed at the same time or one after another?

Authors: Yes, the study was conducted simultaneously at the same time in the three different regions between 2010 and 2016.

22. In multivariate regression, are height, weight and blood pressure entered into covariates?

Authors: Blood pressure has been added as a covariate in multiple regression analysis and was found to have a positive association with DED (Table 5). As height and weight are continuous variables and it is difficult to categorise the patients on its basis, BMI, a composite measure has been added as a covariate in the univariate analysis as well as 
multiple logistic regression analysis for assessing its association with DED (Tables 4 and 5). It was observed that high BMI had a negative association with DED.

"The prevalence of DED was higher in participants with $\mathrm{BMI}<25(27.8 \%)$ when compared to those with $\mathrm{BMI} \geq 25$ (22.4\%) ( $p<0.001)$." (Page 14; Line 294-5)

23. Are the questionnaires participant or interviewer administered? Are there cases where translation of the questionnaires are required? If so are there more than one language version of the questionnaire?

Authors: The questionnaires were interviewer administered. Yes, translation of questionnaire was required into Hindi, Telugu and Assamese for the convenience of comprehension of both the interviewer as well as the participants in the three study centre. The interviewers were initially trained following which a pilot study was conducted at each centre. Kappa value was calculated to assess the inter-observer variation and was found to be within the normal range.

"The questionnaire was translated into the three local languages (Assamese, Hindi and Telugu) and piloted to confirm that the items were comprehensible. These versions were then back translated into English by independent sets of translators conversant with the respective languages. The initial and back-translated versions were compared to assess linguistic validity. As it was a validated questionnaire, face validation with experts was done. The questionnaire was administered by trained interviewers. Kappa values were calculated to assess the inter-observer variation and were found to be within the acceptable range."

(Page 8; Line 144-151)

\section{Discussion}

24. Are there any data on BMI or amount of physical exercise, which may be proxies for general state of health? It is now believed that dry eye is a chronic holistic disease, so people who outdoor and more sun exposure could have more physical exercise (or less sedentary lifestyle) and therefore less dry eye? Refer to studies related to BDNF and stress 
hormones. Currently it is not known whether behavioral modification is purely for the sun exposure or for more physical exercise, more balanced diet, etc.

Authors: Yes, data for BMI is available and details regarding the same have been added to the manuscript in table 4, table 5, and supplementary tables 2 and 3.

"Body mass index (BMI) was calculated as weight in kg divided by the square of height in metres." (Page 8; Line 133-134)

"The BMI was $\geq 25$ in $24.9 \%$ of the participants $(n-2425 / 9,735)$ "

(Page 11; Line 207-208)

"The prevalence of DED was higher in participants with $\mathrm{BMI}<25(27.8 \%)$ when compared to those with BMI >= 25 (22.4\%) ( $p<0.001) . "$ (Page 15; Line - 294-295)

We agree with the reviewer that recently DED is being considered a chronic holistic disease with emphasis on stress factors and depression as a risk factor. In our study only one case suffered from depression and data for physical activity was not collected. However, as data for $\mathrm{BMI}$ and occupation involving predominant outdoor activity was available, we tried to correlate both these factors. A lower proportion of participants engaged in outdoor activity had BMI >25 which maybe an indirect indicator of better physical fitness in these cases. But the prevalence of DED was higher in participants with outdoor activity. Hence, in the absence of direct data for physical activity, it is difficult to conclusively comment on the same from our study. We have added the following discussion to the manuscript:

"Recently, an association between sleep disorder, physical activity, stress factors and depression with DED has come to fore. Additional data on sleep parameters could have been added to the study; however a proper assessment of sleep disorder requires use of validated sleep questionnaire like Pittsburgh Sleep Quality Index (27 questions) or the Epworth Sleepiness Scale (8 questions).[54,55] As this was a large population based survey with 4 independent forms to be filled requiring over one hour per participant for complete evaluation, sleep assessment was not considered feasible. In the current study, only one case suffered from depression. Detailed data for physical activity per se was not collected, hence it is not possible to comment on the relationship from our study. In addition, data on 
usage of contact lens, eye cosmetics and visual display units would have been of additional interest; however as these are not commonly used in the rural Indian population aged $\geq 40$ years studied, hence they could not be separately assessed." (Page 22-23; Line 487-499)

25. The current discussion is mainly on sex and age. There should be more discussion on the other factors, since the strength of this study is on outdoor factors.

Authors: We thank the reviewer for the suggestion. More discussion on the other factors has been incorporated in the discussion

- Oxidative stress, smoking, ultraviolet radiation: line 415

- Wind speed: line 461

- Pollution: line 462

- Physical Activity: Line 488,494

26. Is systolic or diastolic hypertension significant on multivariate after adjusting for other diseases? If not this could be confounded by hyperlipidemia. Since the hypertensive may have more lipidemia which than be associated with MGD or other unknown variables.

Authors: Both systolic and diastolic hypertension were found to be significantly correlated with DED in single variate analysis and hence added to the multivariate analysis in addition to other factors. Only systolic blood pressure was positively associated with DED in multivariate regression analysis.

"Additional sub-analysis of hypertension as systolic and diastolic showed that only systolic hypertension had association with DED on multiple-logistic regression analysis.

(Supplementary Table 3)." (Page 16; Line 326-328)

Supplementary Table 3- Multivariate regression analysis showing correlation of Dry eye disease with various risk factors including systolic and diastolic hypertension

We agree with the reviewer that hyperlipidaemia could be associated with MGD that could precipitate dry eye. However, data for the same was not collected, hence it is difficult to 
comment on this association on the basis of our data. This element has been added in the discussion

"Also, hyperlipidaemia which has been reported to be associated with MGD and DED was not assessed as part of this study." (Page 23; Line - 501-502)

\section{REVIEWER \#2:}

The study titled "Association of Dry Eye Disease and Sun Exposure in Geographically Diverse Populations of India: The SEED (Sun Exposure, Environment and Dry eye disease) Study - Second Report of the ICMR-EYE SEE Study Group" is a very interesting read. The authors can address the following issues to improve the quality of the manuscript:

Authors: We are grateful to the reviewer for taking interest in our paper and providing a list of issues to address to improve the quality of the manuscript. The action taken is explained point by point as follows-

1.If the OSDI questionnaires were administered in the local language, were the translated questionnaires validated? Was any Rasch analysis done for the translated questionnaires, that has been published previously? The OSDI is one of the main pillars of the diagnostic criteria, and there should be no uncertainty regarding its reliability.

Authors: The OSDI was translated into Hindi, Telegu and Assamese and then back translated into English. No discrepancy was observed in the process of translation and back translation. Both forward and backward translation was done and reviewed by experts in these language. Since only the translated original validated OSDI questionnaire was used, Rasch analysis was not performed. Also, various studies have previously reported the use of validated OSDI questionnaire in Indian population. These details have been added in the manuscript as follows:

"The questionnaire was interviewer administered and was translated into local language for convenience of comprehension to both the interviewer as well as participants in the three study centres. The questionnaire was translated into three Indian languages (Assamese, Hindi and Telugu) and then back translated into English by independent sets of translators 
conversant with the respective languages. As it was a validated questionnaire, face validation with experts was done. The interviewers were initially trained following which a pilot study was conducted at each centre. Kappa values were calculated to assess the interobserver variation and were found to be within the acceptable range." (Page 8; Line 144-51)

2. In the Abstract, Schirmer I is mentioned but in the definition of Dry Eye Disease in the text, there is no mention of whether Schirmer was done or if it was used for diagnosis? "OSDI was used as a screening test and participants with OSDI score $\geq 13$ with either TBUT<10 seconds or evidence of ocular surface staining were defined as having DED."

Authors: Schirmer I test was done for all cases and this has now been added in the text in methods. Schirmer I was not used for diagnosis. The diagnosis of DED was based on diagnostic criteria of TFOS DWES II which uses Dry eye questionnaire as a screening tool and TBUT, corneal staining or tear osmolarity for diagnosis. Tear osmolarity was not performed in this study so the objective criteria used were either TBUT $<10$ s or evidence of ocular surface staining. This has now been explained more clearly.

"Diagnosis of dry eye disease (DED) was based on the guidelines defined by TFOS DEWS II which uses Dry eye questionnaire as a screening tool and TBUT, corneal staining or tear osmolarity for diagnosis. [1] OSDI was used as a screening test and participants with OSDI score $\geq 13$ were further assessed with objective tests that included TBUT and ocular surface staining. Tear osmolarity was not performed in this study. Hence, cases with OSDI $>13$ and either TBUT<10s or evidence of ocular surface staining were defined as having DED."

(Page 8; Line 137-142)

3. The authors should also elaborate on how TBUT was done. Is this Fluorescein break-up time? Or Non-invasive break-up time? How was this done in the community, using a hand-help slit lamp? If fluorescein break up was done with a cobalt blue light was it done in low-light conditions or done outdoors (is it possible to be done outdoors in daylight 
with the blue light?) Because of this criteria used, it is impossible to differentiate between evaporative, mixed or aqueous deficiency dry eyes. This is very crucial missing data.

Authors: It is good that the reviewer noted that this was not adequately explained. The details of TBUT examination have now been added in the methodology section:

"All cases underwent a detailed ophthalmic evaluation including uncorrected visual acuity (UCVA) and corrected distance visual acuity (CDVA) on ETDRS chart, intraocular pressure, Schirmer I, slit lamp examination, tear film break-up time (TBUT), ocular surface staining, anterior segment examination and indirect ophthalmoscopy for fundus evaluation in a local indoor clinic set-up at the study site. TBUT was assessed the help of a hand-held slit lamp using cobalt blue filter after instillation of fluorescein stain. Home visits were conducted in special situations like a bed bound or moribund patient." (Page 7; Line 120-126) "TBUT $<10$ seconds was noted in $34.5 \%$ of cases, Schirmer I $<5 \mathrm{~mm}$ in $27.5 \%$ and fluorescein staining in $1.7 \%$ of the population." (Page 12; Line 245-247)

4. Is it possible to have OSDI more than 13 , TBUT less than 10 and no corneal staining? TFOS DEWS II recommends both symptoms and signs have to be present to be classified as DED, symptoms without signs is possible neuropathic pain and not DED. The statement in the results that "Considering an abnormal OSDI score $(\geq 13)$ as a sole criterion, the prevalence of dry eye symptoms was observed in $66.4 \%$ (95\% Cl: $65.4 \%-67.3 \%)$ of the population" is not justified, this cannot be considered dry eyes.

Authors: Yes, it is possible to have TBUT $<10$ and OSDI $>13$ in the absence of corneal staining. In fact only $1.7 \%$ of the participants in the current study showed corneal staining. We agree with the reviewer that OSDI cannot be used as a sole diagnostic criteria for DED and that the symptoms can be due to other causes as well. The sentence was written to highlight that if one went by OSDI alone, a very large percentage of people has such symptoms in the study population. The statement has now been modified as it appears it was conveying an erroneous impression from what we intended to communicate.

"An abnormal OSDI score ( $\geq 13$ ) was observed in $66.4 \%$ (95\% Cl: $65.4 \%-67.3 \%)$ of the population." (Page 12; Line 246-247) 
However, it should be noted that a lot of studies in the past have used OSDI as the only criteria and hence to provide a comparative view the statement of OSDI based results is felt to be necessary. But, considering the fallacy of using it as the only criteria, our study used the TFOS DEWS II for diagnosis of DED as it considers both symptoms as well as signs and therefore is more reliable. This has been made more clear now to avoid confusion.

5.The inclusion criteria clearly states that the patients were $>40$ years of age, but this is not mentioned in the title. In India $>\mathbf{7 0} \%$ of the population is LESS than $\mathbf{4 0}$ years old. So it is unfair to say that this sample is representative of the Indian population, at most the authors can claim that they have sampled middle aged and older Indians. If DED has a bimodal distribution the authors would not be able to pick it up. The data derived a sample representative of less than $30 \%$ of the country's population cannot be extrapolated to a population that largely has the opposite age demographics. The title should be changed for accuracy and the authors should explain why they did not chose a sample representative of the population.

Authors: We agree with the reviewer, hence the title of the study has been revised to:

"Association of Dry Eye Disease and Sun Exposure in Geographically Diverse Adult ( $\geq 40$ years) Populations of India: The SEED (Sun Exposure, Environment and Dry eye disease) Study - Second Report of the ICMR-EYE SEE Study Group"

While it is true that the population chosen was not representative of the entire country's population, however it is important to understand that an important objective of the study was to assess the impact of sunlight and pollution exposure on ocular health. Using a lower cut-off age for recruitment of participants would not have allowed us to explore the effect of these factors which are expected to affect the eye slowly and gradually over time. Also, this work and report is part of a wider study where the other ocular parameters assessed in included cataract (published as the first report).

6. A recent hospital-based study also looked at the association between the presence of dry eye and sociodemographic factors (Incidence, demographics, types and risk factors of dry eye disease in India: Electronic medical records driven big data analytics report I. Ocul 
Surf. 2019;17(2):250-256.), many of the risk-factors identified were similar to the current study, but it has not been cited. Irrespective of the study design it deserves mention. Why did the authors not ask about screen time or use of VDUs?

Authors: We regret the error. The details of this study have been added in the manuscript. "It is interesting that these findings are also reflected in a hospital based study from India where an age and gender stratification showed that males were more frequently affected during the $2^{\text {nd }}$ and $3^{\text {rd }}$ decade of life, while females were more affected during $4^{\text {th }}$ and $5^{\text {th }}$ decade of life, and the sex differences were insignificant beyond the age of 60 years. [22]" (Page 18; Line 375-379)

Regarding the assessment of VDUs, we agree with the reviewer that it is an important risk factor for DED in the current scenario; however it is also important to understand that this study was conducted in rural India wherein resources are limited and use of VDUs is rare. Hence, we presumed asking a separate question related to it may not yield any additional information. This has been mentioned in the discussion as a shortcoming.

"In addition, data on usage of contact lens, eye cosmetics and visual display unit could have provided additional results; however as they are not commonly used in rural Indian population aged $\geq 40$ years, hence was not separately assessed as a part of this study." (Page 23; Line 495-498)

7. The presentation of the data is very text-heavy, there are no visualizations in the form of figures/charts that readers can glance at and quickly grasp the findings of the study. Authors: We are grateful for this practical tip. Four figures have now been added to the manuscript for improving the readability and easy comprehension of the results.

Figure 1 Flowchart showing the study methodology

Figure 2 Bar-graph showing age-wise stratified prevalence of dry eye disease in males and females

Figure 3 Stratification of the overall participants and participants with dry eye disease based on gender, site of residence and occupation 
Figure 4 Stratification of the overall participants and participants with dry eye disease based on risk factors of smoking, sun-exposure and exposure to indoor smoke.

8. How did the authors decide on the three geographical areas? What was the rationale used? India has close to $\mathbf{3 0}$ states, these three regions hardly represent $\mathbf{3}$ states that account for $10 \%$ of the country's population. The heterogeneity in the prevalence between the three areas itself points towards the selection bias. "Delhi NCR (Northern plains) had the highest prevalence (41.3\%) followed by Guwahati (North-eastern hilly) (24\%) and Prakasam (Southern coastal) (9.9\%)." A range between 9.9\% to $41.3 \%$ is very wide and the possible causes for this variation should be discussed.

Authors: One of the main objectives of the study was to assess ocular health in different geographical locations of varying latitude, altitude and distance from the sea. Hence, districts with different environmental and climatic conditions were selected. Also, consideration was given to sites where reliable environmental data was available to the investigators.

High altitude and coastal region have a high ultraviolet radiation exposure, hence they were required to check for its correlation. While it is true that these three regions are very limited and hardy represent a small fraction of the country, they were chosen specifically and selectively to represent three distinct geographical areas to test the hypothesis that different environments do have different effects. The wide range is noticeable and the possible causes for this variation have been added in discussion. This includes various factors including UV radiation, sunlight, pollution, humidity, temperature and wind velocity etc which all have been highlighted in the discussion in relation to the variable prevalence of DED in the three study locations.

9. Delhi NCR is a state, Guwahati is a city and Prakasam is a district. I cannot understand the logic behind selecting these 3 sites. Either $\mathbf{3}$ cities or three districts or three states should have been sampled.

Authors: We are thankful that the reviewer's suggestion corroborates with what has been done, that three districts would be appropriate and are sorry if the choice of study locations 
was not clear enough as described. Three rural districts have been sampled. All the three study locations were individual districts, each in a different geographical location identified by name which was the most prominent locality. Districts were chose to have uniformity as correctly pointed out by the reviewer. Gurgaon district of Delhi NCR, is a district, and was the chosen study location as representative for northern plains and for convenience and easy understanding has been referred to as Delhi NCR (which it is a part of) as has been now more clearly mentioned in the methodology. The study in hills was done in Kamrup district of Guwahati considering that it is a part of the same district and a well-known place that can be easily related by readers. Prakasam district was chosen to represent the southern coastal region. Another very important consideration in choosing the regions was to have sites for which the physical and environmental data was reliably available.

\section{"A multi-centric population based cross-sectional study was conducted at three} geographically diverse places in rural settings of India between 2010 and 2016. Important considerations in choosing the study sites were, to have representation of plains, hilly and coastal areas, and sites should have readily available physical and environmental data. Gurgaon district of National Capital Region (NCR) Delhi, was chosen as representative for northern plains (henceforth referred to as Delhi NCR). The study in hills was done in Kamrup district located adjacent to Guwahati, capital city of the state of Assam (henceforth referred to as Guwahati). Prakasam district was chosen to represent the southern coastal region." (Page 6; Line 90-97)

10. What is the authors hypothesis behind the association between sun exposure and dry eyes? Does sun exposure affect the lacrimal or meibomian glands?

Authors: We hypothesise that sun exposure and other environmental factors result in oxidative stress that causes release of various inflammatory markers. This in turn can damage the conjunctival goblet cells resulting in dry eye disease. Therefore, future studies with tear inflammatory markers and conjunctival impression cytology can be planned along with obtaining history for sun exposure for a better insight in this field. We are not sure of the impact of sun exposure on the meibomian or lacrimal glands and this would require 
further study. These concepts have now been mentioned in the discussion for better understanding.

"Oxidative stress is known to result in ocular surface changes and DED.[31,32] Both smoking and ultraviolet radiation are risk factors for increased oxidative stress and as a corollary can be considered as contributory risk factors for DED; as observed in our study. The role of smoking in oxidative damage to ocular structures resulting in dry eye, lenticular changes and retinal pigment epithelial cell changes has been reported in few studies.[31-34] Ocular exposure with ultraviolet radiation resulting in oxidative stress has been extensively explored in relation to corneal collagen crosslinking. [35] However, its direct impact on the ocular surface is relatively unexplored. The rise of inflammatory mediators as a consequence of oxidative stress can result in goblet cell damage and DED. Future studies evaluating changes in tear film inflammatory markers with levels of UV radiation exposure and conjunctival impression cytology can be performed to quantitatively test this hypothesis and also explore any effects on the meibomian or lacrimal glands." (Page 1920; Line 414-425)

\section{Additional Corrections made by the authors}

Incorporating the additional information (generated by further analysis) in the abstract exceeded the word limit. Hence some minor editorial corrections have been made to adjust the text to remain within 250 words. 
1 Association of Dry Eye Disease and Sun Exposure in Geographically Diverse Adult ( $\geq 40$

2

3

4

5

6

7 Radhika Tandon ${ }^{1}$, Praveen Vashist ${ }^{1}$, Noopur Gupta ${ }^{1}$, Vivek Gupta ${ }^{1}$, Pranita Sahay ${ }^{1}$, Dipali

8

$9{ }^{1}$ Dr. Rajendra Prasad Centre for Ophthalmic Sciences, AlIMS, New Delhi, India

$10 \quad{ }^{2}$ Regional Institute of Ophthalmology, Guwahati, India

11

$12{ }^{4}$ Pushpagiri Vitreo Retina Institute, Secunderabad, Telangana, India

135 Indian Institute of Public Health, Hyderabad, India

14 Short Title: Sun Exposure, Environment and Dry Eye Disease (SEED) Study

Meeting Presentations: Joint meeting of the Asia-Pacific Academy of Ophthalmology and All India Ophthalmological Society, Hyderabad, India - 2013 \& 8th International Conference on

17 the Tear Film \& Ocular Surface: Basic Science \& Clinical Relevance at Montpellier, France-

$18 \quad 2016$

19 Keywords: Epidemiology; Dry Eye; Risk Factors; Age; Sex; Sunlight exposure; Smoking; Indoor smoke exposure; Environment air pollution and geographic location; Systemic

21 diseases hypertension and diabetes. 
23 Dr Radhika Tandon, Professor of Ophthalmology, Faculty in charge Unit 6-Cornea and

24 External Disease, Cataract and refractive Surgery, Ocular Oncology and Low Vision Services.

25 Room 490, $4^{\text {th }}$ Floor, Dr Rajendra Prasad Centre for Ophthalmic Sciences, All India Institute

26 of Medical Sciences, New Delhi-110029, India.

27 Grant

28 The research was funded by Indian Council of Medical Research (ICMR), India - Grant No

$2968 / 4 / 2009-N C D-1$. The funding source had no role in the study design, in the collection,

30 analysis and interpretation of data, writing of the report; and in the decision to submit the

31 article for publication.

32

33 


\section{Purpose}

36 To estimate the prevalence and determine risk factors for dry eye disease (DED) in

37 geographically diverse regions.

\section{Method}

A population based cross-sectional study was conducted on people aged $\geq 40$ years in plain, hilly and coastal areas. Dry eye assessment by objective [tear film break-up time (TBUT), Schirmer I, corneal staining] and subjective [Ocular surface disease Index (OSDI)] parameters was performed with questionnaire-based assessment of exposure to sunlight, cigarette smoke, indoor smoke. The prevalence of DED with age, sex, occupation, location, smoking, exposure to sunlight, indoor smoke, diabetes, hypertension, BMI was subjected to logistic regression analysis.

\section{Results}

9,735 people (age $54.5 \pm 0.1$ years; range $40-99$, males $45.5 \%$ ) were included. The prevalence of DED was $26.2 \%$, was higher in plains $(41.3 \%)$ compared to hilly $(24.0 \%)$ and coastal area $(9.9 \%)(p<0.001)$ and increased with age $(p<0.001)$, female gender $(p<0.001)$, smoking $(p<0.001)$, indoor smoke $(p<0.001)$, diabetes $(p-0.02)$, hypertension $(0.001)$, occupations with predominant outdoor activity ( $p-0.013)$ and increasing exposure to sunlight (trend). Multi-logistic regression showed a positive association with female sex (OR-1.2, Cl-1.01, 1.4), exposure to indoor smoke (OR-1.3, $\mathrm{Cl}-1.1,1.5)$, smoking (OR-1.2; $\mathrm{Cl}-1.03,1.3$ ), prolonged exposure to sunlight (OR-1.8, $\mathrm{Cl}-1.5,2.2)$, hypertension (OR 1.3, $\mathrm{Cl}-1.2,1.4)$, and coastal (OR-0.2; $\mathrm{Cl}-0.1,0.2)$, and $\mathrm{BMI}(\mathrm{OR}-0.8, \mathrm{Cl}-0.7,0.9)$.

\section{Conclusion}


58 DED is common in population $\geq 40$ years of age. Its prevalence is affected by extrinsic

59 (geographic location, exposure to sunlight, smoking, indoor smoke) and intrinsic (age, sex,

60 hypertension, diabetes, BMI) factors.

61 
Dry eye disease has been defined by Tear Film Ocular Surface Society Dry eye workshop II (TFOS DEWS II) as a multi-factorial disorder of the ocular surface characterized by loss of ocular homeostasis resulting in various ocular symptoms. [1] It is a major cause of ocular morbidity which usually does not directly affect vision in most cases, but does affect the quality of life markedly. Its reported prevalence varies from 5\%-75\%.[2-12]

68

The TFOS DEWS II epidemiological report concluded that DED is more common in Asians compared to Caucasians.[3] While there are numerous studies from China[5,13,14], Japan[2], Korea[6,7] and Singapore[8], there are no similar reports from India, world's second most populated country.[3] Additionally, it is hypothesized that geographic location and climate can influence the occurrence of DED; however, this has not been validated by evaluating diverse environmental conditions in a single study.[3] With the geographic and climatic variation in India, we had an opportunity to explore the effect of the same in the prevalence of DED by conducting a multi-centric study with geographic mapping approach including populations from coastal, hilly and plain areas accounting for the effect of variations in humidity and air quality index on DED. Sunlight exposure and smoke are additional risk factors for DED for which, at present, reports are inconclusive. In the current study, their effect was assessed in addition to age, sex, education, job profile, and use of protective eye wear and head gear.

We present herein, the results of, to the best of our knowledge, the first population-based study on dry eye disease from India reporting its prevalence, associated risk factors, with 
the evaluation of the effect of geographical variations, an arena that has not been extensively explored previously.

\section{Methods}

A multi-centric population based cross-sectional study was conducted at three geographically diverse places in rural settings of India between 2010 and 2016. Important considerations in choosing the study sites were, to have representation of plains, hilly and coastal areas, and sites should have readily available physical and environmental data.

\section{Gurgaon district of National Capital Region (NCR) Delhi, was chosen as representative for} northern plains (henceforth referred to as Delhi NCR). The study in hills was done in Kamrup district located adjacent to Guwahati, capital city of the state of Assam (henceforth referred to as Guwahati). Prakasam district was chosen to represent the southern coastal region. The study adhered to the Declaration of Helsinki. The study was approved by Institutional Ethics Committee of All India Institute of Medical Sciences, New Delhi, India (P-16/04.08.2009); Indian Institute of Public Health, Hyderabad, India (33/2011- 08-08); and Regional Institute of Ophthalmology, Guwahati, India (MC/190/2007/1098-23.02.2010). Written informed consent was obtained from all participants prior to enrollment in the study. The detailed methodology of the study has been reported previously and is outlined in Figure 1.[15]

\section{Population}

A target of 3500 participants aged $\geq 40$ years from each location was set. Using census village data, the population was divided into clusters of 400-600 population each having 100-150 eligible participants. Cluster random sampling was used to select 35 clusters at each study site. 


\section{Questionnaire Schedule}

111 House visits were conducted by trained field workers and participants were interviewed

112 using a structured questionnaire schedule. It included questions on socio-demographic

113 information, smoking, indoor smoke exposure, sun exposure and systemic illness.

114 Occupation was classified as primarily indoors or outdoors. Smoking was defined as lifetime

115 history of use of any smoked tobacco product. Indoor smoke exposure was defined as

116 lifetime history of use of biomass fuels (coal, dung-cakes, wood) in the kitchen.

117

\section{Clinical examination}

119 All cases underwent a detailed ophthalmic evaluation including uncorrected visual acuity

120 (UCVA) and corrected distance visual acuity (CDVA) on ETDRS chart, intra-ocular pressure,

121 Schirmer I, slit lamp examination, tear film break-up time (TBUT), ocular surface staining,

122 anterior segment examination and indirect ophthalmoscopy for fundus evaluation in a local

123 indoor clinic set-up at the study site. TBUT was assessed with the help of a hand-held slit

124 lamp using cobalt blue filter after instillation of fluorescein stain. Home visits were

125 conducted in special situations like a bed bound or moribund patient.

126 Systemic examination included measurement of height, weight, random blood sugar and

127 blood pressure (two readings taken five minutes apart). Diabetes mellitus was diagnosed if

128 the random blood sugar level was $\geq 200 \mathrm{mg} / \mathrm{dl}$ or the participant was an already diagnosed

129 case of diabetes mellitus on medical treatment.[16] Hypertension was diagnosed if systolic

130 blood pressure (SBP) was $\geq 140 \mathrm{~mm}$ of $\mathrm{Hg}$ or diastolic blood pressure (DBP) was $\geq 90 \mathrm{~mm}$ of

$131 \mathrm{Hg}$ or a participant was a previously diagnosed case of hypertension on medical 

of height in metres.

136 Diagnosis of dry eye disease (DED) was based on the guidelines defined by TFOS DEWS II

137 which uses dry eye questionnaire as a screening tool and TBUT, corneal staining or tear

138 osmolarity for diagnosis. [1] OSDI was used as a screening test. Participants with OSDI score

$139 \geq 13$ were further assessed with objective tests that included TBUT and ocular surface

140 staining. Tear osmolarity was not performed in this study. Cases with OSDI >13 and either

141 TBUT $<10$ s or evidence of ocular surface staining were defined as having DED.

142 The Ocular Surface Disease Index (OSDI), a 12-item questionnaire, was used for assessment

143 of severity of symptoms related to dry eye and its effect on vision. The questionnaire was

144 translated into the three local languages (Assamese, Hindi and Telugu) and piloted to

145 confirm that the items were comprehensible. These versions were then back translated into

146 English by independent sets of translators conversant with the respective languages. The

147 initial and back-translated versions were compared to assess linguistic validity. As it was a

148 validated questionnaire, face validation with experts was done. The questionnaire was

149 administered by trained interviewers. Kappa values were calculated to assess the inter-

150 observer variation and were found to be within the acceptable range.

151 The response to each question in the OSDI questionnaire has a five-category Likert-type

152 response option. The final OSDI score is calculated by the following formula:

153

OSDI Score $=\frac{\text { Total score }}{\text { Number of questions answered by the participants }} * 25$ 
157 The lifetime effective sun exposure was calculated for every individual using the following

158 formula, based on the Melbourne visual impairment project model:

159 Lifetime Effective Sun Exposure $=\Sigma$ [Daily hours of sun exposure without head gear + (Daily hours of sun exposure using head gear $x$ protection factor)] $\times 365 \times$ Number of years

The number of years refers to the duration from the time respondent crossed the age of 15 years and the time of examination (current age - 15). The sun-protection factors for hats, sunglasses, spectacles, and contact lenses were taken as $0.53,0.07,0.21$ and 0.31 respectively.[18]

\section{Climatic Parameters}

The measurements of aerosol optical depth (AOD) data, total (direct + diffuse) UVA (315-400 $\mathrm{nm})$ and UVB (280-315 $\mathrm{nm}$ ) flux were noted at Delhi between October 2012 to September 2015 and compared with the satellite-based Clouds and Earth's Radiant Energy System (CERES) data products for UVA, UVB to validate the same. The measurements showed excellent agreement $(r \sim 0.92-0.93)$ with satellite-retrieved CERES UV fluxes. [19] Hence, the

172 satellite-based data was used for the long-term UVA, UVB and AOD values in the present 173 study at the three locations. In addition, meteorological data for humidity, precipitation, 174 temperature, wind speed, and air pollutants was also obtained for the three locations. 175 Meteorological data for Prakasam (Southern coastal) was obtained from the nearest center 176 at Vishakhapatnam (representing coastal region). 
179 Double entry of all data was done in a Microsoft Access ${ }^{\mathrm{TM}}$ database to avoid transcription 180 errors. Data was analyzed using Stata 13 (StataCorp, College Station, TX). Participants with 181 incomplete information on sun exposure or ocular examination were excluded. All study 182 participants were distributed into quintiles based on the lifetime effective sun exposure.

183 Pearson chi-square test, $\mathrm{t}$-test and Kruskal-Wallis tests were used for data that was 184 categorical, continuous, and non-parametric continuous respectively. Risk factor 185 comparisons were performed within-site and for combined data. P-value $<0.05$ was considered statistically significant and $95 \%$ confidence intervals $(\mathrm{Cl})$ were calculated. Multivariable logistic regression analysis was performed for all the factors that showed a significant association on simple logistic regression.

\section{Results}

Demographic and Basic Clinical Characteristics

192 A total of 12,021 individuals above 40 years of age were recruited in the study from the three locations (Delhi - 4,353; Guwahati-4,140; Prakasam - 3,528). A comprehensive risk factor and clinical assessment for dry eye disease was completed in $81 \%$ of the recruited population ( $n=9,735 / 12,021$; Delhi- 3,595; Guwahati- 3,231; Prakasam- 2,909). The participation was similar across age groups. (Supplementary Table 1) The characteristics of the participant population is shown in Table 1 and Figure 2. The mean age of the population was $54.5 \pm 0.1$ years. Males constituted $45.5 \%$ and females $54.5 \%$. The occupation included predominant outdoor activity in $82.2 \%$ of the population. No definitive history of occupational exposure to chemicals was reported by any of the participants. Diabetes mellitus was observed in $8.7 \%$ participants, with highest prevalence in Prakasam (Southern coastal) (16.2\%). Hypertension was observed in 38.5\% participants, with highest prevalence 
in Prakasam (Southern coastal) (43.8\%). Allergic conditions like asthma, skin allergy and

sinusitis were observed in $0.56 \%$ of the participants $(n-55 / 9,735)$. Asthma was the most common condition noted in the participants with allergic conditions ( $n-51 / 55)$. The BMI was

$\geq 25$ in $24.9 \%$ of the participants $(n-2425 / 9,408)$. Smoking was reported by $36.8 \%$ of the

participants with $80.9 \%$ participants being current smokers. Among the participants with

history of cigarette smoking, $59.5 \%$ participants were heavy smokers ( $\geq 5$ cigarettes/day).

The presenting visual acuity of the better eye was $\geq 6 / 12$ in $69.9 \%(95 \% \mathrm{Cl}-68.9 \%, 70.8 \%)$ of

the participants. Mild visual impairment $(<6 / 12-6 / 18)$ was observed in $7.8 \%(95 \% \mathrm{Cl}-7.3 \%$,

$8.3 \%)$, moderate visual impairment $(<6 / 18-6 / 60)$ in $17.7 \%(95 \% \mathrm{Cl}-16.9 \%, 18.4 \%)$, severe

visual impairment $(<6 / 60-3 / 60)$ in $1.2 \%(95 \% \mathrm{Cl}-0.9 \%, 1.4 \%)$ and blindness $(<3 / 60)$ in $3.5 \%$

(95\% Cl- 3.1\%, 3.9\%).

Climatic Parameters

216

The only available long-term data of UV is the erythemal UV irradiance data obtained from

Nimbus-7 and Earth probe total ozone mapping spectrometer (TOMS) satellite during the period 1979-2005 over the entire Indian region. The study of these data over Delhi and other Indian stations show that though monthly or seasonal variations do existed but there was no significant change in the UV irradiance in the long-term.[20] In the present study, the data from ground observations as well as CERES products, as mentioned earlier, have been used. The mean values of UVA, UVB flux, aerosol optical depth (AOD) along with the major air pollutants at the mid-point of the study (2013) have been tabulated in Table 2 for

224 all the three stations. The mean UVA and UVB exposure was higher in the coastal region as compared to the hilly region and plains. 
The major air pollutants in these regions are surface $\mathrm{SO}_{2}, \mathrm{NO}_{2}, \mathrm{PM}_{10}, \mathrm{PM}_{2.5}$ and surface ozone. Concentrations of the gaseous pollutants are generally within the National Ambient Air Quality Standards (NAAQS) but particulate matter $\left(\mathrm{PM}_{10}\right.$ and $\left.\mathrm{PM}_{2.5}\right)$ is the major problem in all these areas which is significantly higher than the NAAQS values. Long-term observation suggests a rising trend of pollutants concentration at all the three centers. It was observed that the AOD, AQI, PM10 and atmospheric nitrogen oxide level was highest in Delhi NCR (Northern plains) among the three study locations while the humidity and precipitation level were lowest here highlighting that the environment in Delhi NCR

234 (Northern plains) is relatively dry and polluted when compared to the other study sites. (Table 2) Maximum temperature and rainfall with lowest PM10 value and relatively high humidity was observed in Prakasam (Southern coastal) suggesting that it is hot and humid but the environment is relatively clean compared to other centers. Most of the parameters for air pollution for Guwahati (North-eastern hilly) were in between the two centers. The wind speed was noted to be highest in Prakasam (Southern coastal). (Table 2)

\section{Dry Eye Disease \& Socio-demographic Risk Factors}

242 The overall prevalence of DED was $26.2 \%(95 \% \mathrm{Cl}: 25.3 \%-27.1 \% ; n=2,548 / 9,735)$ based on

243 the TFOS DEWS II diagnostic criteria (OSDI $\geq 13$ and TBUT $<10$ seconds or ocular surface staining. (Table 3) TBUT $<10$ seconds was noted in $34.5 \%$ of cases, Schirmer $\mathrm{I}<5 \mathrm{~mm}$ in $27.5 \%$ and fluorescein staining in $1.7 \%$ of the population. An abnormal OSDI score $(\geq 13)$ was observed in $66.4 \%(95 \% \mathrm{Cl}: 65.4 \%-67.3 \%)$ of the population.

Analysis of OSDI questionnaire items among people with DED revealed that blurred vision was the most common symptom experienced by $94.5 \%(n=2,408 / 2,548)$ followed by poor vision (93.1\%; $n=2,371 / 2,548$ ) and sensitivity to light (57.2\%; $n=1,458 / 2,548)$. Visual 
250 function impairment was noted maximally while reading in $40.5 \%$ ( $n=1,033 / 2,548)$ followed

251 by watching television ( $37.9 \% ; n=965 / 2,548)$. The most common environmental trigger for

252 dry eye was wind (41.2\%; $n=1051 / 2,548)$ followed by dry environment $(36.7 \%$;

$253 n=934 / 2,548)$. Of the cases identified to have DED, mild DED (OSDI score 13-22) was

254 observed in $27.8 \%(707 / 2,548)$, moderate DED (OSDI score $23-32)$ in $27.9 \%(710 / 2,548)$ and

255 severe DED (OSDI score $>32$ ) in $44.4 \%(1,131 / 2,548)$. Based on the clinical noting in the

records, $<10 \%$ participants were using artificial tears.

257

A rising trend of prevalence of DED was observed with increasing age of the population in all

the study centers as well as in the overall population $(p<0.001)$. (Table 4$)$ The prevalence of DED was highest in population aged $\geq 70$ years (37.2\%) and lowest in $40-49$ years age group (20.7\%). Females had a higher prevalence $(28 \%)$ when compared to males $(24 \%)(p<0.001)$ in the overall population. The difference in prevalence of DED between male and female were not statistically significant above the age of 70 years ( $35.6 \%$ vs. $38.8 \%$; $p-0.226)$. (Table 3 and Figure 3) A significant difference was observed between the prevalence of DED from the three study centers ( $p<0.001$ ). Delhi NCR (Northern plains) had the highest prevalence (41.3\%) followed by Guwahati (North-eastern hilly) (24\%) and Prakasam (Southern coastal) higher prevalence of DED compared to those who primarily spent time indoors $(23.8 \%$, $p=0.013)$.

272 The median life-time cumulative effective sun-exposure in the overall population was 95.6

273 thousand-hours (range; 7.3 thousand-hours - 314.1 thousand-hours). A rising trend of 
prevalence of DED with increasing lifetime cumulative effective sun-exposure was observed.

275 The participants with sun exposure in the fifth quintile had the highest prevalence (35.58\%;

$27695 \% \mathrm{Cl}-33.5,37.7)$ when compared to those in the other sub-groups, in the overall study

277 population as well as in each of the three study centers $(p<0.001)$. Also, participants with

278 history of smoking and exposure to indoor smoke showed a higher prevalence $(p<0.001$,

$279<0.001$ ). (Figure 4) No difference was observed in participants with or without the use of

280 protective eye or head gear $(p=0.670) .($ Table 4$)$

281

282 Systemic Risk Factors

283 The prevalence of DED was higher in participants with hypertension in the overall study

284 population $(p=0.001)$, as well as in plains $(p=0.234)$, hilly $(p<0.001)$ and coastal region

285 ( $p=0.007)$. (Table 4) The prevalence of DED was similar in participants with newly detected

286 hypertension not taking any treatment (28.0\%) compared to those already diagnosed and

287 on medication ( $28.3 \%)(p=0.887)$. The prevalence of DED was similar among diabetics and

288 non-diabetics in each of the three sites: Delhi NCR (Northern plains) ( $p=0.112$ ), Guwahati

289 (North-eastern hilly) ( $p=0.667)$ and Prakasam (Southern coastal) $(p=0.234)$, but overall, it

290 was higher among non-diabetics $(p=0.023)$ (Table 4) The prevalence of DED was higher in

291 participants with newly detected diabetes mellitus not taking any treatment $(26.7 \%)$

292 compared to those previously diagnosed and already on treatment (21.5\%), however the

293 difference was not significant $(p=0.105)$. The prevalence of DED was higher in participants

294 with $\mathrm{BMI}<25(27.8 \%)$ when compared to those with $\mathrm{BMI} \geq 25(22.4 \%)(p<0.001)$. A

295 detailed individual drug history for central nervous system (CNS) drugs like opioids and anti-

296 depressants was not obtained separately in this study. However, a positive history for CNS

297 or neuropsychiatric disorders was obtained in participants as follows: stroke (n-9), seizure 
those with Parkinson's disease were on treatment at the time of examination.

\section{Regression Analysis}

302 Multiple logistic regression analysis comparing the association of DED with various risk factors for each center and the overall population is shown in Table 5. Female gender had a higher association with DED (OR-1.2; Cl 1.01-1.4). Hypertension had a higher association with DED (OR 1.3; $\mathrm{Cl} 1.2-1.4)$. People with history of smoking (OR-1.2; $\mathrm{Cl} 1.03-1.3$ ) and indoor smoke exposure (OR-1.3; Cl 1.1-1.5) had a higher likelihood of having DED. Increasing

307 lifetime cumulative effective sun exposure had a positive association with DED. However, a center wise variation was observed in the levels of these results. The population from DelhiNCR (Northern plains) showed a positive association in the fifth quintile (OR-1.5; $\mathrm{Cl} 1.2-1.9$ ) while those from Prakasam (Southern coastal) showed a positive association in the fifth quintile (OR-2.1; $\mathrm{Cl}$ 1.3-3.2). The participants from Guwahati (North-eastern hilly) showed a positive association in the second quintile (OR $1.3 ; \mathrm{Cl}-1.0,1.6)$, third quintile (OR-1.5; $\mathrm{Cl} 1.1$ 1.9), fourth quintile (OR-1.8; $\mathrm{Cl} 1.3-2.4$ ) and fifth quintile (OR-2.8; $\mathrm{Cl}$ 1.7-4.5) of lifetime cumulative effective sun exposure. In the overall population, a higher association was observed with fifth quintile of lifetime cumulative effective sun exposure (OR-1.8; $\mathrm{Cl}$ 1.5-2.2) when compared to the fourth quintile (OR-1.4; $\mathrm{Cl} 1.2-1.6)$ and third quintile (OR-1.3; $\mathrm{Cl} 1.1-$ 1.5). Assessment of study location showed that there was a lower likelihood of DED in populations from Guwahati (North-eastern hilly) (OR-0.5; Cl 0.4-0.6) and Prakasam

319 (Southern coastal) (OR-0.2; Cl 0.1-0.2) when compared to Delhi-NCR (Northern plains). 
wise multi-logistic regression analysis, smoking was non-significant for both males and

323 females, indoor smoke had a positive association in males (OR 1.7; $\mathrm{Cl}-1.4,2.0)$ only, and

diabetes showed a positive association in females (OR 1.3; $\mathrm{Cl}-1.0,1.6)$ only. (Supplementary

table 2). Additional sub-analysis of hypertension as systolic and diastolic showed that only

systolic hypertension had association with DED on multiple-logistic regression analysis.

327 (Supplementary table 3).

\section{Discussion}

330 Dry eye disease is an important entity in clinical practice. It is a common reason for seeking medical help, especially in the elderly and can be quite debilitating when severe. The prevalence and associated risk factors for DED has been extensively studied. (Table 6) However, the lack of clarity in the definitive diagnostic criteria for DED prior to the TFOS DEWS II report, led to non-uniform diagnostic criteria being used in the reported studies making it difficult to make direct comparisons. $[21,22]$ It is difficult to assess the actual disease burden and the inter-play of risk factors in the population based on hospital based data alone and community based studies are hence much required.

The current study is the largest population-based study on dry eye disease from Asia

340 founded on the diagnostic criteria suggested by the TFOS DEWS II. The prevalence of DED in

341 the $\geq 40$ years population in this study was observed as $26.2 \%$. A previous study from North

342 India reported a 32\% prevalence of DED in a hospital based survey with OSDI questionnaire

343 used for diagnosis.[9] However, as symptoms of OSDI are non-specific and can occur due to any ocular surface disorder, it can be fallacious to rely on OSDI as a sole criterion for 
clinical signs in addition to symptoms for DED diagnosis. Literature review suggests that the

347 prevalence of symptomatic DED (both symptoms and signs used for diagnosis) in China is

$34830.1 \%$, Korea is $8 \%$, Spain is $11 \%$, Iran is $8.7 \%$ and France is $10.7 \% .[3,5,7,10,11,23,24]$ The

349 result of our study was close to that observed by Tian et al. in a study from China but higher

350 than that reported from other parts of the world confirming a higher prevalence of DED in

351 the south-east Asian population compared to others. $[3,5,7,10,11,23,24]$ It is noteworthy

352 that Shanti et al. recently reported an even higher 64\% prevalence of DED in population

353 based study from Palestine using the same diagnostic criteria as used in the current study

354 (TFOS DEWS II).[25]

355

356 Analyzing the contributory factors, an increasing prevalence of DED was observed with

357 increasing age in our study. The prevalence in $\geq 70$ years population was 1.8 times higher

358 than that observed in the $40-49$ years age group. A similar trend was observed in the study

359 by Viso et al. in a Spanish population, wherein the prevalence of DED in the 40-49-year age

360 group was $3.6 \%$ while that in the $\geq 80$ years age group was $20.5 \%$.[10] Also, Vehof et al.

361 observed a similar trend in the British population wherein the prevalence of DED increased

362 from $2.7 \%$ in the third decade to $20.0 \%$ in the ninth decade.[26] A population based study

363 from South Korea in participants aged $19-95$ years found age to be a common risk factor for

364 both clinically diagnosed dry eye syndrome and presence of dry eye symptoms. [7] Age

365 related changes in the lacrimal functional unit and prolonged exposure to environmental

366 triggers for ocular surface inflammation are some possible reasons for this age-related

367 increase observed in prevalence of DED. The highest prevalence of DED observed in the $>70$

368 years population could be due to the cumulative impact of exposure to climatic factors and

369 biomass fuels over the life span. 
371 A gender wise difference was observed in the prevalence of DED in our study with a higher

372 prevalence in females ( $27.7 \%$ vs. $23.6 \%)$. However, an age and gender wise stratification of

373 prevalence of DED showed that the difference in prevalence of DED became insignificant

374 after the age of 70 years, thus illustrating the complexity of interplay of these intrinsic

375 factors.(Table 3) It is interesting that these findings are also reflected in a hospital based

376 study from India where an age and gender stratification showed that males were more

377 frequently affected during the $2^{\text {nd }}$ and $3^{\text {rd }}$ decade of life, while females were more affected

378 during $4^{\text {th }}$ and $5^{\text {th }}$ decade of life, and the sex differences were insignificant beyond the age

379 of 60 years. [22] Ahn et al. reported this similarly as noteworthy in their analysis of the

380 above 40 years subset of population of the Korea National Health and Nutrition Examination

381 Survey (2010-2012) wherein the females had a higher prevalence than males (13.6\% vs.

$3824.9 \%)$, but females did not demonstrate an increasing prevalence with age as was seen in males in linear regression models and multivariate logistic regression analysis showed that ageing in females was protectively associated.[27] Tian et al. reported a prevalence of $33.8 \%$ in women and $24.1 \%$ in men in a Chinese population aged $20-95$ years. While most of the studies report a higher prevalence of DED in females, Tong et al. reported a higher prevalence in males (8.2\% vs. $4.9 \%$ ) in a Malayan population. [28] However, as the study was based only on dry eye questionnaire in the absence of clinical grading, it is difficult to compare the results of this study with the present study.

Exposure to sunlight particularly ultraviolet radiation are hypothesized to be associated with

391 the occurrence of DED with limited data available in literature. In the current study, the effect of sun exposure was evaluated and a positive association was observed with DED. A stronger association was observed between higher cumulative effective sun exposure and 

positive association between DED and longer exposure to sunshine (OR 1.015; $\mathrm{Cl}$ 1.006for analysis overlooking the inter-individual differences in the exposure to sunlight based on variation in the lifestyle and occupation of the individual. In the present study, an individualized approach was used for calculating the approximate cumulative lifetime effective sunlight exposure taking into account the effect of protective head gear and eye

402 gear with the help of Melbourne formula.[18] This observed association between DED and ocular exposure to sunlight can have a strong clinical implication. Avoiding sunlight exposure to the eyes can be added to the list of factors included in the lifestyle modification which is core to the management of cases presenting with symptomatic DED. In the present study history of smoking was found to have a positive association with DED.

407 Previous studies have shown variable results for smoking as a risk factor for DED and a meta-analysis of available literature indicated that smoking may be associated with the risk of DED in the normal population.[29] Similarly, Moss et al. in a population based study from USA reported a positive association between smoking and DED (OR -1.44; $\mathrm{Cl} 1.13-1.83$ ) in

411 the participants aged 43-84 years after adjusting for age and gender.[30]Hence, avoidance 412 and cessation of smoking are worthwhile preventative and ameliorative measures to 413 suggest in this regard.

414 Oxidative stress is known to result in ocular surface changes and DED.[31,32] Both smoking 415 and ultraviolet radiation are risk factors for increased oxidative stress and as a corollary can be considered as contributory risk factors for DED; as observed in our study. The role of smoking in oxidative damage to ocular structures resulting in dry eye, lenticular changes and 
retinal pigment epithelial cell changes has been reported in few studies.[31-34] Ocular

exposure with ultraviolet radiation resulting in oxidative stress has been extensively

explored in relation to corneal collagen crosslinking.[35] However, its direct impact on the

ocular surface is relatively unexplored. The rise of inflammatory mediators as a

and also explore any effects on the meibomian or lacrimal glands.

As far as exposure to indoor smoke is concerned, as wood, biomass fuel and coal is still used

427 by large proportion of the rural population in the world for the purpose of cooking and heating, it still remains a tangible problem.[36-39] Respiratory disorders and increased risk of cardiovascular events are the known complications of increased exposure to indoor smoke.[36-41] In the present study, a positive association was observed between exposure to indoor smoke and presence of DED. Hence, the proven associated health hazards highlight a real need to sensitize the population and step-up supportive policies to switch to smokeless fuel alternatives.

435 Regarding the effect of systemic diseases of hypertension and DM, both were found to be risk factors for DED in our study. Some population based studies have shown similar results

437 while other have not. [2,42-44] Several factors can account for such variations such as 438 inherent differences in populations studied, other linked complex factors, limitations of 439 accuracy of determining the proper diagnosis, particularly exact duration of the illness along with full details of nature and duration of treatment in epidemiological surveys in rural 
areas. However, the results do confirm that underlying presence of both hypertension and

442 diabetes can affect the occurrence of DED and should be accounted for if needed.

444 As for the effect of geographic location, the prevalence of DED showed a distinct variation in

445 our study with the highest observed prevalence in Delhi NCR (Northern plains) (41.3\%)

446 compared to Guwahati (North-eastern hilly) (24\%) and Prakasam (Southern coastal) (9.9\%).

447 Various climatic and environmental factors like sun-exposure, humidity and air pollution

448 may be responsible for the observed difference in the three study locations. Literature

449 review suggests that studies performed in controlled environment chambers report a more

450 stable tear film in high humidity and low ambient temperatures.[45-47] In the current

451 study, it was observed that Prakasam (Southern coastal), the center with highest humidity,

452 had the lowest prevalence of DED while Delhi NCR (Northern plains), the center with the

453 lowest humidity, had the highest prevalence of DED. This highlights the inverse relation of

454 humidity as a risk factor for DED.

455

456 Delhi NCR (Northern plains), the location with highest air pollution level had the highest

457 prevalence of DED in the population residing in this location. Similarly, Prakasam (Southern

458 coastal), the location with lowest air pollution level had the lowest prevalence of DED. This

459 observation supports the notion that air pollution is a risk factor for DED. Also, the average

460 wind speed was highest in Prakasam (Southern coastal). This may explain a reduced

461 exposure of the ocular surface to some air pollutants and resultant low prevalence of DED.

462 Literature review also suggests a positive association between air pollution and prevalence of DED.[6,38,48-51] Exploring the interaction of pollution variables with DED in multi- 
variables were not individual specific as the data was collected at the city level and hence could not be assessed in multi-logistic regression analysis. For the sake of scientific rigor, further validation of this aspect may be considered in future studies with long term monitoring of indoor air quality parameters of the participants using portable devices.

As for effect of altitude, in the current study, comparatively low prevalence of DED was observed in the population from the hilly region of Guwahati. Generally, literature suggests

472 a high prevalence of DED in natives residing in very high altitudes. [2,12-14] This difference can be because the hills of Guwahati do not have a very high altitude. Moreover, the people residing there are also exposed to riverine and char environments. Therefore, the effect of altitude could not be conclusively determined in our study and needs to be further explored by assessing populations residing in extremely high altitude.

478 The study has strengths of providing a large population-based dataset with evaluation of both intrinsic and extrinsic risk factors following the guidelines of TFOS DEWS II in definitions and analysis, but may be considered to have some lacunae . Lack of individualized data for the air quality parameters and absence of detailed drug history for participants with history of hypertension on medication make it difficult to ascertain the exact impact of different air quality parameters or specific environmental pollutants and if

484 the higher observed prevalence of DED in hypertensives was due to the hypertension per se or an adverse effect of particular anti-hypertensive agents such as beta blockers and diuretics as is currently believed.[52,53] Recently, an association between sleep disorder, physical activity, stress factors and depression with DED has come to fore. Additional data 
large population based survey with 4 independent forms to be filled requiring over one hour

would have been of additional interest; however as these are not commonly used in the

rural Indian population aged $\geq 40$ years studied, hence they could not be separately

which could be a contributing factor for symptoms of DED, though evaluated clinically on slit

lamp examination, was not analysed. Also, hyperlipidaemia which has been reported to be

been included in the ongoing phase 2 of the study.

\section{Conclusion}

To conclude, this study has provided reliable new information on the prevalence of dry eye in India in populations residing in geographically diverse regions and evaluated the various

507 known risk factors for DED and sun exposure. The study has confirmed the association of

508 DED with intrinsic factors like increasing age, female gender, BMI, hypertension and diabetes mellitus, and extrinsic factors like exposure to sunlight, smoking and indoor smoke.

510 The place of residence and livelihood influenced the prevalence of DED which had the

511 highest prevalence in plains when compared to hills and coastal region for which air

512 pollution and humidity could have had important influences as the prevalence of DED was 
513 highest in the location with highest air pollution and lowest humidity. The study highlights

514 the importance of various extrinsic risk factors for DED which are often missed out while

515 counselling patients presenting with DED. This information can help in advocacy, guide

516 policy making and allocation of resources for preventive and therapeutic measures and

517 these factors can be added to the list of lifestyle modification which is an essential

518 component in the management of all patients of DED. It makes a strong case for counselling

519 to minimize direct sun-exposure of eye, cease smoking, reduce indoor air pollution by using

520 smokeless fuels and if necessary for patients severely affected, greater measures to improve

521 living environments with avoidance of high pollution and low humidity levels. Lastly, the

522 study has highlighted the complex interplay of a multitude of factors involved in the genesis

523 and manifestations of DED and indicates the care needed to interpret and apply information

524 generated by various studies.

525 
527 The research was funded by Indian Council of Medical Research (ICMR), India - Grant No

$52868 / 4 / 2009-N C D-1$. The funding source had no role in the study design, in the collection,

529 analysis and interpretation of data, writing of the report; and in the decision to submit the

530 article for publication.

531

532 Conflict of Interest

533 The authors have no conflict of interest.

534

535

Acknowledgements

536 Dr. Saurabh Agarwal Jwalaprasad, Dr. Bhagbat Nayak, Dr. Jayanta Thakuria, Dr. Indrani

537 Goswami, Ms. Tanya Patel, Ms. Ankita Mall, Dr. Rupesh M Das are acknowledged for their

538 contribution to data acquisition. Mr Amit Bhardwaj and Mr Deepak Kumar are

539 acknowledged for their contribution to data management and analysis. We would like to

540 acknowledge the ICMR Task Force on global climate change and health chaired by Prof.

541 Seyed E. Hasnain, IIT Delhi, for periodic review and technical inputs during the course of the

542 study. All the members of the ICMR Eye Sun Exposure \& Environment "EYE SEE" study group

543 are acknowledged for their contributions to the project.

544 THE ICMR EYE SUN EXPOSURE \& ENVIRONMENT “EYE SEE” STUDY GROUP

\begin{tabular}{|c|c|c|c|}
\hline Centers & $\begin{array}{l}\text { Principal } \\
\text { Investigators }\end{array}$ & Co-investigators & $\begin{array}{l}\text { Scientist/Research } \\
\text { officers }\end{array}$ \\
\hline $\begin{array}{l}\text { Dr. Rajendra Prasad } \\
\text { Centre for } \\
\text { Ophthalmic Sciences, } \\
\text { AlIMS, New Delhi } \\
\text { (Coordinating } \\
\text { Center) }\end{array}$ & $\begin{array}{l}\text { Dr. Radhika Tandon } \\
\text { Dr. Praveen Vashist }\end{array}$ & $\begin{array}{l}\text { Dr. Noopur Gupta } \\
\text { Dr. Vivek Gupta* }\end{array}$ & $\begin{array}{l}\text { Dr. Pranita Sahay } \\
\text { Dr. Rashmi Singh } \\
\text { Dr. Meenakshi Wadhwani } \\
\text { Dr. Shweta } \\
\text { Dr. Aparna Gupta } \\
\text { Dr. Saurabh Agarwal } \\
\text { Jwalaprasad }\end{array}$ \\
\hline
\end{tabular}




\begin{tabular}{|l|l|l|l|}
\hline & & & Dr. Bhagbat Nayak \\
\hline $\begin{array}{l}\text { Indian Institute of } \\
\text { Public Health, } \\
\text { Hyderabad }\end{array}$ & Dr. GVS Murthy & Dr. K. Vishwanath & $\begin{array}{l}\text { Dr. Hemant Kumar } \\
\text { Dr. Vijay Kiran }\end{array}$ \\
\hline $\begin{array}{l}\text { Regional Institute of } \\
\text { Ophthalmology, } \\
\text { Guwahati }\end{array}$ & $\begin{array}{l}\text { Dr. C.K.Barua } \\
\text { Dr. Dipali Deka }\end{array}$ & & $\begin{array}{l}\text { Dr. Jayanta Thakuria } \\
\text { Dr. Indrani Goswami }\end{array}$ \\
\hline $\begin{array}{l}\text { National Physical } \\
\text { Laboratory, New } \\
\text { Delhi }\end{array}$ & $\begin{array}{l}\text { Dr Sachchidanand } \\
\text { Singh }\end{array}$ & & $\begin{array}{l}\text { Ms. Tanya Patel } \\
\text { Ms. Ankita Mall } \\
\text { Dr. Rupesh M Das }\end{array}$ \\
\hline
\end{tabular}


547

548

549

550

551

552

553

554

555

556

557

558

559

560

561

562

563

564

565

566

567

568

569

570

571

572

573

574

575

576

577

578

579

580

581

582

583

584

585

586

587

588

589

590

591

592

593

\section{References}

[1] Craig JP, Nichols KK, Akpek EK, Caffery B, Dua HS, Joo C-K, et al. TFOS DEWS II Definition and Classification Report. Ocul Surf 2017;15:276-83. https://doi.org/10.1016/j.jtos.2017.05.008.

[2] Uchino M, Nishiwaki Y, Michikawa T, Shirakawa K, Kuwahara E, Yamada M, et al. Prevalence and risk factors of dry eye disease in Japan: Koumi study. Ophthalmology 2011;118:2361-7. https://doi.org/10.1016/j.ophtha.2011.05.029.

[3] Stapleton F, Alves M, Bunya VY, Jalbert I, Lekhanont K, Malet F, et al. TFOS DEWS II Epidemiology Report. Ocul Surf 2017;15:334-65. https://doi.org/10.1016/j.jtos.2017.05.003.

[4] Chia E-M, Mitchell P, Rochtchina E, Lee AJ, Maroun R, Wang JJ. Prevalence and associations of dry eye syndrome in an older population: the Blue Mountains Eye Study. Clin Experiment Ophthalmol 2003;31:229-32. https://doi.org/10.1046/j.14429071.2003.00634.x.

[5] Song P, Xia W, Wang M, Chang X, Wang J, Jin S, et al. Variations of dry eye disease prevalence by age, sex and geographic characteristics in China: a systematic review and meta-analysis. J Glob Health 2018;8:020503. https://doi.org/10.7189/jogh.08.020503.

[6] Um S-B, Kim NH, Lee HK, Song JS, Kim HC. Spatial epidemiology of dry eye disease: findings from South Korea. International Journal of Health Geographics 2014;13:31. https://doi.org/10.1186/1476-072X-13-31.

[7] Ahn JM, Lee SH, Rim THT, Park RJ, Yang HS, Kim T im, et al. Prevalence of and Risk Factors Associated With Dry Eye: The Korea National Health and Nutrition Examination Survey 2010-2011. American Journal of Ophthalmology 2014;158:1205-1214.e7. https://doi.org/10.1016/j.ajo.2014.08.021.

[8] Tan LL, Morgan P, Cai ZQ, Straughan RA. Prevalence of and risk factors for symptomatic dry eye disease in Singapore. Clin Exp Optom 2015;98:45-53. https://doi.org/10.1111/cxo.12210.

[9] Titiyal JS, Falera RC, Kaur M, Sharma V, Sharma N. Prevalence and risk factors of dry eye disease in North India: Ocular surface disease index-based cross-sectional hospital study. Indian J Ophthalmol 2018;66:207-11. https://doi.org/10.4103/ijo.IJO_698_17.

[10] Viso E, Rodriguez-Ares MT, Gude F. Prevalence of and associated factors for dry eye in a Spanish adult population (the Salnes Eye Study). Ophthalmic Epidemiol 2009;16:1521. https://doi.org/10.1080/09286580802228509.

[11] Hashemi H, Khabazkhoob M, Kheirkhah A, Emamian MH, Mehravaran S, Shariati M, et al. Prevalence of dry eye syndrome in an adult population. Clin Experiment Ophthalmol 2014;42:242-8. https://doi.org/10.1111/ceo.12183.

[12] Gupta N, Prasad I, Himashree G, D'Souza P. Prevalence of dry eye at high altitude: a case controlled comparative study. High Alt Med Biol 2008;9:327-34. https://doi.org/10.1089/ham.2007.1055.

[13] Guo B, Lu P, Chen X, Zhang W, Chen R. Prevalence of dry eye disease in Mongolians at high altitude in China: the Henan eye study. Ophthalmic Epidemiol 2010;17:234-41. https://doi.org/10.3109/09286586.2010.498659.

[14] Lu P, Chen X, Liu X, Yu L, Kang Y, Xie Q, et al. Dry eye syndrome in elderly Tibetans at high altitude: a population-based study in China. Cornea 2008;27:545-51. https://doi.org/10.1097/ICO.0b013e318165b1b7.

[15] Vashist P, Tandon R, Murthy GVS, Barua CK, Deka D, Singh S, et al. Association of cataract and sun exposure in geographically diverse populations of India: The CASE 
600

601

602

603

604

605

606

607

608

609

610

611

612

613

614

615

616

617

618

619

620

621

622

623

624

625

626

627

628

629

630

631

632

633

634

635

636

637

638 study. First Report of the ICMR-EYE SEE Study Group. PLoS ONE 2020;15:e0227868. https://doi.org/10.1371/journal.pone.0227868.

[16] Association AD. 2. Classification and Diagnosis of Diabetes: Standards of Medical Care in Diabetes-2019. Diabetes Care 2019;42:S13-28. https://doi.org/10.2337/dc19-S002.

[17] Program NHBPE. Classification of Blood Pressure. National Heart, Lung, and Blood Institute (US); 2004.

[18] McCarty CA, Lee SE, Livingston PM, Bissinella M, Taylor HR. Ocular exposure to UV-B in sunlight: the Melbourne visual impairment project model. Bull World Health Organ 1996;74:353-60.

[19] Singh S, Lodhi NK, Mishra AK, Jose S, Kumar SN, Kotnala RK. Assessment of satelliteretrieved surface UVA and UVB radiation by comparison with ground-measurements and trends over Mega-city Delhi. Atmospheric Environment 2018;188:60-70. https://doi.org/10.1016/j.atmosenv.2018.06.027.

[20] Ganguly ND, Iyer KN. Long-Term Trend in Ozone and Erythemal UV at Indian Latitudes. J Atmos Chem 2006;55:227-39. https://doi.org/10.1007/s10874-006-9035-9.

[21] The definition and classification of dry eye disease: report of the Definition and Classification Subcommittee of the International Dry Eye WorkShop (2007). Ocul Surf 2007;5:75-92.

[22] Donthineni PR, Kammari P, Shanbhag SS, Singh V, Das AV, Basu S. Incidence, demographics, types and risk factors of dry eye disease in India: Electronic medical records driven big data analytics report I. Ocul Surf 2019;17:250-6. https://doi.org/10.1016/j.jtos.2019.02.007.

[23] Malet F, Le Goff M, Colin J, Schweitzer C, Delyfer M-N, Korobelnik J-F, et al. Dry eye disease in French elderly subjects: the Alienor Study. Acta Ophthalmol 2014;92:e429436. https://doi.org/10.1111/aos.12174.

[24] Tian Y-J, Liu Y, Zou H-D, Jiang Y-J, Liang X-Q, Sheng M-J, et al. [Epidemiologic study of dry eye in populations equal or over 20 years old in Jiangning District of Shanghai]. Zhonghua Yan Ke Za Zhi 2009;45:486-91.

[25] Shanti Y, Shehada R, Bakkar MM, Qaddumi J. Prevalence and associated risk factors of dry eye disease in 16 northern West bank towns in Palestine: a cross-sectional study. BMC Ophthalmology 2020;20:26. https://doi.org/10.1186/s12886-019-1290-z.

[26] Vehof J, Kozareva D, Hysi PG, Hammond CJ. Prevalence and risk factors of dry eye disease in a British female cohort. Br J Ophthalmol 2014;98:1712-7.

https://doi.org/10.1136/bjophthalmol-2014-305201.

[27] Ahn JH, Choi Y-H, Paik HJ, Kim MK, Wee WR, Kim DH. Sex differences in the effect of aging on dry eye disease. Clin Interv Aging 2017;12:1331-8. https://doi.org/10.2147/CIA.S140912.

[28] Tong L, Tongg L, Saw S-M, Lamoureux EL, Wang JJ, Rosman M, et al. A questionnairebased assessment of symptoms associated with tear film dysfunction and lid margin disease in an Asian population. Ophthalmic Epidemiol 2009;16:31-7. https://doi.org/10.1080/09286580802521317.

[29] Xu L, Zhang W, Zhu X-Y, Suo T, Fan X-Q, Fu Y. Smoking and the risk of dry eye: a Metaanalysis. Int J Ophthalmol 2016;9:1480-6. https://doi.org/10.18240/ijo.2016.10.19.

[30] Moss SE, Klein R, Klein BE. Prevalence of and risk factors for dry eye syndrome. Arch Ophthalmol 2000;118:1264-8. https://doi.org/10.1001/archopht.118.9.1264. 
[31] Dogru M, Kojima T, Simsek C, Tsubota K. Potential Role of Oxidative Stress in Ocular Surface Inflammation and Dry Eye Disease. Invest Ophthalmol Vis Sci 2018;59:DES1638. https://doi.org/10.1167/iovs.17-23402.

[32] Seen S, Tong L. Dry eye disease and oxidative stress. Acta Ophthalmol 2018;96:e41220. https://doi.org/10.1111/aos.13526.

[33] Fujihara M, Nagai N, Sussan TE, Biswal S, Handa JT. Chronic cigarette smoke causes oxidative damage and apoptosis to retinal pigmented epithelial cells in mice. PLoS ONE 2008;3:e3119. https://doi.org/10.1371/journal.pone.0003119.

[34] Shalini VK, Luthra M, Srinivas L, Rao SH, Basti S, Reddy M, et al. Oxidative damage to the eye lens caused by cigarette smoke and fuel smoke condensates. Indian J Biochem Biophys 1994;31:261-6.

[35] Wollensak G, Spoerl E, Seiler T. Riboflavin/ultraviolet-a-induced collagen crosslinking for the treatment of keratoconus. Am J Ophthalmol 2003;135:620-7.

[36] Smith KR, Mehta S. The burden of disease from indoor air pollution in developing countries: comparison of estimates. Int J Hyg Environ Health 2003;206:279-89. https://doi.org/10.1078/1438-4639-00224.

[37] Chen $\mathrm{BH}$, Hong $\mathrm{CJ}$, Pandey MR, Smith KR. Indoor air pollution in developing countries. World Health Stat Q 1990;43:127-38.

[38] Mestl HES, Edwards R. Global burden of disease as a result of indoor air pollution in Shaanxi, Hubei and Zhejiang, China. Sci Total Environ 2011;409:1391-8. https://doi.org/10.1016/j.scitotenv.2011.01.020.

[39] Torres-Duque C, Maldonado D, Pérez-Padilla R, Ezzati M, Viegi G, Forum of International Respiratory Studies (FIRS) Task Force on Health Effects of Biomass Exposure. Biomass fuels and respiratory diseases: a review of the evidence. Proc Am Thorac Soc 2008;5:577-90. https://doi.org/10.1513/pats.200707-100RP.

[40] Agrawal S. Effect of indoor air pollution from biomass and solid fuel combustion on prevalence of self-reported asthma among adult men and women in India: findings from a nationwide large-scale cross-sectional survey. J Asthma 2012;49:355-65. https://doi.org/10.3109/02770903.2012.663030.

[41] Norman R, Barnes B, Mathee A, Bradshaw D, South African Comparative Risk Assessment Collaborating Group. Estimating the burden of disease attributable to indoor air pollution from household use of solid fuels in South Africa in 2000. S Afr Med J 2007; 97:764-71.

[42] Yoo TK, Oh E. Diabetes mellitus is associated with dry eye syndrome: a meta-analysis. Int Ophthalmol 2019;39:2611-20. https://doi.org/10.1007/s10792-019-01110-y.

[43] Zhang X, Zhao L, Deng S, Sun X, Wang N. Dry Eye Syndrome in Patients with Diabetes Mellitus: Prevalence, Etiology, and Clinical Characteristics. J Ophthalmol 2016;2016:8201053. https://doi.org/10.1155/2016/8201053.

[44] Ferrero A, Alassane S, Binquet C, Bretillon L, Acar N, Arnould L, et al. Dry eye disease in the elderly in a French population-based study (the Montrachet study: Maculopathy, Optic Nerve, nuTRition, neurovAsCular and HEarT diseases): Prevalence and associated factors. Ocul Surf 2018;16:112-9. https://doi.org/10.1016/j.jtos.2017.09.008.

[45] Abusharha AA, Pearce El. The effect of low humidity on the human tear film. Cornea 2013;32:429-34. https://doi.org/10.1097/ICO.0b013e31826671ab.

[46] López-Miguel A, Tesón M, Martín-Montañez V, Enríquez-de-Salamanca A, Stern ME, Calonge $\mathrm{M}$, et al. Dry eye exacerbation in patients exposed to desiccating stress under 
controlled environmental conditions. Am J Ophthalmol 2014;157:788-798.e2. https://doi.org/10.1016/j.ajo.2014.01.001.

[47] Abusharha AA, Pearce El, Fagehi R. Effect of Ambient Temperature on the Human Tear Film. Eye Contact Lens 2016;42:308-12. https://doi.org/10.1097/ICL.0000000000000210.

690

691

692

693

694

695

696

697

698

699

700

701

702

703

704

705

706

707

708

709

710

711

712

713

[48] Galor A, Kumar N, Feuer W, Lee DJ. Environmental factors affect the risk of dry eye syndrome in a United States veteran population. Ophthalmology 2014;121:972-3. https://doi.org/10.1016/j.ophtha.2013.11.036.

[49] Zhong J-Y, Lee Y-C, Hsieh C-J, Tseng C-C, Yiin L-M. Association between Dry Eye Disease, Air Pollution and Weather Changes in Taiwan. Int J Environ Res Public Health 2018;15. https://doi.org/10.3390/ijerph15102269.

[50] Yu D, Deng Q, Wang J, Chang X, Wang S, Yang R, et al. Air Pollutants are associated with Dry Eye Disease in Urban Ophthalmic Outpatients: a Prevalence Study in China. J Transl Med 2019;17:46. https://doi.org/10.1186/s12967-019-1794-6.

[51] Gupta SK, Gupta SC, Agarwal R, Sushma S, Agrawal SS, Saxena R. A multicentric casecontrol study on the impact of air pollution on eyes in a metropolitan city of India. Indian J Occup Environ Med 2007;11:37-40. https://doi.org/10.4103/00195278.32463.

[52] Apostol S, Filip M, Dragne C, Filip A. Dry eye syndrome. Etiological and therapeutic aspects. Oftalmologia 2003;59:28-31.

[53] Jaanus SD. Ocular side effects of selected systemic drugs. Optom Clin 1992;2:73-96.

[54] Wu M, Liu X, Han J, Shao T, Wang Y. Association Between Sleep Quality, Mood Status, and Ocular Surface Characteristics in Patients With Dry Eye Disease. Cornea 2019;38:311-7. https://doi.org/10.1097/ICO.0000000000001854.

[55] Kawashima M, Uchino M, Yokoi N, Uchino Y, Dogru M, Komuro A, et al. The association of sleep quality with dry eye disease: the Osaka study. Clinical Ophthalmology (Auckland, NZ) 2016;10:1015. https://doi.org/10.2147/OPTH.S99620. 
715 Figure 1: Flowchart showing the study methodology

716 Figure 2: Bar-graph showing age-wise stratified prevalence of dry eye disease in males and 717 females

718 Figure 3: Stratification of the overall participants and participants with dry eye disease

719 based on gender, site of residence and occupation

720 Figure 4: Stratification of the overall participants and participants with dry eye disease

721 based on risk factors of smoking, sun-exposure and exposure to indoor smoke.

722

723 Table legends

724 Table 1: Demographic characteristics of participants examined for the SEED (Sun Exposure, 725 Environment and Dry eye disease) study

726 Table 2: Climatic parameters at the three locations during mid-point of the study (2013)

727 Table 3: Prevalence (95\% Confidence Intervals, $\mathrm{CI}$ ) of Dry Eye Disease (DED) in three

728 geographical locations of India, among population aged $\geq 40$ years

729 Table 4: Site-specific prevalence of dry eye disease (DED) and its association with various 730 risk factors

731 Table 5: Multiple logistic regression showing association of dry eye disease with various risk 732 factors

733 Table 6: Review of literature of studies evaluating environmental risk factors for Dry Eye 734 Disease (DED)

735 Supplementary Table 1: Demographic profile of the participant and non-participant 736 population of the study

737 Supplementary Table 2: A gender wise multi-logistic regression analysis showing association 738 of DED with various risk factors

739 Supplementary Table 3: Multivariate regression analysis showing correlation of Dry eye 740 disease with various risk factors including systolic and diastolic hypertension 
Table 1: Demographic characteristics of participants examined for the SEED (Sun Exposure,

743 Environment and Dry eye disease) study

\begin{tabular}{|c|c|c|c|c|}
\hline & $\begin{array}{c}\text { Delhi-NCR } \\
\text { (Northern Plains) } \\
\mathrm{n}(\%)\end{array}$ & $\begin{array}{c}\text { Guwahati } \\
\text { (North-eastern } \\
\text { Hilly) } \\
\text { n (\%) }\end{array}$ & $\begin{array}{c}\text { Prakasam } \\
\text { (Southern } \\
\text { Coastal) } \\
\mathrm{n}(\%)\end{array}$ & All Centers \\
\hline \multicolumn{5}{|l|}{ Age (Years) } \\
\hline Mean age $( \pm S E)$ & $55.3(0.20)$ & $53.4(0.20)$ & $54.6(0.21)$ & $54.5(0.12)$ \\
\hline \multicolumn{5}{|l|}{ Gender } \\
\hline Male & $1,614(44.9)$ & $1,491(46.2)$ & $1,321(45.4)$ & $4,426(45.5)$ \\
\hline Female & $1,981(55.1)$ & $1,740(53.9)$ & $1,588(54.6)$ & $5,309(54.5)$ \\
\hline \multicolumn{5}{|l|}{ Education $\mathrm{n}(\%)$} \\
\hline Illiterate & $1,769(49.2)$ & $1,306(40.4)$ & $1,924(66.2)$ & $5,000(51.4)$ \\
\hline Studied up to primary & $532(14.8)$ & $779(24.1)$ & $487(16.7)$ & $1,798(18.5)$ \\
\hline Middle School (class 6-8) & $471(13.1)$ & $294(9.1)$ & $169(5.8)$ & $934(9.6)$ \\
\hline High School (class 9-12) & $721(20.1)$ & $742(23.0)$ & $262(9.0)$ & 1,725 (17.7) \\
\hline Graduation & $102(2.8)$ & $101(3.1)$ & $65(2.2)$ & $268(2.8)$ \\
\hline \multicolumn{5}{|l|}{ Occupation (\%) } \\
\hline Primarily Indoor & 569 (15.9) & $102(3.2)$ & $1,062(36.5)$ & $1,733(17.8)$ \\
\hline Primarily Outdoor & $3,021(84.2)$ & $3,121(96.8)$ & $1,847(63.5)$ & $7,989(82.2)$ \\
\hline Diabetes Mellitus (\%) & $206(5.8)$ & $166(5.3)$ & $460(16.2)$ & $832(8.7)$ \\
\hline Hypertension (\%) & $1,309(36.7)$ & $1,140(35.6)$ & $1,247(43.8)$ & $3,696(38.5)$ \\
\hline \multicolumn{5}{|l|}{ Body Mass Index (\%) } \\
\hline$<25 \mathrm{~kg} / \mathrm{m}^{2}$ & $2554(71.8)$ & $2686(85.5)$ & $1743(64.3)$ & $6983(74.2)$ \\
\hline$\geq 25 \mathrm{~kg} / \mathrm{m}^{2}$ & $1002(28.1)$ & $456(14.5)$ & $967(35.7)$ & $2425(25.8)$ \\
\hline \multicolumn{5}{|c|}{ Lifetime cumulative effective sun exposure (Thousand hours) } \\
\hline Median & 114.14 & 72.76 & 109.89 & 96.067 \\
\hline Range (min.-max.) & $7.30-314.10$ & $7.30-223.76$ & $7.30-252.18$ & $7.305-314.10$ \\
\hline
\end{tabular}

744

745 
Table 2: Climatic parameters at the three locations in India during the mid-point of the

747 study (2013)

\begin{tabular}{|c|c|c|c|}
\hline $\begin{array}{l}\text { Region } \\
\text { Parameters }\end{array}$ & $\begin{array}{c}\text { Delhi-NCR } \\
\text { (Northern Plains) }\end{array}$ & $\begin{array}{c}\text { Guwahati } \\
\text { (North-eastern Hilly) }\end{array}$ & $\begin{array}{c}\text { Prakasam } \\
\text { (Southern Coastal) }\end{array}$ \\
\hline UVA $($ mean $\pm S D)\left(\mathrm{Wm}^{-2}\right)$ & $10.92 \pm 3.87$ & $11.23 \pm 3.33$ & $13.05 \pm 3.48$ \\
\hline UVB $($ mean $\pm S D)\left(W^{-2}\right)$ & $0.25 \pm 0.11$ & $0.28 \pm 0.11$ & $0.35 \pm 0.10$ \\
\hline AOD (mean $\pm S D)$ & $0.64 \pm 0.38$ & $0.49 \pm 0.36$ & $0.46+0.19$ \\
\hline AQI & 179 & 127 & 68 \\
\hline Humidity (mean \pm SD) (\%) & $65.24 \pm 21.70$ & $80.57 \pm 9.09$ & $73.94 \pm 4.86$ \\
\hline Precipitation $(\mathrm{mm})$ & 1085.4 & 1650.5 & 1219.2 \\
\hline $\begin{array}{l}\text { Temperature }\left({ }^{\circ} \mathrm{C}\right) \\
\text { Mean } \pm \mathrm{SD} \\
\text { Minimum } \\
\text { Maximum }\end{array}$ & $\begin{array}{c}24.51 \pm 7.41 \\
19.0 \\
31.8\end{array}$ & $\begin{array}{c}24.91 \pm 4.77 \\
19.4 \\
31.1\end{array}$ & $\begin{array}{c}28.03 \pm 2.10 \\
24.2 \\
31.8\end{array}$ \\
\hline Average Wind Speed $(\mathrm{km} / \mathrm{hr})$ & 6.5 & 3.4 & 8.4 \\
\hline \multicolumn{4}{|l|}{ Air pollutants $\left(\mu \mathrm{g} / \mathrm{m}^{3}\right)$} \\
\hline $\begin{array}{l}\text { Mean } \\
\text { Maximum } \\
\text { Minimum }\end{array}$ & $\begin{array}{c}4.1 \\
10.5 \\
3.4\end{array}$ & $\begin{array}{c}7 \\
12 \\
3.2\end{array}$ & $\begin{array}{c}13.4 \\
56.1 \\
4\end{array}$ \\
\hline Nitrogen dioxide & & & \\
\hline Mean & 63.7 & 15.7 & 18 \\
\hline Maximum & 108.2 & 22.7 & 81.3 \\
\hline Minimum & 31.7 & 9.8 & 8.9 \\
\hline PM10 & & & \\
\hline Mean & 218.8 & 141.2 & 67.8 \\
\hline Maximum & 473.5 & 325.7 & 198.4 \\
\hline Minimum & 60.2 & 38 & 19 \\
\hline
\end{tabular}

748

\section{Footnote}

750 NCR- National capital region; UVA- Ultraviolet-A; UVB- Ultraviolet-B; AOD- Aerosol optical

751 depth; AQI- Air quality index; PM10- Particulate matter $\leq 10 \mu \mathrm{m}$. 
753 Table 3: Age-wise Prevalence (95\% Confidence Intervals, $\mathrm{Cl}$ ) of Dry Eye Disease (DED) in 754 three geographical locations of India, among population aged $\geq \mathbf{4 0}$ years

755

\begin{tabular}{|c|c|c|c|c|c|c|c|}
\hline & \multicolumn{2}{|c|}{ Overall } & \multicolumn{5}{|c|}{ Gender } \\
\hline & \multirow[b]{2}{*}{$\mathbf{n}$} & \multirow[b]{2}{*}{$\begin{array}{l}\text { DED } \\
\%(C I)\end{array}$} & \multicolumn{2}{|c|}{ Male } & \multicolumn{2}{|c|}{ Female } & \multirow[b]{2}{*}{$p t$} \\
\hline & & & $\mathbf{n}$ & $\begin{array}{l}\text { DED } \\
\%(C I)\end{array}$ & $\mathbf{n}$ & $\begin{array}{l}\text { DED } \\
\%(\mathrm{Cl})\end{array}$ & \\
\hline All participants & 9733 & $\begin{array}{c}26.2 \\
(25.3-27.1)\end{array}$ & 4,426 & $\begin{array}{c}24.0 \\
(22.7-25.2)\end{array}$ & 5,307 & $\begin{array}{c}28.0 \\
(26.8-29.2)\end{array}$ & $<0.001$ \\
\hline \multicolumn{8}{|l|}{ Age Group } \\
\hline $40-49$ years & 3,998 & $\begin{array}{c}20.7 \\
(19.5-22.0)\end{array}$ & 1727 & $\begin{array}{c}18.9 \\
(17.0-20.7)\end{array}$ & 2271 & $\begin{array}{c}22.1 \\
(20.4-23.9)\end{array}$ & 0.011 \\
\hline $50-59$ years & 2,438 & $\begin{array}{c}26.8 \\
(25.1-28.6)\end{array}$ & 1138 & $\begin{array}{c}22.8 \\
(20.4-25.3)\end{array}$ & 1300 & $\begin{array}{c}30.3 \\
(27.8-32.8)\end{array}$ & 0.000 \\
\hline $60-69$ years & 1,981 & $\begin{array}{c}29.1 \\
(27.1-31.1)\end{array}$ & 900 & $\begin{array}{c}26.8 \\
(23.9-29.7)\end{array}$ & 1081 & $\begin{array}{c}31.0 \\
(28.2-33.8)\end{array}$ & 0.040 \\
\hline$>70$ years & 1,316 & $\begin{array}{c}37.2 \\
(34.5-39.8)\end{array}$ & 661 & $\begin{array}{c}35.6 \\
(31.9-39.2)\end{array}$ & 655 & $\begin{array}{c}38.8 \\
(35-42.5)\end{array}$ & 0.226 \\
\hline$p$ value* & & $<0.001$ & & $<0.001$ & & $<0.001$ & \\
\hline
\end{tabular}

756 Footnote

757 * represents $p$-value of comparison of prevalence across age-groups, calculated using Chi758 square tests

$759+$ represents $p$-value of comparison of prevalence across males and females, calculated

760 using Chi-square tests

761 
Table 4: Site-specific prevalence of dry eye disease (DED) and its association with various

risk factors

\begin{tabular}{|c|c|c|c|c|c|c|c|c|}
\hline \multirow[t]{2}{*}{ Risk Factor } & \multicolumn{2}{|c|}{$\begin{array}{c}\text { Delhi NCR } \\
\text { (Northern Plains) } \\
\end{array}$} & \multicolumn{2}{|c|}{$\begin{array}{c}\text { Guwahati } \\
\text { (North-eastern Hilly) }\end{array}$} & \multicolumn{2}{|c|}{$\begin{array}{c}\text { Prakasam } \\
\text { (Southern Coastal) }\end{array}$} & \multicolumn{2}{|c|}{ Overall } \\
\hline & $n$ & DED * & $\mathbf{N}$ & DED * & $n$ & DED & $\mathbf{n}$ & DED* \\
\hline \multicolumn{9}{|c|}{ SOCIO-DEMOGRAPHIC FACTORS } \\
\hline \multicolumn{9}{|c|}{ Age Group } \\
\hline $40-49$ years & 1427 & $461(32.3)$ & 1454 & $279(19.2)$ & 1117 & $89(8.0)$ & 3,998 & $829(20.7)$ \\
\hline $50-59$ years & 881 & $374(42.5)$ & 802 & 200 (24.9) & 755 & $80(10.6)$ & 2,438 & $654(26.8)$ \\
\hline $60-69$ years & 746 & $345(46.3)$ & 603 & $162(26.9)$ & 632 & $69(10.9)$ & 1,981 & $576(29.1)$ \\
\hline $70+$ years & 540 & $304(56.3)$ & 371 & 135 (36.4) & 405 & $50(12.4)$ & 1,316 & $489(37.2)$ \\
\hline$p$ valuet & & $<0.001$ & & $<0.001$ & & 0.036 & & $<0.001$ \\
\hline \multicolumn{9}{|l|}{ Gender } \\
\hline Male & 1614 & $645(40.0)$ & 1491 & $298(20.0)$ & 1321 & $119(9.0)$ & 4,426 & $1062(24.0)$ \\
\hline Female & 1980 & $839(42.4)$ & 1739 & $478(27.5)$ & 1588 & $169(10.6)$ & 5,307 & $1486(28.0)$ \\
\hline$p$ valuet & & 0.144 & & $<0.001$ & & 0.142 & & $<0.001$ \\
\hline \multicolumn{9}{|l|}{ Site } \\
\hline Delhi NCR/Plain & - & - & - & - & - & - & 3,594 & $1484(41.3)$ \\
\hline Guwahati/Hilly & - & - & - & - & - & - & 3,230 & $776(24.0)$ \\
\hline Prakasam/Coastal & - & - & - & - & - & - & 2,909 & $288(9.9)$ \\
\hline$p$ valuet & - & - & - & - & - & - & & $<0.001$ \\
\hline \multicolumn{9}{|l|}{ Occupation } \\
\hline Primarily Indoor & 569 & $259(45.5)$ & 101 & $37(36.6)$ & 1062 & $116(10.9)$ & 1732 & $412(23.8)$ \\
\hline Primarily Outdoor & 3020 & $1223(40.5)$ & 3121 & $737(23.6)$ & 1847 & $172(9.3)$ & 7988 & $2132(26.7)$ \\
\hline$p$ valuet & & 0.026 & & 0.003 & & 0.160 & & 0.013 \\
\hline \multicolumn{9}{|c|}{ HEALTH BEHAVIOR RISK FACTORS } \\
\hline \multicolumn{9}{|c|}{ Smoking } \\
\hline Yes & 1993 & 874 (43.9) & 723 & $153(21.2)$ & 868 & $71(8.2)$ & 3584 & 1098 (30.6) \\
\hline No & 1601 & $610(38.1)$ & 2501 & $622(24.9)$ & 2041 & $217(10.6)$ & 6143 & 1449 (23.6) \\
\hline$p$ valuet & & $<0.001$ & & 0.040 & & 0.043 & & $<0.001$ \\
\hline \multicolumn{9}{|c|}{ Indoor smoke exposure } \\
\hline Yes & 2323 & 997 (42.9) & 2958 & $748(25.3)$ & 1651 & $175(10.6)$ & 6932 & $1920(27.7)$ \\
\hline No & 1271 & $487(38.3)$ & 272 & $28(10.3)$ & 1258 & $113(9.0)$ & 2801 & $628(22.4)$ \\
\hline$p$ valuet & & 0.007 & & $<0.001$ & & 0.148 & & $<0.001$ \\
\hline \multicolumn{9}{|c|}{ Lifetime cumulative effective sun exposure } \\
\hline $1^{\text {st }}$ quintile & 468 & $166(35.5)$ & 912 & 180 (19.7) & 567 & $38(6.7)$ & 1947 & $384(19.7)$ \\
\hline $2^{\text {nd }}$ quintile & 506 & $188(37.2)$ & 1186 & $277(23.4)$ & 253 & $15(5.9)$ & 1945 & $480(24.7)$ \\
\hline $3^{\text {rd }}$ quintile & 649 & $248(38.2)$ & 682 & $179(26.3)$ & 616 & $50(8.1)$ & 1947 & $477(24.5)$ \\
\hline $4^{\text {th }}$ quintile & 840 & 334 (39.8) & 347 & $102(29.4)$ & 760 & $79(10.4)$ & 1947 & $515(26.5)$ \\
\hline $5^{\text {th }}$ quintile & 1131 & $548(48.5)$ & 100 & $37(37.0)$ & 711 & 106 (14.9) & 1942 & $691(35.6)$ \\
\hline$p$ valuet & & $<0.001$ & & $<0.001$ & & $<0.001$ & & $<0.001$ \\
\hline \multicolumn{9}{|c|}{ Protective eye gear/ head gear use } \\
\hline Yes & 3533 & 1461 (41.4) & 3015 & $728(24.2)$ & 2900 & $288(9.9)$ & 9448 & $2477(26.2)$ \\
\hline No & 61 & $23(37.7)$ & 214 & $48(22.4)$ & 8 & $0(0.0)$ & 283 & $71(25.1)$ \\
\hline$p$ valuet & & 0.566 & & 0.570 & & 0.348 & & 0.670 \\
\hline
\end{tabular}




\section{SYSTEMIC RISK FACTORS}

\section{Diabetes Mellitus}

$\begin{array}{lcccccccc}\text { Yes } & 206 & 96(46.6) & 166 & 42(25.3) & 460 & 53(11.5) & 832 & 191(23.0) \\ \text { No } & 3365 & 1379(41.0) & 2995 & 714(23.8) & 2381 & 231(9.7) & 8741 & 2324(26.6) \\ p \text { valuet } & & 0.112 & & 0.667 & & 0.234 & 0.023\end{array}$

\section{Hypertension}

Yes

130

No

$2254 \quad 849(38.0) \quad 2061$

$311(28.5)$

$1247 \quad 102(8.2) \quad 3695$

1038 (28.1)

No

$p$ valuet

$<0.001$

459 (21.7)

1599

$183(11.4) \quad 5914$

1484 (25.1)

Body Mass Index

$<25 \mathrm{~kg} / \mathrm{m}^{2}$

$2553 \quad 1087(42.6) \quad 2686$

$<0.001$

0.004

0.001

$\geq 25 \mathrm{~kg} / \mathrm{m}^{2}$

$1002 \quad 378(37.7) \quad 456$

635 (23.6) 1743

220 (12.6)

6974

$1942(27.8)$

$p$ value +

0.008

0.597

$51(5.2)$

$2423 \quad 542$ (22.4)

764

765

Note: * values represent number of participants with DED and row \%; + p-value calculated using chi-square test 

of dry eye disease with various risk factors

\begin{tabular}{|c|c|c|c|c|c|c|c|c|}
\hline & \multicolumn{2}{|c|}{$\begin{array}{c}\text { Delhi-NCR } \\
\text { (Northern Plains) } \\
n=3595 \\
\end{array}$} & \multicolumn{2}{|c|}{$\begin{array}{c}\text { Guwahati } \\
\text { (North-eastern Hilly) } \\
n=3231 \\
\end{array}$} & \multicolumn{2}{|c|}{$\begin{array}{c}\text { Prakasam } \\
\text { (Southern Coastal) } \\
n=2909 \\
\end{array}$} & \multicolumn{2}{|c|}{$\begin{array}{l}\text { All Centers } \\
n=9735 \\
\end{array}$} \\
\hline & OR (95\% Cl) & $p$ value & OR (95\% Cl) & $p$ value & OR $(95 \% \mathrm{Cl})$ & $p$ value & OR (95\% Cl) & $p$ value \\
\hline \multicolumn{9}{|l|}{ Gender } \\
\hline Male & 1 & - & 1 & - & 1 & - & 1 & - \\
\hline Female & $1.0(0.8,1.3)$ & 0.889 & $1.4(1.1,1.7)$ & 0.001 & $0.8(0.4,1.5)$ & 0.462 & $1.2(1.0,1.4)$ & 0.017 \\
\hline \multicolumn{9}{|l|}{ Smoking } \\
\hline No & 1 & - & 1 & - & 1 & - & 1 & - \\
\hline Yes & $1.3(1.1,1.6)$ & $<0.001$ & $1.0(0.8,1.3)$ & 0.739 & $0.7(0.5,1.1)$ & 0.107 & $1.2(1.0,1.3)$ & 0.019 \\
\hline \multicolumn{9}{|l|}{ Indoor Smoke } \\
\hline No & 1 & - & 1 & - & 1 & - & 1 & - \\
\hline Yes & $1.4(1.1,1.7)$ & 0.014 & $2.7(1.8,4.2)$ & $<0.001$ & $1.6(0.8,3.1)$ & 0.144 & $1.3(1.1,1.5)$ & 0.006 \\
\hline \multicolumn{9}{|c|}{ Lifetime Cumulative Effective Sun Exposure } \\
\hline $1^{\text {st }}$ quintile & 1 & - & 1 & - & 1 & - & 1 & - \\
\hline $2^{\text {nd }}$ quintile & $1.1(0.8,1.4)$ & 0.640 & $1.3(1.0,1.6)$ & 0.043 & $0.8(0.4,1.6)$ & 0.603 & $1.2(1.0,1.4)$ & 0.056 \\
\hline $3^{\text {rd }}$ quintile & $1.1(0.9,1.4)$ & 0.459 & $1.5(1.1,1.9)$ & 0.002 & $1.0(0.7,1.7)$ & 0.861 & $1.3(1.1,1.5)$ & 0.005 \\
\hline $4^{\text {th }}$ quintile & $1.1(0.9,1.4)$ & 0.382 & $1.8(1.3,2.4)$ & $<0.001$ & $1.5(1.0,2.3)$ & 0.072 & $1.4(1.2,1.6)$ & $<0.001$ \\
\hline $5^{\text {th }}$ quintile & $1.5(1.2,1.9)$ & 0.001 & $2.8(1.7,4.5)$ & $<0.001$ & $2.1(1.3,3.2)$ & 0.001 & $1.8(1.5,2.2)$ & $<0.001$ \\
\hline \multicolumn{9}{|l|}{ Diabetes Mellitus } \\
\hline No & 1 & - & 1 & - & 1 & - & 1 & - \\
\hline Yes & $1.2(0.9,1.6)$ & 0.205 & $1.0(0.7,1.5)$ & 0.980 & $1.8(1.3,2.6)$ & 0.001 & $1.2(1.0,1.5)$ & 0.031 \\
\hline \multicolumn{9}{|l|}{ Hypertension } \\
\hline No & 1 & - & 1 & - & 1 & - & 1 & - \\
\hline Yes & $1.5(1.3,1.7)$ & $<0.001$ & $1.3(1.1,1.5)$ & 0.009 & $0.7(0.5,0.9)$ & 0.003 & $1.3(1.2,1.4)$ & $<0.001$ \\
\hline \multicolumn{9}{|l|}{ BMI } \\
\hline$<25 \mathrm{~kg} / \mathrm{m}^{2}$ & 1 & & 1 & & 1 & & 1 & \\
\hline$\geq 25 \mathrm{~kg} / \mathrm{m}^{2}$ & $0.8(0.7,0.9)$ & 0.009 & $1.0(0.8,1.3)$ & 0.923 & $0.4(0.3,0.6)$ & $<0.001$ & $0.8(0.7,0.9)$ & $<0.001$ \\
\hline \multicolumn{9}{|l|}{ Site } \\
\hline Delhi NCR/Plain & - & & - & & - & & 1 & - \\
\hline Guwahati/Hilly & - & & - & & - & & $0.5(0.4,0.6)$ & $<0.001$ \\
\hline Prakasam/Coastal & - & & - & & - & & $0.2(0.1,0.2)$ & $<0.001$ \\
\hline \multicolumn{9}{|c|}{ Footnotes } \\
\hline $\begin{array}{l}\text { Note: Only par } \\
\text { with no dry ey } \\
\text { National capit } \\
\text { The values of } \\
\text { Independent } v \\
\text { exposure, diab }\end{array}$ & $\begin{array}{l}\text { ticipants with } \\
\text { e disease were } \\
\text { al region. } \\
\text { DR and } \mathrm{Cl} \text { have } \\
\text { ariables incluo } \\
\text { etes mellitus, }\end{array}$ & been rou & $\begin{array}{l}\text { oded off to firs } \\
\text { Smoking, Ind } \\
\text { on and site of }\end{array}$ & $\begin{array}{l}\text { decimal } \\
\text { or Smok } \\
\text { tudy }\end{array}$ & place. & sed and & $\begin{array}{l}\text { articipants } \\
\text { al; NCR- }\end{array}$ & \\
\hline
\end{tabular}


778 Table 6: Review of literature of studies evaluating environmental risk factors for Dry Eye Disease (DED)

\begin{tabular}{|c|c|c|c|c|c|c|c|c|c|c|}
\hline Author & $\begin{array}{l}\text { Type of } \\
\text { Study }\end{array}$ & $\begin{array}{l}\text { Sample } \\
\text { Size }\end{array}$ & $\begin{array}{l}\text { Site of } \\
\text { Study }\end{array}$ & Study population & $\begin{array}{l}\text { Age } \\
\text { (mean) }\end{array}$ & $\begin{array}{l}\text { Gender } \\
\text { (M/F) }\end{array}$ & $\begin{array}{l}\text { Diagnostic } \\
\text { criteria }\end{array}$ & Prevalence & Risk Factors Assessed & Results \\
\hline $\begin{array}{l}\text { Um et } \\
\text { al.[6], } \\
2014\end{array}$ & $\begin{array}{l}\text { Population } \\
\text { based } \\
\text { Cross- } \\
\text { sectional } \\
\text { study }\end{array}$ & 16,431 & $\begin{array}{l}\text { South } \\
\text { Korea }\end{array}$ & $\begin{array}{l}>30 \text { years age of } \\
\text { the } 5 \text { th KNHANES }\end{array}$ & NA & $43: 57$ & $\begin{array}{l}\text { Previously } \\
\text { diagnosed } \\
\text { by } \\
\text { ophthalmo } \\
\text { logist with } \\
\text { presence } \\
\text { of } \\
\text { symptoms }\end{array}$ & $\begin{array}{l}10.4 \% \\
\text { (Diagnosed } \\
\text { cases) } \\
\\
17.7 \% \\
\text { (Symptom } \\
\text { s only) }\end{array}$ & $\begin{array}{l}\text { Age, gender, sunshine } \\
\text { exposure, region } \\
\text { (urban/rural), city size, } \\
\text { temperature, wind } \\
\text { speed, humidity, } \\
\text { sunshine duration, } \\
\text { precipitation, air } \\
\text { pollutants ( } \mathrm{SO}_{2}, \mathrm{NO}_{2} \text {, } \\
\mathrm{CO}, \text { Ozone, } \mathrm{PM} 10 \text { ) }\end{array}$ & $\begin{array}{l}\text { Positive association } \\
\text { Age } \\
\text { Female gender } \\
\text { Urban area } \\
\text { Higher temperature } \\
\text { Longer sunshine } \\
\text { Air pollutant- } \mathrm{SO}_{2} \\
\text { Negative association } \\
\text { Humidity }\end{array}$ \\
\hline $\begin{array}{l}\text { Galor } \\
\text { et } \\
\text { al.[48], } \\
2014\end{array}$ & $\begin{array}{l}\text { Retrospect } \\
\text { ive study }\end{array}$ & $3,410,000$ & USA & $\begin{array}{l}\text { Patients with ICD- } \\
9 \text { code for DED in } \\
\text { Veterans } \\
\text { Administration } \\
\text { eye between } \\
2006-2011\end{array}$ & NA & NA & NA & $19.6 \%$ & $\begin{array}{l}\text { AOD, } \\
\text { Atmospheric pressure, } \\
\text { Humidity, } \\
\text { temperature }\end{array}$ & $\begin{array}{l}\text { Positive association } \\
\text { Air pollution } \\
\text { Air pressure } \\
\text { Longitude } \\
\text { Latitude } \\
\text { Negative association } \\
\text { Wind speed } \\
\text { Humidity }\end{array}$ \\
\hline $\begin{array}{l}\text { Zhong } \\
\text { et } \\
\text { al.[49], } \\
2018\end{array}$ & $\begin{array}{l}\text { Retrospect } \\
\text { ive study }\end{array}$ & 25,818 & Taiwan & $\begin{array}{l}\text { Patients with ICD- } \\
9 \text { code for DED at } \\
\text { National Health } \\
\text { Insurance of } \\
\text { Taiwan from } 2004 \\
\text { to } 2013\end{array}$ & $\begin{array}{l}51.1 \pm 17.7 \\
\text { years }\end{array}$ & $31: 69$ & NA & - & $\begin{array}{l}\text { Air pollutants - } \mathrm{CO} \text {, } \\
\mathrm{NO}_{2}, \text { Ozone, } \mathrm{PM} 2.5, \\
\mathrm{PM}_{10} \text {, and } \mathrm{SO}_{2} \text {, and } \\
\text { meteorological data, } \\
\text { Relative humidity and } \\
\text { temperature }\end{array}$ & $\begin{array}{l}\text { Positive association } \\
\text { Age } \\
\text { Female gender } \\
\text { Air pollution - } \mathrm{CO}, \mathrm{NO}_{2} \\
\text { Temperature } \\
\text { Negative association } \\
\text { Relative humidity }\end{array}$ \\
\hline $\begin{array}{l}\text { Yu et } \\
\text { al.[50] } \\
\text { A, 2019 }\end{array}$ & $\begin{array}{l}\text { Hospital } \\
\text { based } \\
\text { cross } \\
\text { sectional } \\
\text { study }\end{array}$ & 23,922 & China & $\begin{array}{l}\text { Cases presenting } \\
\text { to ophthalmology } \\
\text { clinics in China } \\
\text { between July to } \\
\text { December } 2013\end{array}$ & NA & $49: 51$ & $\begin{array}{l}\text { Chinese } \\
\text { dry-eye } \\
\text { diagnostic } \\
\text { criteria* }\end{array}$ & $61.6 \%$ & $\begin{array}{l}\text { Age, gender, history of } \\
\text { kerato-refractive } \\
\text { surgery, history of } \\
\text { diseases (DM, arthritis } \\
\text { and thyroid diseases), } \\
\text { medication history, air }\end{array}$ & $\begin{array}{l}\text { Positive association } \\
\text { Age } \\
\text { Female gender } \\
\text { History of kerato- } \\
\text { refractive surgery } \\
\text { Arthritis, thyroid disease }\end{array}$ \\
\hline
\end{tabular}




\begin{tabular}{|c|c|c|c|c|c|c|c|c|c|c|}
\hline & & & & & & & & & $\begin{array}{l}\text { pollutant data (CO, } \\
\mathrm{NO}_{2}, \text { Ozone, } \mathrm{PM} 10 \text {, } \\
\left.\mathrm{PM}_{2.5}, \mathrm{SO}_{2}\right) \text {, relative } \\
\text { humidity, mean air } \\
\text { pressure, and air } \\
\text { temperature }\end{array}$ & 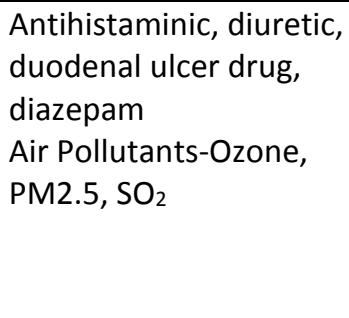 \\
\hline $\begin{array}{l}\text { Current } \\
\text { study }\end{array}$ & $\begin{array}{l}\text { Population } \\
\text { based } \\
\text { Cross- } \\
\text { sectional } \\
\text { study (part } \\
\text { of ICMR- } \\
\text { EYE SEE } \\
\text { Study) }\end{array}$ & 9,735 & $\begin{array}{l}\text { India- } \\
\text { Plain/ } \\
\text { Delhi } \\
\text { NCR, } \\
\text { Hilly/G } \\
\text { uwaha } \\
\text { ti, } \\
\text { Coastal } \\
\text { /Praka } \\
\text { sam }\end{array}$ & $\begin{array}{l}\text { Population with } \\
\text { age } \geq 40 \text { years }\end{array}$ & $\begin{array}{l}54.5 \pm 0.1 \\
\text { years }\end{array}$ & $46: 54$ & $\begin{array}{l}\text { TFOS- } \\
\text { DEWS II } \\
\text { diagnostic } \\
\text { criteria } \\
\text { (OSDI } \geq 13 \\
\text { and } \\
\text { TBUT<10 } \\
\text { or ocular } \\
\text { surface } \\
\text { staining> } 5 \\
\text { corneal } \\
\text { spots/>9 } \\
\text { conjunctiv } \\
\text { al spots) }\end{array}$ & $\begin{array}{l}26.2 \% \\
\text { (TBUT <10- } \\
34.5 \% ; \\
\text { Schirmer I } \\
<5-27.5 \% \text {; } \\
\text { Ocular } \\
\text { surface } \\
\text { staining - } \\
1.7 \% ; \\
\text { OSDI } \geq 13 \text { - } \\
65.4 \% \text { ) }\end{array}$ & $\begin{array}{l}\text { Age, Gender, } \\
\text { Occupation, DM, HTN, } \\
\text { life-time cumulative } \\
\text { effective sun-exposure, } \\
\text { smoking, indoor } \\
\text { smoke, ultra-violet } \\
\text { radiation, humidity, } \\
\text { temperature, air } \\
\text { pollution }(\mathrm{AOD}, \mathrm{AQ} \text {, } \\
\left.\mathrm{PM} 10, \mathrm{SO}_{2}, \mathrm{NO}_{2}\right) \text {, }\end{array}$ & $\begin{array}{l}\text { Positive association } \\
\text { Age } \\
\text { Female gender } \\
\text { HTN } \\
\text { Lifetime cumulative } \\
\text { effective sun-exposure } \\
\text { Smoking } \\
\text { Indoor smoke } \\
\text { Negative association } \\
\text { Site of residence (hills \& } \\
\text { coastal region) } \\
\text { Possible positive } \\
\text { association } \\
\text { Air pollution - NO }{ }_{2} \text {, } \\
\text { PM10, AQI, AOD } \\
\text { Possible negative } \\
\text { association } \\
\text { Humidity } \\
\text { Temperature } \\
\text { Wind speed }\end{array}$ \\
\hline
\end{tabular}

* (1) presence of at least one of the six symptoms: dry sensation, foreign body sensation, burning sensation, eyesight fatigue, discomfort and vision fluctuation; (2) TBUT $\leq 5 \mathrm{~s}$ or $\mathrm{Schirmer}$ I test $\leq 5 \mathrm{~mm} / 5 \mathrm{~min}$; (3) a positive diagnosis of fluorescein staining accompanied by one of the results: $5 \mathrm{~s}<\mathrm{TBUT} \leq 10 \mathrm{~s}$ or $5 \mathrm{~mm} / 5 \mathrm{~min}<\mathrm{Schirmer}$ I test $\leq 10 \mathrm{~mm} / 5 \mathrm{~min}$. The presence of (1) was essential for disease diagnosis. Subjects showing the presence of a combination of (1) and (2), or (1) and (3) were diagnosed with DED.

Footnotes: KNHANES - Korea National Health and Nutrition Examination Survey; $\mathrm{SO}_{2}$ - Sulphur dioxide; $\mathrm{NO}_{2}$ - Nitrogen dioxide; $\mathrm{CO}$ - Carbon mono-oxide; PM10 - Particulate matter 10 um; ICD - International classification of disease; DED - Dry eye disease; AOD- aerosol optical depth; PM2.5 - Particulate matter $2.5 \mu$ m; NCR- National capital region; DM - Diabetes mellitus; OSDIOcular Surface Disease Index; TBUT- Tear break up time; HTN -Hypertension; AQI-Air quality index. 
Supplementary Table 1: Demographic profile of the participant and non-participant population of the study

789

\begin{tabular}{lccc}
\hline & $\begin{array}{c}\text { Non-Participant } \\
\mathbf{n}(\%)\end{array}$ & $\begin{array}{c}\text { Participant } \\
\mathbf{n}(\%)\end{array}$ & $\begin{array}{c}\text { Overall } \\
\mathbf{n}(\%)\end{array}$ \\
\hline $\begin{array}{l}\text { Age group } \\
40-49\end{array}$ & $1,169(22.6)$ & $3,998(77.4)$ & $5,167(100)$ \\
$50-59$ & $610(20)$ & $2,437(80)$ & $3,047(100)$ \\
$60-69$ & $320(13.9)$ & $1,981(86.1)$ & $2,301(100)$ \\
$\geq 70$ & $189(12.5)$ & $1,317(87.5)$ & $1,506(100)$ \\
Gender & & & \\
Male & $1614(26.7)$ & $4426(73.3)$ & $6040(100)$ \\
Female & $674(11.3)$ & $5307(88.7)$ & $5981(100)$ \\
Study Site & & & \\
Delhi & & $3595(84.6)$ & \\
Guwahati & & $3229(78)$ & $4353(100)$ \\
Prakasam & $758(17.4)$ & $2909(82.5)$ & $4140(100)$ \\
\hline
\end{tabular}



association of DED with various risk factors

795

\begin{tabular}{|c|c|c|c|c|}
\hline & \multicolumn{2}{|c|}{$\begin{array}{c}\text { Male } \\
n=4314\end{array}$} & \multicolumn{2}{|c|}{$\begin{array}{c}\text { Female } \\
n=5143\end{array}$} \\
\hline & OR $(95 \% \mathrm{Cl})$ & p value & OR (95\% Cl) & $p$ value \\
\hline \multicolumn{5}{|l|}{ Smoking } \\
\hline No & 1 & - & 1 & - \\
\hline Yes & $1.2(1.0,1.4)$ & 0.112 & $1.1(0.9,1.4)$ & 0.16 \\
\hline \multicolumn{5}{|l|}{ Indoor Smoke } \\
\hline No & 1 & & 1 & \\
\hline Yes & $1.7(1.4,2.0)$ & $<0.001$ & $1.1(0.3,1.4)$ & 0.294 \\
\hline \multicolumn{5}{|c|}{ Lifetime Cumulative Effective Sun Exposure } \\
\hline $1^{\text {st }}$ quintile & 1 & - & 1 & - \\
\hline $2^{\text {nd }}$ quintile & $1.2(0.9,1.5)$ & 0.172 & $1.2(0.9,1.4)$ & 0.168 \\
\hline $3^{\text {rd }}$ quintile & $1.6(1.3,2.1)$ & $<0.001$ & $1.1(0.9,1.4)$ & 0.420 \\
\hline $4^{\text {th }}$ quintile & $1.6(1.3,2.0)$ & $<0.001$ & $1.3(1.1,1.7)$ & 0.013 \\
\hline $5^{\text {th }}$ quintile & $2.1(1.3,268)$ & $<0.001$ & $1.8(1.4,2.3)$ & $<0.001$ \\
\hline \multicolumn{5}{|l|}{ Diabetes Mellitus } \\
\hline No & 1 & - & 1 & - \\
\hline Yes & $1.2(0.9,1.6)$ & 0.226 & $1.3(1.0,1.6)$ & 0.06 \\
\hline \multicolumn{5}{|l|}{ Hypertension } \\
\hline No & 1 & - & 1 & - \\
\hline Yes & $1.3(1.1,1.6)$ & 0.001 & $1.2(1.1,1.4)$ & 0.002 \\
\hline \multicolumn{5}{|l|}{ BMI } \\
\hline$<25$ & 1 & - & 1 & - \\
\hline$>=25$ & $.7(0.5-0.8)$ & $<0.001$ & $0.8(0.7-0.97)$ & 0.021 \\
\hline \multicolumn{5}{|l|}{ Site } \\
\hline Delhi NCR/Plain & 1 & - & 1 & - \\
\hline Guwahati/Hilly & $0.3(0.3,0.4)$ & $<0.001$ & $0.6(0.5,0.7)$ & $<0.001$ \\
\hline Prakasam/Coastal & $0.2(0.1,0.2)$ & $<0.001$ & $0.2(0.1,0.2)$ & $<0.001$ \\
\hline
\end{tabular}

797 OR- Odd's ratio; Cl- Confidence interval; NCR- National capital region 
Supplementary Table 3: Multivariate regression analysis showing association of dry eye

800 disease with various risk factors including systolic and diastolic hypertension

801

\begin{tabular}{|c|c|c|c|c|c|c|c|c|}
\hline & \multicolumn{2}{|c|}{$\begin{array}{c}\text { Delhi } \\
\mathrm{n}=3534\end{array}$} & \multicolumn{2}{|c|}{$\begin{array}{c}\text { Guwahati } \\
n=3065\end{array}$} & \multicolumn{2}{|c|}{$\begin{array}{c}\text { Prakasam } \\
n=2620\end{array}$} & \multicolumn{2}{|c|}{$\begin{array}{c}\text { Overall Population } \\
n=9219\end{array}$} \\
\hline & OR (95\% Cl) & $p$ value & OR (95\% Cl) & $p$ value & OR (95\% Cl) & $p$ value & OR (95\% Cl) & $p$ value \\
\hline \multicolumn{9}{|l|}{ Gender } \\
\hline Male & 1 & & 1 & & 1 & & 1 & \\
\hline Female & $1.0(0.8,1.3)$ & 0.860 & $1.4(1.1,1.7)$ & 0.001 & $0.8(0.4,1.5)$ & 0.446 & $1.2(1.0,1.4)$ & 0.014 \\
\hline \multicolumn{9}{|l|}{ Smoking } \\
\hline No & 1 & & 1 & & 1 & & 1 & \\
\hline Yes & $1.3(1.1,1.6)$ & $<0.001$ & $1.0(0.8,1.3)$ & 0.811 & $0.7(0.5,1.1)$ & 0.092 & $1.2(1.0,1.3)$ & 0.022 \\
\hline \multicolumn{9}{|l|}{ Indoor Smoke } \\
\hline No & 1 & & 1 & & 1 & & 1 & \\
\hline Yes & $1.4(1.1,1.7)$ & 0.012 & $2.7(1.8,4.2)$ & $<0.001$ & $1.6(0.9,3.1)$ & 0.141 & $1.3(1.1,1.5)$ & 0.004 \\
\hline \multicolumn{9}{|c|}{ Lifetime Cumulative Effective Sun Exposure } \\
\hline $1^{\text {st }}$ quintile & 1 & & 1 & & 1 & & 1 & \\
\hline $2^{\text {nd }}$ quintile & $1.1(0.8,1.4)$ & 0.524 & $1.2(1.0,1.6)$ & 0.047 & $0.8(0.4,1.6)$ & 0.595 & $1.2(1.0,1.4)$ & 0.056 \\
\hline $3^{\text {rd }}$ quintile & $1.1(0.9,1.4)$ & 0.368 & $1.5(1.1,1.9)$ & 0.003 & $1.0(0.7,1.7)$ & 0.861 & $1.3(1.1,1.5)$ & 0.005 \\
\hline $4^{\text {th }}$ quintile & $1.1(0.9,1.5)$ & 0.280 & $1.8(1.4,2.5)$ & $<0.001$ & $1.5(1.0,2.3)$ & 0.061 & $1.4(1.2,1.7)$ & $<0.001$ \\
\hline $5^{\text {th }}$ quintile & $1.5(1.2,1.9)$ & $<0.001$ & $2.9(1.8,4.6)$ & $<0.001$ & $2.1(1.4,3.3)$ & 0.001 & $1.9(1.6,2.2)$ & $<0.001$ \\
\hline \multicolumn{9}{|l|}{ Diabetes Mellitus } \\
\hline No & 1 & & 1 & & 1 & & 1 & \\
\hline Yes & $1.2(0.9,1.7)$ & 0.161 & $1.0(0.7,1.5)$ & 0.984 & $1.7(1.2,2.5)$ & 0.002 & $1.3(1.0,1.5)$ & 0.017 \\
\hline \multicolumn{9}{|c|}{ Systolic Hypertension } \\
\hline No & 1 & & 1 & & 1 & & 1 & \\
\hline Yes & $1.4(1.2,1.6)$ & $<0.001$ & $1.1(0.9,1.4)$ & 0.243 & $0.6(0.5,0.9)$ & 0.009 & $1.2(1.0,1.3)$ & 0.010 \\
\hline \multicolumn{9}{|c|}{ Diastolic Hypertension } \\
\hline No & 1 & & 1 & & 1 & & 1 & \\
\hline Yes & $1.1(0.9,1.4)$ & 0.305 & $1.2(0.9,1.6)$ & 0.290 & $1.0(0.6,1.6)$ & 0.990 & $1.1(1.0,1.3)$ & 0.111 \\
\hline \multicolumn{9}{|l|}{ BMI } \\
\hline$<25 \mathrm{~kg} / \mathrm{m}^{2}$ & 1 & & 1 & & 1 & & 1 & \\
\hline$\geq 25 \mathrm{~kg} / \mathrm{m}^{2}$ & $0.8(0.7,0.9)$ & 0.007 & $1.0(0.8,1.3)$ & 0.789 & $0.4(0.3,0.5)$ & $<0.001$ & $0.8(0.7,0.9)$ & $<0.001$ \\
\hline \multicolumn{9}{|l|}{ Site } \\
\hline Delhi NCR/Plain & - & - & - & - & - & - & - & \\
\hline Guwahati/Hilly & - & - & - & - & - & - & $0.5(0.5,0.6)$ & $<0.001$ \\
\hline Prakasam/Coastal & - & - & - & - & - & - & $0.2(0.1,0.2)$ & $<0.001$ \\
\hline
\end{tabular}




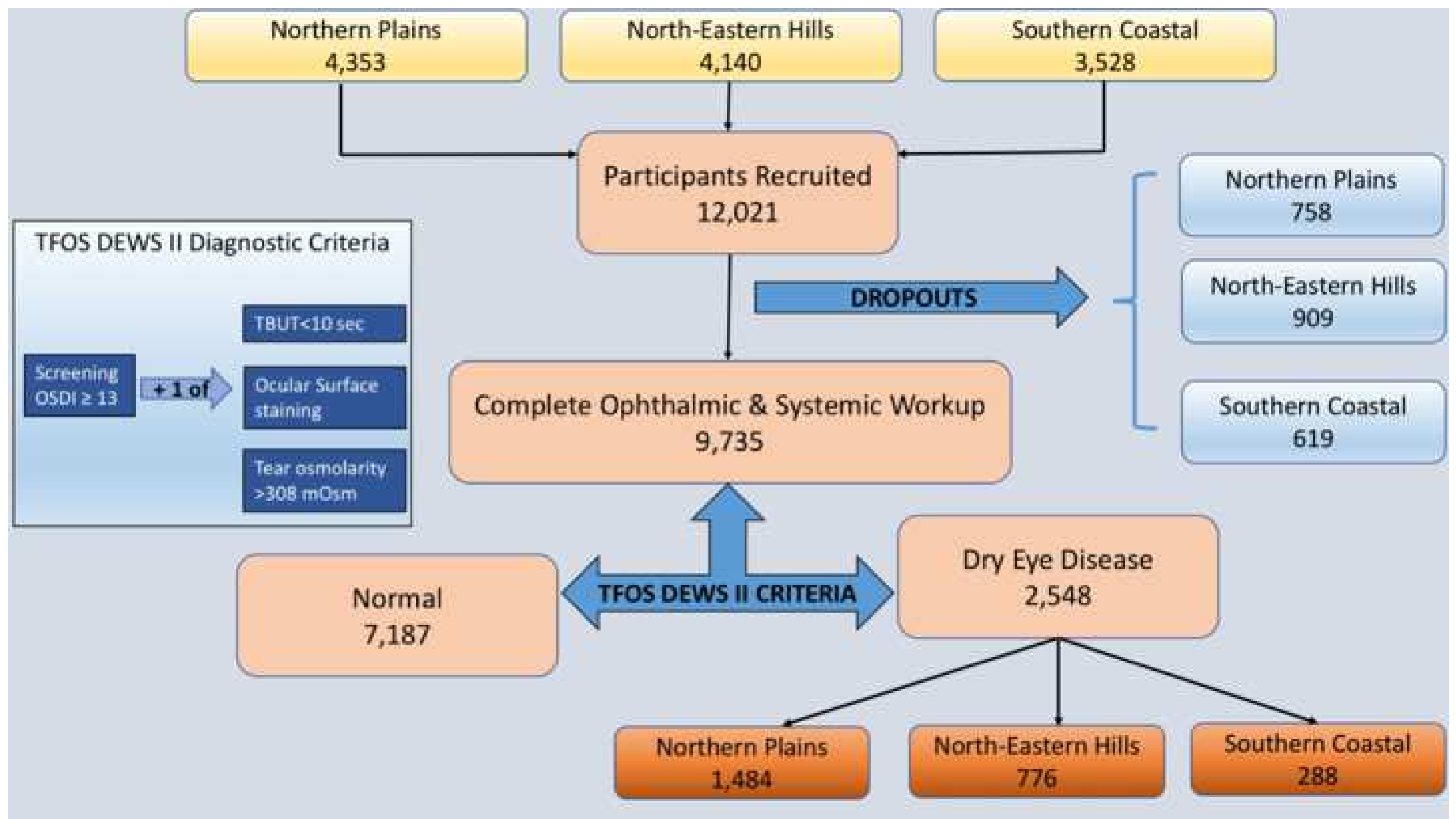




\section{Age-wise Stratified Prevalence of Dry Eye Disease}

45

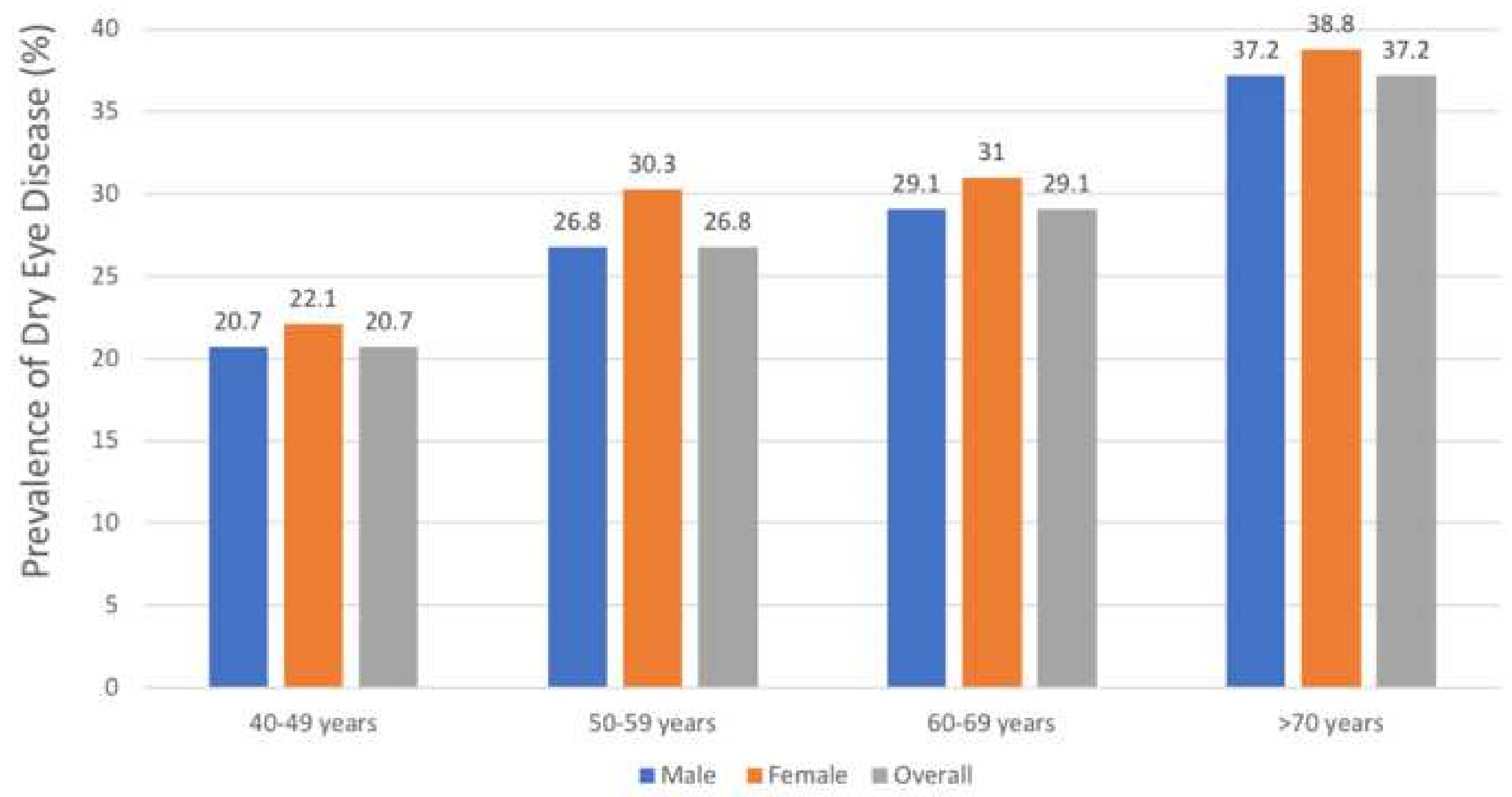




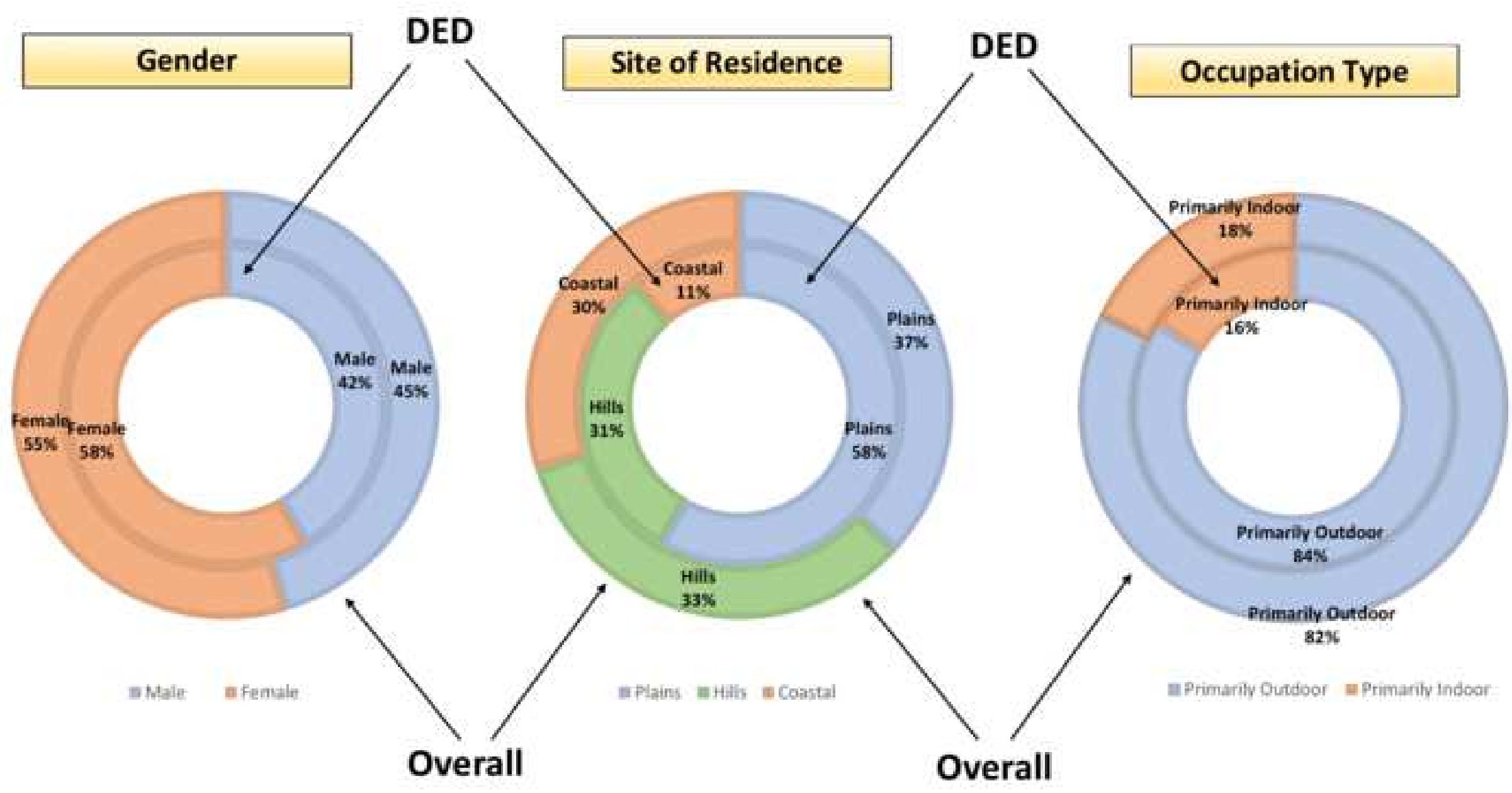




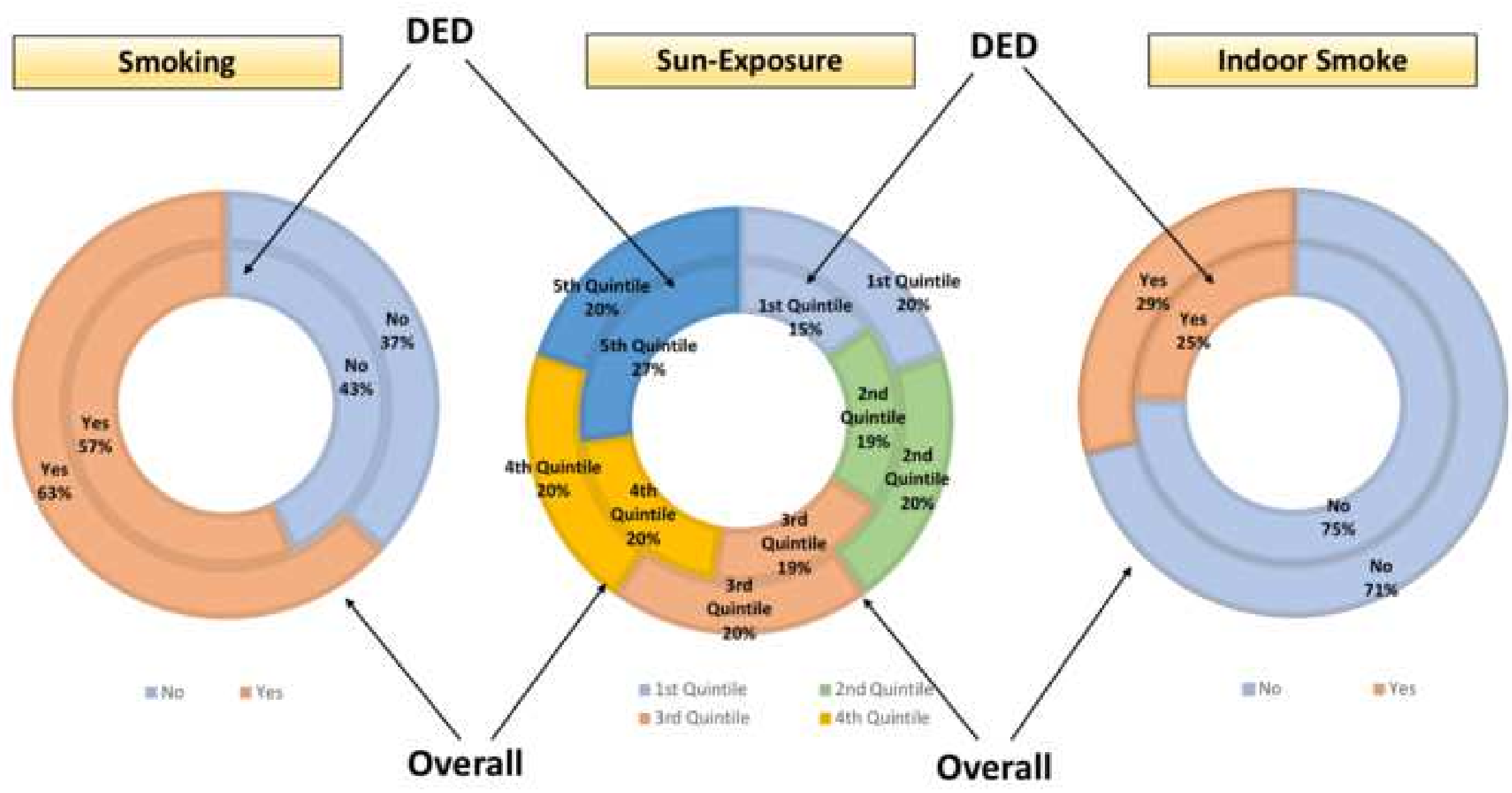




\section{Please wait...}

If this message is not eventually replaced by the proper contents of the document, your PDF viewer may not be able to display this type of document.

You can upgrade to the latest version of Adobe Reader for Windows®, Mac, or Linux® by visiting http://www.adobe.com/go/reader_download.

For more assistance with Adobe Reader visit http://www.adobe.com/go/acrreader.

Windows is either a registered trademark or a trademark of Microsoft Corporation in the United States and/or other countries. Mac is a trademark of Apple Inc., registered in the United States and other countries. Linux is the registered trademark of Linus Torvalds in the U.S. and other countries. 


\section{Please wait...}

If this message is not eventually replaced by the proper contents of the document, your PDF viewer may not be able to display this type of document.

You can upgrade to the latest version of Adobe Reader for Windows®, Mac, or Linux® by visiting http://www.adobe.com/go/reader_download.

For more assistance with Adobe Reader visit http://www.adobe.com/go/acrreader.

Windows is either a registered trademark or a trademark of Microsoft Corporation in the United States and/or other countries. Mac is a trademark of Apple Inc., registered in the United States and other countries. Linux is the registered trademark of Linus Torvalds in the U.S. and other countries. 


\section{Please wait...}

If this message is not eventually replaced by the proper contents of the document, your PDF viewer may not be able to display this type of document.

You can upgrade to the latest version of Adobe Reader for Windows®, Mac, or Linux® by visiting http://www.adobe.com/go/reader_download.

For more assistance with Adobe Reader visit http://www.adobe.com/go/acrreader.

Windows is either a registered trademark or a trademark of Microsoft Corporation in the United States and/or other countries. Mac is a trademark of Apple Inc., registered in the United States and other countries. Linux is the registered trademark of Linus Torvalds in the U.S. and other countries. 


\section{Please wait...}

If this message is not eventually replaced by the proper contents of the document, your PDF viewer may not be able to display this type of document.

You can upgrade to the latest version of Adobe Reader for Windows®, Mac, or Linux® by visiting http://www.adobe.com/go/reader_download.

For more assistance with Adobe Reader visit http://www.adobe.com/go/acrreader.

Windows is either a registered trademark or a trademark of Microsoft Corporation in the United States and/or other countries. Mac is a trademark of Apple Inc., registered in the United States and other countries. Linux is the registered trademark of Linus Torvalds in the U.S. and other countries. 


\section{Please wait...}

If this message is not eventually replaced by the proper contents of the document, your PDF viewer may not be able to display this type of document.

You can upgrade to the latest version of Adobe Reader for Windows®, Mac, or Linux® by visiting http://www.adobe.com/go/reader_download.

For more assistance with Adobe Reader visit http://www.adobe.com/go/acrreader.

Windows is either a registered trademark or a trademark of Microsoft Corporation in the United States and/or other countries. Mac is a trademark of Apple Inc., registered in the United States and other countries. Linux is the registered trademark of Linus Torvalds in the U.S. and other countries. 


\section{Please wait...}

If this message is not eventually replaced by the proper contents of the document, your PDF viewer may not be able to display this type of document.

You can upgrade to the latest version of Adobe Reader for Windows®, Mac, or Linux® by visiting http://www.adobe.com/go/reader_download.

For more assistance with Adobe Reader visit http://www.adobe.com/go/acrreader.

Windows is either a registered trademark or a trademark of Microsoft Corporation in the United States and/or other countries. Mac is a trademark of Apple Inc., registered in the United States and other countries. Linux is the registered trademark of Linus Torvalds in the U.S. and other countries. 


\section{Please wait...}

If this message is not eventually replaced by the proper contents of the document, your PDF viewer may not be able to display this type of document.

You can upgrade to the latest version of Adobe Reader for Windows®, Mac, or Linux® by visiting http://www.adobe.com/go/reader_download.

For more assistance with Adobe Reader visit http://www.adobe.com/go/acrreader.

Windows is either a registered trademark or a trademark of Microsoft Corporation in the United States and/or other countries. Mac is a trademark of Apple Inc., registered in the United States and other countries. Linux is the registered trademark of Linus Torvalds in the U.S. and other countries. 


\section{Please wait...}

If this message is not eventually replaced by the proper contents of the document, your PDF viewer may not be able to display this type of document.

You can upgrade to the latest version of Adobe Reader for Windows®, Mac, or Linux® by visiting http://www.adobe.com/go/reader_download.

For more assistance with Adobe Reader visit http://www.adobe.com/go/acrreader.

Windows is either a registered trademark or a trademark of Microsoft Corporation in the United States and/or other countries. Mac is a trademark of Apple Inc., registered in the United States and other countries. Linux is the registered trademark of Linus Torvalds in the U.S. and other countries. 


\section{Please wait...}

If this message is not eventually replaced by the proper contents of the document, your PDF viewer may not be able to display this type of document.

You can upgrade to the latest version of Adobe Reader for Windows®, Mac, or Linux® by visiting http://www.adobe.com/go/reader_download.

For more assistance with Adobe Reader visit http://www.adobe.com/go/acrreader.

Windows is either a registered trademark or a trademark of Microsoft Corporation in the United States and/or other countries. Mac is a trademark of Apple Inc., registered in the United States and other countries. Linux is the registered trademark of Linus Torvalds in the U.S. and other countries. 
1 Association of Dry Eye Disease and Sun Exposure in Geographically Diverse Adult ( $\geq 40$

2 years) Populations of India: The SEED (Sun Exposure, Environment and Dry eye disease)

3

4

5

6

7 Radhika Tandon ${ }^{1}$, Praveen Vashist ${ }^{1}$, Noopur Gupta ${ }^{1}$, Vivek Gupta ${ }^{1}$, Pranita Sahay ${ }^{1}$, Dipali

8

$9{ }^{1}$ Dr. Rajendra Prasad Centre for Ophthalmic Sciences, AlIMS, New Delhi, India

$10 \quad{ }^{2}$ Regional Institute of Ophthalmology, Guwahati, India

$11{ }^{3}$ CSIR-National Physical Laboratory, New Delhi, India

$12{ }^{4}$ Pushpagiri Vitreo Retina Institute, Secunderabad, Telangana, India

$13{ }^{5}$ Indian Institute of Public Health, Hyderabad, India

14 Short Title: Sun Exposure, Environment and Dry Eye Disease (SEED) Study

15 Meeting Presentations: Joint meeting of the Asia-Pacific Academy of Ophthalmology and All

16 India Ophthalmological Society, Hyderabad, India - 2013 \& 8th International Conference on

17 the Tear Film \& Ocular Surface: Basic Science \& Clinical Relevance at Montpellier, France-

$18 \quad 2016$

19 Keywords: Epidemiology; Dry Eye; Risk Factors; Age; Sex; Sunlight exposure; Smoking;

20 Indoor smoke exposure; Environment air pollution and geographic location; Systemic

21 diseases hypertension and diabetes.

22 
23 Dr Radhika Tandon, Professor of Ophthalmology, Faculty in charge Unit 6-Cornea and

24 External Disease, Cataract and refractive Surgery, Ocular Oncology and Low Vision Services.

25 Room 490, $4^{\text {th }}$ Floor, Dr Rajendra Prasad Centre for Ophthalmic Sciences, All India Institute

26 of Medical Sciences, New Delhi-110029, India.

27 Grant

28 The research was funded by Indian Council of Medical Research (ICMR), India - Grant No

$2968 / 4 / 2009-N C D-1$. The funding source had no role in the study design, in the collection,

30 analysis and interpretation of data, writing of the report; and in the decision to submit the

31 article for publication.

32

33 


\section{Abstract (250 words)}

\section{Purpose}

36 To estimate the prevalence and determine risk factors for dry eye disease (DED) in

37 geographically diverse regions of India.

\section{Method}

A population based cross-sectional study was conducted on people aged $\geq 40$ years in plain, hilly and coastal areas. Dry eye assessment by objective [tear film break-up time (TBUT), Schirmer I, corneal staining] and subjective [Ocular surface disease Index (OSDI)] parameters was performed with questionnaire-based assessment of exposure to sunlight, cigarette smoke, indoor smoke. The prevalence of DED with age, sex, occupation, location, smoking, exposure to sunlight, indoor smoke, diabetes, hypertension, was subjected to logistic regression analysis.

\section{Results}

9,735 people (age $54.5 \pm 0.1$ years; range $40-99$, males $45.5 \%$ ) were included. The prevalence of DED was $26.2 \%$, was higher in plains $(41.3 \%)$ compared to hilly $(24.0 \%)$ and coastal area $(9.9 \%)(p<0.001)$ and increased with age $(p<0.001)$, female gender $(p<0.001)$, smoking $(p<0.001)$, indoor smoke $(p<0.001)$, diabetes $(p-0.02)$, hypertension $(0.001)$, occupations with predominant outdoor activity ( $p-0.013)$ and increasing exposure to sunlight (trend). Multi-logistic regression showed a positive association with female sex (OR-1.2, Cl-1.01, 1.4), exposure to indoor smoke (OR-1.3, $\mathrm{Cl}-1.1,1.5)$, smoking (OR-1.2; $\mathrm{Cl}-1.03,1.3)$, prolonged exposure to sunlight (OR-1.8, $\mathrm{Cl}-1.5,2.2)$, hypertension (OR 1.3, $\mathrm{Cl}-1.2,1.4)$, diabetes (OR-1.2, $\mathrm{Cl}-1,1.5)$ and negative association with region - hilly (OR-0.5, $\mathrm{Cl}-0.4,0.6)$ and coastal (OR-0.2; $\mathrm{Cl}-0.1,0.2)$, and $\mathrm{BMI}(\mathrm{OR}-0.8, \mathrm{Cl}-0.7,0.9)$.

\section{Conclusion}


58 DED is common in population $\geq 40$ years of age. Its prevalence is affected by extrinsic

59 (geographic location, exposure to sunlight, smoking, indoor smoke) and intrinsic (age, sex,

60 hypertension, diabetes, BMI) factors.

61 
Dry eye disease has been defined by Tear Film Ocular Surface Society Dry eye workshop II (TFOS DEWS II) as a multi-factorial disorder of the ocular surface characterized by loss of ocular homeostasis resulting in various ocular symptoms. [1] It is a major cause of ocular morbidity which usually does not directly affect vision in most cases, but does affect the quality of life markedly. Its reported prevalence varies from 5\%-75\%.[2-12]

68

The TFOS DEWS II epidemiological report concluded that DED is more common in Asians compared to Caucasians.[3] While there are numerous studies from China[5,13,14], Japan[2], Korea[6,7] and Singapore[8], there are no similar reports from India, world's second most populated country.[3] Additionally, it is hypothesized that geographic location and climate can influence the occurrence of DED; however, this has not been validated by evaluating diverse environmental conditions in a single study.[3] With the geographic and climatic variation in India, we had an opportunity to explore the effect of the same in the prevalence of DED by conducting a multi-centric study with geographic mapping approach including populations from coastal, hilly and plain areas accounting for the effect of variations in humidity and air quality index on DED. Sunlight exposure and smoke are additional risk factors for DED for which, at present, reports are inconclusive. In the current study, their effect was assessed in addition to age, sex, education, job profile, and use of protective eye wear and head gear.

We present herein, the results of, to the best of our knowledge, the first population-based study on dry eye disease from India reporting its prevalence, associated risk factors, with 
the evaluation of the effect of geographical variations, an arena that has not been extensively explored previously.

\section{Methods}

A multi-centric population based cross-sectional study was conducted at three geographically diverse places in rural settings of India between 2010 and 2016. Important considerations in choosing the study sites were, to have representation of plains, hilly and coastal areas, and sites should have readily available physical and environmental data.

Gurgaon district of National Capital Region (NCR) Delhi, was chosen as representative for northern plains (henceforth referred to as Delhi NCR). The study in hills was done in Kamrup district located adjacent to Guwahati, capital city of the state of Assam (henceforth referred to as Guwahati). Prakasam district was chosen to represent the southern coastal region. The study adhered to the Declaration of Helsinki. The study was approved by Institutional Ethics Committee of All India Institute of Medical Sciences, New Delhi, India (P-16/04.08.2009); Indian Institute of Public Health, Hyderabad, India (33/2011-08-08); and Regional Institute of Ophthalmology, Guwahati, India (MC/190/2007/1098-23.02.2010). Written informed consent was obtained from all participants prior to enrollment in the study. The detailed methodology of the study has been reported previously and is outlined in Figure 1.[15]

\section{Population}

A target of 3500 participants aged $\geq 40$ years from each location was set. Using census village data, the population was divided into clusters of 400-600 population each having 100-150 eligible participants. Cluster random sampling was used to select 35 clusters at each study site. 


\section{Questionnaire Schedule}

111 House visits were conducted by trained field workers and participants were interviewed

112 using a structured questionnaire schedule. It included questions on socio-demographic

113 information, smoking, indoor smoke exposure, sun exposure and systemic illness.

114 Occupation was classified as primarily indoors or outdoors. Smoking was defined as lifetime

115 history of use of any smoked tobacco product. Indoor smoke exposure was defined as

116 lifetime history of use of biomass fuels (coal, dung-cakes, wood) in the kitchen.

117

\section{Clinical examination}

119 All cases underwent a detailed ophthalmic evaluation including uncorrected visual acuity

120 (UCVA) and corrected distance visual acuity (CDVA) on ETDRS chart, intra-ocular pressure,

121 Schirmer I, slit lamp examination, tear film break-up time (TBUT), ocular surface staining,

122 anterior segment examination and indirect ophthalmoscopy for fundus evaluation in a local

123 indoor clinic set-up at the study site. TBUT was assessed with the help of a hand-held slit

124 lamp using cobalt blue filter after instillation of fluorescein stain. Home visits were

125 conducted in special situations like a bed bound or moribund patient.

126 Systemic examination included measurement of height, weight, random blood sugar and

127 blood pressure (two readings taken five minutes apart). Diabetes mellitus was diagnosed if

128 the random blood sugar level was $\geq 200 \mathrm{mg} / \mathrm{dl}$ or the participant was an already diagnosed

129 case of diabetes mellitus on medical treatment.[16] Hypertension was diagnosed if systolic

130 blood pressure (SBP) was $\geq 140 \mathrm{~mm}$ of $\mathrm{Hg}$ or diastolic blood pressure (DBP) was $\geq 90 \mathrm{~mm}$ of

$131 \mathrm{Hg}$ or a participant was a previously diagnosed case of hypertension on medical 
132 treatment.[17] Body mass index (BMI) was calculated as weight in kg divided by the square 133 of height in metres.

136 Diagnosis of dry eye disease (DED) was based on the guidelines defined by TFOS DEWS II

137 which uses dry eye questionnaire as a screening tool and TBUT, corneal staining or tear

138 osmolarity for diagnosis. [1] OSDI was used as a screening test. Participants with OSDI score

$139 \geq 13$ were further assessed with objective tests that included TBUT and ocular surface

140 staining. Tear osmolarity was not performed in this study. Cases with OSDI >13 and either

141 TBUT<10s or evidence of ocular surface staining were defined as having DED.

142 The Ocular Surface Disease Index (OSDI), a 12-item questionnaire, was used for assessment

143 of severity of symptoms related to dry eye and its effect on vision. The questionnaire was

144 translated into the three local languages (Assamese, Hindi and Telugu) and piloted to

145 confirm that the items were comprehensible. These versions were then back translated into

146 English by independent sets of translators conversant with the respective languages. The

147 initial and back-translated versions were compared to assess linguistic validity. As it was a

148 validated questionnaire, face validation with experts was done. The questionnaire was

149 administered by trained interviewers. Kappa values were calculated to assess the inter-

150 observer variation and were found to be within the acceptable range.

151 The response to each question in the OSDI questionnaire has a five-category Likert-type

152 response option. The final OSDI score is calculated by the following formula:

153

OSDI Score $=\frac{\text { Total score }}{\text { Number of questions answered by the participants }}^{25}$ 
157 The lifetime effective sun exposure was calculated for every individual using the following 158 formula, based on the Melbourne visual impairment project model:

159 Lifetime Effective Sun Exposure $=\Sigma$ [Daily hours of sun exposure without head gear + (Daily hours of sun exposure using head gear $x$ protection factor)] $\times 365 \times$ Number of years

161 The number of years refers to the duration from the time respondent crossed the age of 15 years and the time of examination (current age - 15). The sun-protection factors for hats, sunglasses, spectacles, and contact lenses were taken as $0.53,0.07,0.21$ and 0.31 respectively.[18]

\section{Climatic Parameters}

The measurements of aerosol optical depth (AOD) data, total (direct + diffuse) UVA (315-400 $\mathrm{nm})$ and UVB (280-315 $\mathrm{nm}$ ) flux were noted at Delhi between October 2012 to September 2015 and compared with the satellite-based Clouds and Earth's Radiant Energy System (CERES) data products for UVA, UVB to validate the same. The measurements showed excellent agreement $(r \sim 0.92-0.93)$ with satellite-retrieved CERES UV fluxes.[19] Hence, the

172 satellite-based data was used for the long-term UVA, UVB and AOD values in the present 173 study at the three locations. In addition, meteorological data for humidity, precipitation, 174 temperature, wind speed, and air pollutants was also obtained for the three locations. 175 Meteorological data for Prakasam (Southern coastal) was obtained from the nearest center 176 at Vishakhapatnam (representing coastal region). 
179 Double entry of all data was done in a Microsoft Access ${ }^{\mathrm{TM}}$ database to avoid transcription 180 errors. Data was analyzed using Stata 13 (StataCorp, College Station, TX). Participants with 181 incomplete information on sun exposure or ocular examination were excluded. All study 182 participants were distributed into quintiles based on the lifetime effective sun exposure.

183 Pearson chi-square test, $\mathrm{t}$-test and Kruskal-Wallis tests were used for data that was 184 categorical, continuous, and non-parametric continuous respectively. Risk factor 185 comparisons were performed within-site and for combined data. P-value $<0.05$ was considered statistically significant and $95 \%$ confidence intervals $(\mathrm{Cl})$ were calculated. Multivariable logistic regression analysis was performed for all the factors that showed a significant association on simple logistic regression.

\section{Results}

Demographic and Basic Clinical Characteristics

192 A total of 12,021 individuals above 40 years of age were recruited in the study from the three locations (Delhi -4,353; Guwahati-4,140; Prakasam - 3,528). A comprehensive risk

194 factor and clinical assessment for dry eye disease was completed in $81 \%$ of the recruited population ( $n=9,735 / 12,021$; Delhi- 3,595; Guwahati- 3,231; Prakasam- 2,909). The participation was similar across age groups. (Supplementary Table 1) The characteristics of the participant population is shown in Table 1 and Figure 2. The mean age of the population was $54.5 \pm 0.1$ years. Males constituted $45.5 \%$ and females $54.5 \%$. The occupation included predominant outdoor activity in $82.2 \%$ of the population. No definitive history of occupational exposure to chemicals was reported by any of the participants. Diabetes mellitus was observed in $8.7 \%$ participants, with highest prevalence in Prakasam (Southern coastal) (16.2\%). Hypertension was observed in 38.5\% participants, with highest prevalence 
in Prakasam (Southern coastal) (43.8\%). Allergic conditions like asthma, skin allergy and

204 sinusitis were observed in $0.56 \%$ of the participants $(n-55 / 9,735)$. Asthma was the most common condition noted in the participants with allergic conditions ( $n-51 / 55)$. The BMI was $\geq 25$ in $24.9 \%$ of the participants $(n-2425 / 9,408)$. Smoking was reported by $36.8 \%$ of the participants with $80.9 \%$ participants being current smokers. Among the participants with history of cigarette smoking, $59.5 \%$ participants were heavy smokers ( $\geq 5$ cigarettes/day). The presenting visual acuity of the better eye was $\geq 6 / 12$ in $69.9 \%(95 \% \mathrm{Cl}-68.9 \%, 70.8 \%)$ of the participants. Mild visual impairment $(<6 / 12-6 / 18)$ was observed in $7.8 \%(95 \% \mathrm{Cl}-7.3 \%$, $8.3 \%)$, moderate visual impairment $(<6 / 18-6 / 60)$ in $17.7 \%(95 \% \mathrm{Cl}-16.9 \%, 18.4 \%)$, severe visual impairment $(<6 / 60-3 / 60)$ in $1.2 \%(95 \% \mathrm{Cl}-0.9 \%, 1.4 \%)$ and blindness $(<3 / 60)$ in $3.5 \%$ (95\% Cl- 3.1\%, 3.9\%).

Climatic Parameters

216

The only available long-term data of UV is the erythemal UV irradiance data obtained from Nimbus-7 and Earth probe total ozone mapping spectrometer (TOMS) satellite during the period 1979-2005 over the entire Indian region. The study of these data over Delhi and other Indian stations show that though monthly or seasonal variations do existed but there was no significant change in the UV irradiance in the long-term.[20] In the present study, the data from ground observations as well as CERES products, as mentioned earlier, have been used. The mean values of UVA, UVB flux, aerosol optical depth (AOD) along with the major air pollutants at the mid-point of the study (2013) have been tabulated in Table 2 for

224 all the three stations. The mean UVA and UVB exposure was higher in the coastal region as compared to the hilly region and plains. 
The major air pollutants in these regions are surface $\mathrm{SO}_{2}, \mathrm{NO}_{2}, \mathrm{PM}_{10}, \mathrm{PM}_{2.5}$ and surface ozone. Concentrations of the gaseous pollutants are generally within the National Ambient

228 Air Quality Standards (NAAQS) but particulate matter $\left(\mathrm{PM}_{10}\right.$ and $\left.\mathrm{PM}_{2.5}\right)$ is the major problem in all these areas which is significantly higher than the NAAQS values. Long-term observation suggests a rising trend of pollutants concentration at all the three centers. It was observed that the AOD, AQI, PM10 and atmospheric nitrogen oxide level was highest in Delhi NCR (Northern plains) among the three study locations while the humidity and precipitation level were lowest here highlighting that the environment in Delhi NCR

234 (Northern plains) is relatively dry and polluted when compared to the other study sites. (Table 2) Maximum temperature and rainfall with lowest PM10 value and relatively high humidity was observed in Prakasam (Southern coastal) suggesting that it is hot and humid but the environment is relatively clean compared to other centers. Most of the parameters for air pollution for Guwahati (North-eastern hilly) were in between the two centers. The wind speed was noted to be highest in Prakasam (Southern coastal). (Table 2)

\section{Dry Eye Disease \& Socio-demographic Risk Factors}

242 The overall prevalence of DED was $26.2 \%$ (95\% Cl: $25.3 \%-27.1 \% ; n=2,548 / 9,735)$ based on

243 the TFOS DEWS II diagnostic criteria (OSDI $\geq 13$ and TBUT $<10$ seconds or ocular surface 244 staining. (Table 3) TBUT < 10 seconds was noted in $34.5 \%$ of cases, Schirmer I $<5 \mathrm{~mm}$ in $27.5 \%$ and fluorescein staining in $1.7 \%$ of the population. An abnormal OSDI score $(\geq 13)$ was observed in $66.4 \%(95 \% \mathrm{Cl}: 65.4 \%-67.3 \%)$ of the population. was the most common symptom experienced by $94.5 \%(n=2,408 / 2,548)$ followed by poor vision (93.1\%; $n=2,371 / 2,548)$ and sensitivity to light $(57.2 \% ; n=1,458 / 2,548)$. Visual 

by watching television ( $37.9 \% ; n=965 / 2,548)$. The most common environmental trigger for dry eye was wind (41.2\%; $n=1051 / 2,548)$ followed by dry environment $(36.7 \%$; $n=934 / 2,548)$. Of the cases identified to have DED, mild DED (OSDI score 13-22) was observed in $27.8 \%(707 / 2,548)$, moderate DED (OSDI score $23-32$ ) in $27.9 \%(710 / 2,548$ ) and severe DED (OSDI score $>32$ ) in $44.4 \%(1,131 / 2,548)$. Based on the clinical noting in the

256 records, $<$ _ $10 \%$ participants were using artificial tears.

A rising trend of prevalence of DED was observed with increasing age of the population in all the study centers as well as in the overall population $(p<0.001)$. (Table 4$)$ The prevalence of DED was highest in population aged $\geq 70$ years (37.2\%) and lowest in $40-49$ years age group (20.7\%). Females had a higher prevalence $(28 \%)$ when compared to males $(24 \%)(p<0.001)$ in the overall population. The difference in prevalence of DED between male and female were not statistically significant above the age of 70 years ( $35.6 \%$ vs. $38.8 \%$; $p-0.226)$. (Table 3 and Figure 3) A significant difference was observed between the prevalence of DED from the three study centers ( $p<0.001$ ). Delhi NCR (Northern plains) had the highest prevalence (41.3\%) followed by Guwahati (North-eastern hilly) (24\%) and Prakasam (Southern coastal) higher prevalence of DED compared to those who primarily spent time indoors $(23.8 \%$, $p=0.013)$.

\section{Health Behavior Risk Factors}

272 The median life-time cumulative effective sun-exposure in the overall population was 95.6

273 thousand-hours (range; 7.3 thousand-hours - 314.1 thousand-hours). A rising trend of 
prevalence of DED with increasing lifetime cumulative effective sun-exposure was observed.

275 The participants with sun exposure in the fifth quintile had the highest prevalence (35.58\%;

$27695 \% \mathrm{Cl}-33.5,37.7)$ when compared to those in the other sub-groups, in the overall study

277 population as well as in each of the three study centers $(p<0.001)$. Also, participants with

278 history of smoking and exposure to indoor smoke showed a higher prevalence $(p<0.001$,

$279<0.001$ ). (Figure 4) No difference was observed in participants with or without the use of

280 protective eye or head gear $(p=0.670)$. (Table 4$)$

281

282 Systemic Risk Factors

283 The prevalence of DED was higher in participants with hypertension in the overall study

284 population $(p=0.001)$, as well as in plains $(p=0.234)$, hilly $(p<0.001)$ and coastal region

285 ( $p=0.007)$. (Table 4) The prevalence of DED was similar in participants with newly detected hypertension not taking any treatment (28.0\%) compared to those already diagnosed and on medication (28.3\%) ( $p=0.887)$. The prevalence of DED was similar among diabetics and non-diabetics in each of the three sites: Delhi NCR (Northern plains) ( $p=0.112)$, Guwahati

289 (North-eastern hilly) ( $p=0.667)$ and Prakasam (Southern coastal) $(p=0.234)$, but overall, it was higher among non-diabetics ( $p=0.023$ ) (Table 4) The prevalence of DED was higher in participants with newly detected diabetes mellitus not taking any treatment (26.7\%) compared to those previously diagnosed and already on treatment (21.5\%), however the difference was not significant $(p=0.105)$. The prevalence of DED was higher in participants with $\mathrm{BMI}<25(27.8 \%)$ when compared to those with $\mathrm{BMI} \geq 25(22.4 \%)(\mathrm{p}<0.001)$. A

295 detailed individual drug history for central nervous system (CNS) drugs like opioids and antidepressants was not obtained separately in this study. However, a positive history for CNS 

those with Parkinson's disease were on treatment at the time of examination.

\section{Regression Analysis}

302 Multiple logistic regression analysis comparing the association of DED with various risk factors for each center and the overall population is shown in Table 5. Female gender had a higher association with DED (OR-1.2; Cl 1.01-1.4). Hypertension had a higher association with DED (OR 1.3; $\mathrm{Cl} 1.2-1.4)$. People with history of smoking (OR-1.2; $\mathrm{Cl} 1.03-1.3$ ) and indoor smoke exposure (OR-1.3; $\mathrm{Cl} 1.1-1.5)$ had a higher likelihood of having DED. Increasing 307 lifetime cumulative effective sun exposure had a positive association with DED. However, a center wise variation was observed in the levels of these results. The population from DelhiNCR (Northern plains) showed a positive association in the fifth quintile (OR-1.5; $\mathrm{Cl} 1.2-1.9$ ) while those from Prakasam (Southern coastal) showed a positive association in the fifth quintile (OR-2.1; $\mathrm{Cl}$ 1.3-3.2). The participants from Guwahati (North-eastern hilly) showed a positive association in the second quintile (OR 1.3; $\mathrm{Cl}-1.0,1.6)$, third quintile (OR-1.5; $\mathrm{Cl} 1.1$ 1.9), fourth quintile (OR-1.8; $\mathrm{Cl} 1.3-2.4)$ and fifth quintile (OR-2.8; $\mathrm{Cl}$ 1.7-4.5) of lifetime cumulative effective sun exposure. In the overall population, a higher association was observed with fifth quintile of lifetime cumulative effective sun exposure (OR-1.8; $\mathrm{Cl} 1.5-2.2$ ) when compared to the fourth quintile (OR-1.4; $\mathrm{Cl} 1.2-1.6)$ and third quintile (OR-1.3; $\mathrm{Cl} 1.1-$

317 1.5). Assessment of study location showed that there was a lower likelihood of DED in populations from Guwahati (North-eastern hilly) (OR-0.5; Cl 0.4-0.6) and Prakasam

319 (Southern coastal) (OR-0.2; Cl 0.1-0.2) when compared to Delhi-NCR (Northern plains). 320 Analysis for BMI showed a negative association with DED (OR 0.8; $\mathrm{Cl}-0.7-0.9$ ) in the overall B21 population. On performing additional analysis for males and females separately, gender 
B22 wise multi-logistic regression analysis, smoking was non-significant for both males and

323 females, indoor smoke had a positive association in males (OR 1.7; Cl-1.4, 2.0) only, and

324 diabetes showed a positive association in females (OR 1.3; $\mathrm{Cl}-1.0,1.6)$ only. (Supplementary table 2). Additional sub-analysis of hypertension as systolic and diastolic showed that only systolic hypertension had association with DED on multiple-logistic regression analysis.

327 (Supplementary table 3).

\section{Discussion}

330 Dry eye disease is an important entity in clinical practice. It is a common reason for seeking medical help, especially in the elderly and can be quite debilitating when severe. The prevalence and associated risk factors for DED has been extensively studied. (Table 6) However, the lack of clarity in the definitive diagnostic criteria for DED prior to the TFOS DEWS II report, led to non-uniform diagnostic criteria being used in the reported studies making it difficult to make direct comparisons. $[21,22]$ It is difficult to assess the actual disease burden and the inter-play of risk factors in the population based on hospital based data alone and community based studies are hence much required.

The current study is the largest population-based study on dry eye disease from Asia

340 founded on the diagnostic criteria suggested by the TFOS DEWS II. The prevalence of DED in

341 the $\geq 40$ years population in this study was observed as $26.2 \%$. A previous study from North 342 India reported a 32\% prevalence of DED in a hospital based survey with OSDI questionnaire 343 used for diagnosis.[9] However, as symptoms of OSDI are non-specific and can occur due to any ocular surface disorder, it can be fallacious to rely on OSDI as a sole criterion for diagnosis of DED; hence the TFOS DEWS II criteria were applied that take into consideration 
clinical signs in addition to symptoms for DED diagnosis. Literature review suggests that the

347 prevalence of symptomatic DED (both symptoms and signs used for diagnosis) in China is

$34830.1 \%$, Korea is $8 \%$, Spain is $11 \%$, Iran is $8.7 \%$ and France is $10.7 \% .[3,5,7,10,11,23,24]$ The

349 result of our study was close to that observed by Tian et al. in a study from China but higher

350 than that reported from other parts of the world confirming a higher prevalence of DED in

351 the south-east Asian population compared to others. $[3,5,7,10,11,23,24]$ It is noteworthy

352 that Shanti et al. recently reported an even higher 64\% prevalence of DED in population

353 based study from Palestine using the same diagnostic criteria as used in the current study

354 (TFOS DEWS II).[25]

355

356 Analyzing the contributory factors, an increasing prevalence of DED was observed with

357 increasing age in our study. The prevalence in $\geq 70$ years population was 1.8 times higher

358 than that observed in the $40-49$ years age group. A similar trend was observed in the study

359 by Viso et al. in a Spanish population, wherein the prevalence of DED in the 40-49-year age

360 group was $3.6 \%$ while that in the $\geq 80$ years age group was $20.5 \%$.[10] Also, Vehof et al.

361 observed a similar trend in the British population wherein the prevalence of DED increased

362 from $2.7 \%$ in the third decade to $20.0 \%$ in the ninth decade.[26] A population based study

363 from South Korea in participants aged $19-95$ years found age to be a common risk factor for

364 both clinically diagnosed dry eye syndrome and presence of dry eye symptoms. [7] Age

365 related changes in the lacrimal functional unit and prolonged exposure to environmental

366 triggers for ocular surface inflammation are some possible reasons for this age-related

367 increase observed in prevalence of DED. The highest prevalence of DED observed in the $>70$

368 years population could be due to the cumulative impact of exposure to climatic factors and

369 biomass fuels over the life span. 
371 A gender wise difference was observed in the prevalence of DED in our study with a higher

372 prevalence in females ( $27.7 \%$ vs. $23.6 \%)$. However, an age and gender wise stratification of

373 prevalence of DED showed that the difference in prevalence of DED became insignificant

374 after the age of 70 years, thus illustrating the complexity of interplay of these intrinsic

375 factors.(Table 3) It is interesting that these findings are also reflected in a hospital based

376 study from India where an age and gender stratification showed that males were more

377 frequently affected during the $2^{\text {nd }}$ and $3^{\text {rd }}$ decade of life, while females were more affected

378 during $4^{\text {th }}$ and $5^{\text {th }}$ decade of life, and the sex differences were insignificant beyond the age

379 of 60 years. [22] Ahn et al. reported this similarly as noteworthy in their analysis of the

380 above 40 years subset of population of the Korea National Health and Nutrition Examination

381 Survey (2010-2012) wherein the females had a higher prevalence than males (13.6\% vs.

$3824.9 \%)$, but females did not demonstrate an increasing prevalence with age as was seen in

383 males in linear regression models and multivariate logistic regression analysis showed that

384 ageing in females was protectively associated.[27] Tian et al. reported a prevalence of 33.8\%

385 in women and $24.1 \%$ in men in a Chinese population aged $20-95$ years. While most of the

386 studies report a higher prevalence of DED in females, Tong et al. reported a higher

387 prevalence in males ( $8.2 \%$ vs. $4.9 \%$ ) in a Malayan population. [28] However, as the study was

388 based only on dry eye questionnaire in the absence of clinical grading, it is difficult to

389 compare the results of this study with the present study.

390 Exposure to sunlight particularly ultraviolet radiation are hypothesized to be associated with

391 the occurrence of DED with limited data available in literature. In the current study, the

392 effect of sun exposure was evaluated and a positive association was observed with DED. A

393 stronger association was observed between higher cumulative effective sun exposure and 

positive association between DED and longer exposure to sunshine (OR 1.015; $\mathrm{Cl}$ 1.006for analysis overlooking the inter-individual differences in the exposure to sunlight based on variation in the lifestyle and occupation of the individual. In the present study, an individualized approach was used for calculating the approximate cumulative lifetime effective sunlight exposure taking into account the effect of protective head gear and eye

402 gear with the help of Melbourne formula.[18] This observed association between DED and ocular exposure to sunlight can have a strong clinical implication. Avoiding sunlight exposure to the eyes can be added to the list of factors included in the lifestyle modification which is core to the management of cases presenting with symptomatic DED. In the present study history of smoking was found to have a positive association with DED. Previous studies have shown variable results for smoking as a risk factor for DED and a meta-analysis of available literature indicated that smoking may be associated with the risk of DED in the normal population.[29] Similarly, Moss et al. in a population based study from USA reported a positive association between smoking and DED (OR -1.44; $\mathrm{Cl} 1.13-1.83$ ) in

411 the participants aged 43-84 years after adjusting for age and gender.[30]Hence, avoidance and cessation of smoking are worthwhile preventative and ameliorative measures to

413 suggest in this regard.

414 Oxidative stress is known to result in ocular surface changes and DED.[31,32] Both smoking 415 and ultraviolet radiation are risk factors for increased oxidative stress and as a corollary can 416 be considered as contributory risk factors for DED; as observed in our study. The role of 417 smoking in oxidative damage to ocular structures resulting in dry eye, lenticular changes and 
418 retinal pigment epithelial cell changes has been reported in few studies.[31-34] Ocular

419 exposure with ultraviolet radiation resulting in oxidative stress has been extensively

420 explored in relation to corneal collagen crosslinking.[35] However, its direct impact on the

421 ocular surface is relatively unexplored. The rise of inflammatory mediators as a

422 consequence of oxidative stress can result in goblet cell damage and DED. Future studies

423 evaluating changes in tear film inflammatory markers with levels of UV radiation exposure

424 and conjunctival impression cytology can be performed to quantitatively test this hypothesis

425 and also explore any effects on the meibomian or lacrimal glands.

426 As far as exposure to indoor smoke is concerned, as wood, biomass fuel and coal is still used

427 by large proportion of the rural population in the world for the purpose of cooking and

428 heating, it still remains a tangible problem.[36-39] Respiratory disorders and increased risk

429 of cardiovascular events are the known complications of increased exposure to indoor

430 smoke.[36-41] In the present study, a positive association was observed between exposure

431 to indoor smoke and presence of DED. Hence, the proven associated health hazards

432 highlight a real need to sensitize the population and step-up supportive policies to switch to

433 smokeless fuel alternatives.

434

435 Regarding the effect of systemic diseases of hypertension and DM, both were found to be 436 risk factors for DED in our study. Some population based studies have shown similar results

437 while other have not. [2,42-44] Several factors can account for such variations such as

438 inherent differences in populations studied, other linked complex factors, limitations of

439 accuracy of determining the proper diagnosis, particularly exact duration of the illness along

440 with full details of nature and duration of treatment in epidemiological surveys in rural 
areas. However, the results do confirm that underlying presence of both hypertension and

442 diabetes can affect the occurrence of DED and should be accounted for if needed.

444 As for the effect of geographic location, the prevalence of DED showed a distinct variation in

445 our study with the highest observed prevalence in Delhi NCR (Northern plains) (41.3\%) compared to Guwahati (North-eastern hilly) (24\%) and Prakasam (Southern coastal) (9.9\%).

447 Various climatic and environmental factors like sun-exposure, humidity and air pollution

448 may be responsible for the observed difference in the three study locations. Literature

449 review suggests that studies performed in controlled environment chambers report a more

450 stable tear film in high humidity and low ambient temperatures.[45-47] In the current

451 study, it was observed that Prakasam (Southern coastal), the center with highest humidity,

452 had the lowest prevalence of DED while Delhi NCR (Northern plains), the center with the

453 lowest humidity, had the highest prevalence of DED. This highlights the inverse relation of

454 humidity as a risk factor for DED.

456 Delhi NCR (Northern plains), the location with highest air pollution level had the highest

457 prevalence of DED in the population residing in this location. Similarly, Prakasam (Southern

458 coastal), the location with lowest air pollution level had the lowest prevalence of DED. This

459 observation supports the notion that air pollution is a risk factor for DED. Also, the average

460 wind speed was highest in Prakasam (Southern coastal). This may explain a reduced

461 exposure of the ocular surface to some air pollutants and resultant low prevalence of DED.

462 Literature review also suggests a positive association between air pollution and prevalence of DED.[6,38,48-51] Exploring the interaction of pollution variables with DED in multi-

464 logistic regression analysis could have added valuable information. However, the pollution 
465 variables were not individual specific as the data was collected at the city level and hence could not be assessed in multi-logistic regression analysis. For the sake of scientific rigor,

467 further validation of this aspect may be considered in future studies with long term monitoring of indoor air quality parameters of the participants using portable devices.

As for effect of altitude, in the current study, comparatively low prevalence of DED was observed in the population from the hilly region of Guwahati. Generally, literature suggests

472 a high prevalence of DED in natives residing in very high altitudes.[2,12-14] This difference can be because the hills of Guwahati do not have a very high altitude. Moreover, the people residing there are also exposed to riverine and char environments. Therefore, the effect of altitude could not be conclusively determined in our study and needs to be further explored by assessing populations residing in extremely high altitude.

478 The study has strengths of providing a large population-based dataset with evaluation of both intrinsic and extrinsic risk factors following the guidelines of TFOS DEWS II in definitions and analysis, but may be considered to have some lacunae . Lack of individualized data for the air quality parameters and absence of detailed drug history for participants with history of hypertension on medication make it difficult to ascertain the exact impact of different air quality parameters or specific environmental pollutants and if

484 the higher observed prevalence of DED in hypertensives was due to the hypertension per se or an adverse effect of particular anti-hypertensive agents such as beta blockers and diuretics as is currently believed.[52,53] Recently, an association between sleep disorder, physical activity, stress factors and depression with DED has come to fore. Additional data on sleep parameters could have been added to the study; however a proper assessment of 
sleep disorder requires use of validated sleep questionnaire like Pittsburgh Sleep Quality Index (27 questions) or the Epworth Sleepiness Scale (8 questions). [54,55] As this was a

491 large population based survey with 4 independent forms to be filled requiring over one hour 492 per participant for complete evaluation, sleep assessment was not considered feasible. In

493 the current study, only one case suffered from depression. Detailed data for physical activity per se was not collected, hence it is not possible to comment on the relationship from our study. In addition, data on usage of contact lens, eye cosmetics and visual display units would have been of additional interest; however as these are not commonly used in the rural Indian population aged $\geq 40$ years studied, hence they could not be separately assessed. Similarly, the nature, pattern and extent of Meibomian gland dysfunction (MGD) which could be a contributing factor for symptoms of DED, though evaluated clinically on slit lamp examination, was not analysed. Also, hyperlipidaemia which has been reported to be associated with MGD and DED was not assessed as part of this study. These aspects have been included in the ongoing phase 2 of the study.

\section{Conclusion}

505 To conclude, this study has provided reliable new information on the prevalence of dry eye 506 in India in populations residing in geographically diverse regions and evaluated the various 507 known risk factors for DED and sun exposure. The study has confirmed the association of

508 DED with intrinsic factors like increasing age, female gender, BMI, hypertension and diabetes mellitus, and extrinsic factors like exposure to sunlight, smoking and indoor smoke.

510 The place of residence and livelihood influenced the prevalence of DED which had the

511 highest prevalence in plains when compared to hills and coastal region for which air 512 pollution and humidity could have had important influences as the prevalence of DED was 
513 highest in the location with highest air pollution and lowest humidity. The study highlights

514 the importance of various extrinsic risk factors for DED which are often missed out while

515 counselling patients presenting with DED. This information can help in advocacy, guide

516 policy making and allocation of resources for preventive and therapeutic measures and

517 these factors can be added to the list of lifestyle modification which is an essential

518 component in the management of all patients of DED. It makes a strong case for counselling

519 to minimize direct sun-exposure of eye, cease smoking, reduce indoor air pollution by using

520 smokeless fuels and if necessary for patients severely affected, greater measures to improve

521 living environments with avoidance of high pollution and low humidity levels. Lastly, the

522 study has highlighted the complex interplay of a multitude of factors involved in the genesis

523 and manifestations of DED and indicates the care needed to interpret and apply information

524 generated by various studies.

525 
527 The research was funded by Indian Council of Medical Research (ICMR), India - Grant No

$52868 / 4 / 2009-N C D-1$. The funding source had no role in the study design, in the collection, 529 analysis and interpretation of data, writing of the report; and in the decision to submit the 530 article for publication.

531

532 Conflict of Interest

533 The authors have no conflict of interest.

534

535

Acknowledgements

536 Dr. Saurabh Agarwal Jwalaprasad, Dr. Bhagbat Nayak, Dr. Jayanta Thakuria, Dr. Indrani

537 Goswami, Ms. Tanya Patel, Ms. Ankita Mall, Dr. Rupesh M Das are acknowledged for their

538 contribution to data acquisition. Mr Amit Bhardwaj and Mr Deepak Kumar are

539 acknowledged for their contribution to data management and analysis. We would like to

540 acknowledge the ICMR Task Force on global climate change and health chaired by Prof.

541 Seyed E. Hasnain, IIT Delhi, for periodic review and technical inputs during the course of the

542 study. All the members of the ICMR Eye Sun Exposure \& Environment "EYE SEE" study group

543 are acknowledged for their contributions to the project.

544 THE ICMR EYE SUN EXPOSURE \& ENVIRONMENT “EYE SEE” STUDY GROUP

\begin{tabular}{|c|c|c|c|}
\hline Centers & $\begin{array}{l}\text { Principal } \\
\text { Investigators }\end{array}$ & Co-investigators & $\begin{array}{l}\text { Scientist/Research } \\
\text { officers }\end{array}$ \\
\hline $\begin{array}{l}\text { Dr. Rajendra Prasad } \\
\text { Centre for } \\
\text { Ophthalmic Sciences, } \\
\text { AlIMS, New Delhi } \\
\text { (Coordinating } \\
\text { Center) }\end{array}$ & $\begin{array}{l}\text { Dr. Radhika Tandon } \\
\text { Dr. Praveen Vashist }\end{array}$ & $\begin{array}{l}\text { Dr. Noopur Gupta } \\
\text { Dr. Vivek Gupta* }\end{array}$ & $\begin{array}{l}\text { Dr. Pranita Sahay } \\
\text { Dr. Rashmi Singh } \\
\text { Dr. Meenakshi Wadhwani } \\
\text { Dr. Shweta } \\
\text { Dr. Aparna Gupta } \\
\text { Dr. Saurabh Agarwal } \\
\text { Jwalaprasad }\end{array}$ \\
\hline
\end{tabular}




\begin{tabular}{|l|l|l|l|}
\hline & & & Dr. Bhagbat Nayak \\
\hline $\begin{array}{l}\text { Indian Institute of } \\
\text { Public Health, } \\
\text { Hyderabad }\end{array}$ & Dr. GVS Murthy & Dr. K. Vishwanath & $\begin{array}{l}\text { Dr. Hemant Kumar } \\
\text { Dr. Vijay Kiran }\end{array}$ \\
\hline $\begin{array}{l}\text { Regional Institute of } \\
\text { Ophthalmology, } \\
\text { Guwahati }\end{array}$ & $\begin{array}{l}\text { Dr. C.K.Barua } \\
\text { Dr. Dipali Deka }\end{array}$ & & $\begin{array}{l}\text { Dr. Jayanta Thakuria } \\
\text { Dr. Indrani Goswami }\end{array}$ \\
\hline $\begin{array}{l}\text { National Physical } \\
\text { Laboratory, New } \\
\text { Delhi }\end{array}$ & $\begin{array}{l}\text { Dr Sachchidanand } \\
\text { Singh }\end{array}$ & & $\begin{array}{l}\text { Ms. Tanya Patel } \\
\text { Ms. Ankita Mall } \\
\text { Dr. Rupesh M Das }\end{array}$ \\
\hline
\end{tabular}


547

548

549

550

551

552

553

554

555

556

557

558

559

560

561

562

563

564

565

566

567

568

569

570

571

572

573

574

575

576

577

578

579

580

581

582

583

584

585

586

587

588

589

590

591

592

593

\section{References}

[1] Craig JP, Nichols KK, Akpek EK, Caffery B, Dua HS, Joo C-K, et al. TFOS DEWS II Definition and Classification Report. Ocul Surf 2017;15:276-83. https://doi.org/10.1016/j.jtos.2017.05.008.

[2] Uchino M, Nishiwaki Y, Michikawa T, Shirakawa K, Kuwahara E, Yamada M, et al. Prevalence and risk factors of dry eye disease in Japan: Koumi study. Ophthalmology 2011;118:2361-7. https://doi.org/10.1016/j.ophtha.2011.05.029.

[3] Stapleton F, Alves M, Bunya VY, Jalbert I, Lekhanont K, Malet F, et al. TFOS DEWS II Epidemiology Report. Ocul Surf 2017;15:334-65. https://doi.org/10.1016/j.jtos.2017.05.003.

[4] Chia E-M, Mitchell P, Rochtchina E, Lee AJ, Maroun R, Wang JJ. Prevalence and associations of dry eye syndrome in an older population: the Blue Mountains Eye Study. Clin Experiment Ophthalmol 2003;31:229-32. https://doi.org/10.1046/j.14429071.2003.00634.x.

[5] Song P, Xia W, Wang M, Chang X, Wang J, Jin S, et al. Variations of dry eye disease prevalence by age, sex and geographic characteristics in China: a systematic review and meta-analysis. J Glob Health 2018;8:020503. https://doi.org/10.7189/jogh.08.020503.

[6] Um S-B, Kim NH, Lee HK, Song JS, Kim HC. Spatial epidemiology of dry eye disease: findings from South Korea. International Journal of Health Geographics 2014;13:31. https://doi.org/10.1186/1476-072X-13-31.

[7] Ahn JM, Lee SH, Rim THT, Park RJ, Yang HS, Kim T im, et al. Prevalence of and Risk Factors Associated With Dry Eye: The Korea National Health and Nutrition Examination Survey 2010-2011. American Journal of Ophthalmology 2014;158:1205-1214.e7. https://doi.org/10.1016/j.ajo.2014.08.021.

[8] Tan LL, Morgan P, Cai ZQ, Straughan RA. Prevalence of and risk factors for symptomatic dry eye disease in Singapore. Clin Exp Optom 2015;98:45-53. https://doi.org/10.1111/cxo.12210.

[9] Titiyal JS, Falera RC, Kaur M, Sharma V, Sharma N. Prevalence and risk factors of dry eye disease in North India: Ocular surface disease index-based cross-sectional hospital study. Indian J Ophthalmol 2018;66:207-11. https://doi.org/10.4103/ijo.IJO_698_17.

[10] Viso E, Rodriguez-Ares MT, Gude F. Prevalence of and associated factors for dry eye in a Spanish adult population (the Salnes Eye Study). Ophthalmic Epidemiol 2009;16:1521. https://doi.org/10.1080/09286580802228509.

[11] Hashemi H, Khabazkhoob M, Kheirkhah A, Emamian MH, Mehravaran S, Shariati M, et al. Prevalence of dry eye syndrome in an adult population. Clin Experiment Ophthalmol 2014;42:242-8. https://doi.org/10.1111/ceo.12183.

[12] Gupta N, Prasad I, Himashree G, D'Souza P. Prevalence of dry eye at high altitude: a case controlled comparative study. High Alt Med Biol 2008;9:327-34. https://doi.org/10.1089/ham.2007.1055.

[13] Guo B, Lu P, Chen X, Zhang W, Chen R. Prevalence of dry eye disease in Mongolians at high altitude in China: the Henan eye study. Ophthalmic Epidemiol 2010;17:234-41. https://doi.org/10.3109/09286586.2010.498659.

[14] Lu P, Chen X, Liu X, Yu L, Kang Y, Xie Q, et al. Dry eye syndrome in elderly Tibetans at high altitude: a population-based study in China. Cornea 2008;27:545-51. https://doi.org/10.1097/ICO.0b013e318165b1b7.

[15] Vashist P, Tandon R, Murthy GVS, Barua CK, Deka D, Singh S, et al. Association of cataract and sun exposure in geographically diverse populations of India: The CASE 
600

601

602

603

604

605

606

607

608

609

610

611

612

613

614

615

616

617

618

619

620

621

622

623

624

625

626

627

628

629

630

631

632

633

634

635

636

637

638

study. First Report of the ICMR-EYE SEE Study Group. PLoS ONE 2020;15:e0227868. https://doi.org/10.1371/journal.pone.0227868.

[16] Association AD. 2. Classification and Diagnosis of Diabetes: Standards of Medical Care in Diabetes-2019. Diabetes Care 2019;42:S13-28. https://doi.org/10.2337/dc19-S002.

[17] Program NHBPE. Classification of Blood Pressure. National Heart, Lung, and Blood Institute (US); 2004.

[18] McCarty CA, Lee SE, Livingston PM, Bissinella M, Taylor HR. Ocular exposure to UV-B in sunlight: the Melbourne visual impairment project model. Bull World Health Organ 1996;74:353-60.

[19] Singh S, Lodhi NK, Mishra AK, Jose S, Kumar SN, Kotnala RK. Assessment of satelliteretrieved surface UVA and UVB radiation by comparison with ground-measurements and trends over Mega-city Delhi. Atmospheric Environment 2018;188:60-70. https://doi.org/10.1016/j.atmosenv.2018.06.027.

[20] Ganguly ND, Iyer KN. Long-Term Trend in Ozone and Erythemal UV at Indian Latitudes. J Atmos Chem 2006;55:227-39. https://doi.org/10.1007/s10874-006-9035-9.

[21] The definition and classification of dry eye disease: report of the Definition and Classification Subcommittee of the International Dry Eye WorkShop (2007). Ocul Surf 2007;5:75-92.

[22] Donthineni PR, Kammari P, Shanbhag SS, Singh V, Das AV, Basu S. Incidence, demographics, types and risk factors of dry eye disease in India: Electronic medical records driven big data analytics report I. Ocul Surf 2019;17:250-6. https://doi.org/10.1016/j.jtos.2019.02.007.

[23] Malet F, Le Goff M, Colin J, Schweitzer C, Delyfer M-N, Korobelnik J-F, et al. Dry eye disease in French elderly subjects: the Alienor Study. Acta Ophthalmol 2014;92:e429436. https://doi.org/10.1111/aos.12174.

[24] Tian Y-J, Liu Y, Zou H-D, Jiang Y-J, Liang X-Q, Sheng M-J, et al. [Epidemiologic study of dry eye in populations equal or over 20 years old in Jiangning District of Shanghai]. Zhonghua Yan Ke Za Zhi 2009;45:486-91.

[25] Shanti Y, Shehada R, Bakkar MM, Qaddumi J. Prevalence and associated risk factors of dry eye disease in 16 northern West bank towns in Palestine: a cross-sectional study. BMC Ophthalmology 2020;20:26. https://doi.org/10.1186/s12886-019-1290-z.

[26] Vehof J, Kozareva D, Hysi PG, Hammond CJ. Prevalence and risk factors of dry eye disease in a British female cohort. Br J Ophthalmol 2014;98:1712-7. https://doi.org/10.1136/bjophthalmol-2014-305201.

[27] Ahn JH, Choi Y-H, Paik HJ, Kim MK, Wee WR, Kim DH. Sex differences in the effect of aging on dry eye disease. Clin Interv Aging 2017;12:1331-8. https://doi.org/10.2147/CIA.S140912.

[28] Tong L, Tongg L, Saw S-M, Lamoureux EL, Wang JJ, Rosman M, et al. A questionnairebased assessment of symptoms associated with tear film dysfunction and lid margin disease in an Asian population. Ophthalmic Epidemiol 2009;16:31-7. https://doi.org/10.1080/09286580802521317.

[29] Xu L, Zhang W, Zhu X-Y, Suo T, Fan X-Q, Fu Y. Smoking and the risk of dry eye: a Metaanalysis. Int J Ophthalmol 2016;9:1480-6. https://doi.org/10.18240/ijo.2016.10.19.

[30] Moss SE, Klein R, Klein BE. Prevalence of and risk factors for dry eye syndrome. Arch Ophthalmol 2000;118:1264-8. https://doi.org/10.1001/archopht.118.9.1264. 
[31] Dogru M, Kojima T, Simsek C, Tsubota K. Potential Role of Oxidative Stress in Ocular Surface Inflammation and Dry Eye Disease. Invest Ophthalmol Vis Sci 2018;59:DES1638. https://doi.org/10.1167/iovs.17-23402.

[32] Seen S, Tong L. Dry eye disease and oxidative stress. Acta Ophthalmol 2018;96:e41220. https://doi.org/10.1111/aos.13526.

[33] Fujihara M, Nagai N, Sussan TE, Biswal S, Handa JT. Chronic cigarette smoke causes oxidative damage and apoptosis to retinal pigmented epithelial cells in mice. PLoS ONE 2008;3:e3119. https://doi.org/10.1371/journal.pone.0003119.

[34] Shalini VK, Luthra M, Srinivas L, Rao SH, Basti S, Reddy M, et al. Oxidative damage to the eye lens caused by cigarette smoke and fuel smoke condensates. Indian J Biochem Biophys 1994;31:261-6.

[35] Wollensak G, Spoerl E, Seiler T. Riboflavin/ultraviolet-a-induced collagen crosslinking for the treatment of keratoconus. Am J Ophthalmol 2003;135:620-7.

[36] Smith KR, Mehta S. The burden of disease from indoor air pollution in developing countries: comparison of estimates. Int J Hyg Environ Health 2003;206:279-89. https://doi.org/10.1078/1438-4639-00224.

[37] Chen BH, Hong CJ, Pandey MR, Smith KR. Indoor air pollution in developing countries. World Health Stat Q 1990;43:127-38.

[38] Mestl HES, Edwards R. Global burden of disease as a result of indoor air pollution in Shaanxi, Hubei and Zhejiang, China. Sci Total Environ 2011;409:1391-8. https://doi.org/10.1016/j.scitotenv.2011.01.020.

[39] Torres-Duque C, Maldonado D, Pérez-Padilla R, Ezzati M, Viegi G, Forum of International Respiratory Studies (FIRS) Task Force on Health Effects of Biomass Exposure. Biomass fuels and respiratory diseases: a review of the evidence. Proc Am Thorac Soc 2008;5:577-90. https://doi.org/10.1513/pats.200707-100RP.

[40] Agrawal S. Effect of indoor air pollution from biomass and solid fuel combustion on prevalence of self-reported asthma among adult men and women in India: findings from a nationwide large-scale cross-sectional survey. J Asthma 2012;49:355-65. https://doi.org/10.3109/02770903.2012.663030.

[41] Norman R, Barnes B, Mathee A, Bradshaw D, South African Comparative Risk Assessment Collaborating Group. Estimating the burden of disease attributable to indoor air pollution from household use of solid fuels in South Africa in 2000. S Afr Med J 2007; 97:764-71.

[42] Yoo TK, Oh E. Diabetes mellitus is associated with dry eye syndrome: a meta-analysis. Int Ophthalmol 2019;39:2611-20. https://doi.org/10.1007/s10792-019-01110-y.

[43] Zhang X, Zhao L, Deng S, Sun X, Wang N. Dry Eye Syndrome in Patients with Diabetes Mellitus: Prevalence, Etiology, and Clinical Characteristics. J Ophthalmol 2016;2016:8201053. https://doi.org/10.1155/2016/8201053.

[44] Ferrero A, Alassane S, Binquet C, Bretillon L, Acar N, Arnould L, et al. Dry eye disease in the elderly in a French population-based study (the Montrachet study: Maculopathy, Optic Nerve, nuTRition, neurovAsCular and HEarT diseases): Prevalence and associated factors. Ocul Surf 2018;16:112-9. https://doi.org/10.1016/j.jtos.2017.09.008.

[45] Abusharha AA, Pearce El. The effect of low humidity on the human tear film. Cornea 2013;32:429-34. https://doi.org/10.1097/ICO.0b013e31826671ab.

[46] López-Miguel A, Tesón M, Martín-Montañez V, Enríquez-de-Salamanca A, Stern ME, Calonge $\mathrm{M}$, et al. Dry eye exacerbation in patients exposed to desiccating stress under 
controlled environmental conditions. Am J Ophthalmol 2014;157:788-798.e2. https://doi.org/10.1016/j.ajo.2014.01.001.

[47] Abusharha AA, Pearce El, Fagehi R. Effect of Ambient Temperature on the Human Tear Film. Eye Contact Lens 2016;42:308-12. https://doi.org/10.1097/ICL.0000000000000210.

690

691

692

693

694

695

696

697

698

699

700

701

702

703

704

705

706

707

708

709

710

711

712

713

[48] Galor A, Kumar N, Feuer W, Lee DJ. Environmental factors affect the risk of dry eye syndrome in a United States veteran population. Ophthalmology 2014;121:972-3. https://doi.org/10.1016/j.ophtha.2013.11.036.

[49] Zhong J-Y, Lee Y-C, Hsieh C-J, Tseng C-C, Yiin L-M. Association between Dry Eye Disease, Air Pollution and Weather Changes in Taiwan. Int J Environ Res Public Health 2018;15. https://doi.org/10.3390/ijerph15102269.

[50] Yu D, Deng Q, Wang J, Chang X, Wang S, Yang R, et al. Air Pollutants are associated with Dry Eye Disease in Urban Ophthalmic Outpatients: a Prevalence Study in China. J Transl Med 2019;17:46. https://doi.org/10.1186/s12967-019-1794-6.

[51] Gupta SK, Gupta SC, Agarwal R, Sushma S, Agrawal SS, Saxena R. A multicentric casecontrol study on the impact of air pollution on eyes in a metropolitan city of India. Indian J Occup Environ Med 2007;11:37-40. https://doi.org/10.4103/00195278.32463.

[52] Apostol S, Filip M, Dragne C, Filip A. Dry eye syndrome. Etiological and therapeutic aspects. Oftalmologia 2003;59:28-31.

[53] Jaanus SD. Ocular side effects of selected systemic drugs. Optom Clin 1992;2:73-96.

[54] Wu M, Liu X, Han J, Shao T, Wang Y. Association Between Sleep Quality, Mood Status, and Ocular Surface Characteristics in Patients With Dry Eye Disease. Cornea 2019;38:311-7. https://doi.org/10.1097/ICO.0000000000001854.

[55] Kawashima M, Uchino M, Yokoi N, Uchino Y, Dogru M, Komuro A, et al. The association of sleep quality with dry eye disease: the Osaka study. Clinical Ophthalmology (Auckland, NZ) 2016;10:1015. https://doi.org/10.2147/OPTH.S99620. 
715 Figure 1: Flowchart showing the study methodology

716 Figure 2: Bar-graph showing age-wise stratified prevalence of dry eye disease in males and 717 females

718 Figure 3: Stratification of the overall participants and participants with dry eye disease

719 based on gender, site of residence and occupation

720 Figure 4: Stratification of the overall participants and participants with dry eye disease

721 based on risk factors of smoking, sun-exposure and exposure to indoor smoke.

722

723 Table legends

724 Table 1: Demographic characteristics of participants examined for the SEED (Sun Exposure, 725 Environment and Dry eye disease) study

726 Table 2: Climatic parameters at the three locations during mid-point of the study (2013)

727 Table 3: Prevalence (95\% Confidence Intervals, $\mathrm{CI}$ ) of Dry Eye Disease (DED) in three 728 geographical locations of India, among population aged $\geq 40$ years

729 Table 4: Site-specific prevalence of dry eye disease (DED) and its association with various 730 risk factors

731 Table 5: Multiple logistic regression showing association of dry eye disease with various risk 732 factors

733 Table 6: Review of literature of studies evaluating environmental risk factors for Dry Eye 734 Disease (DED)

735 Supplementary Table 1: Demographic profile of the participant and non-participant 736 population of the study

737 Supplementary Table 2: A gender wise multi-logistic regression analysis showing association 738 of DED with various risk factors

739 Supplementary Table 3: Multivariate regression analysis showing correlation of Dry eye 740 disease with various risk factors including systolic and diastolic hypertension 
Table 1: Demographic characteristics of participants examined for the SEED (Sun Exposure,

743 Environment and Dry eye disease) study

\begin{tabular}{|c|c|c|c|c|}
\hline & $\begin{array}{c}\text { Delhi-NCR } \\
\text { (Northern Plains) } \\
\mathrm{n}(\%)\end{array}$ & $\begin{array}{c}\text { Guwahati } \\
\text { (North-eastern } \\
\text { Hilly) } \\
\text { n (\%) }\end{array}$ & $\begin{array}{c}\text { Prakasam } \\
\text { (Southern } \\
\text { Coastal) } \\
\text { n (\%) }\end{array}$ & $\begin{array}{c}\text { All Centers } \\
n(\%)\end{array}$ \\
\hline \multicolumn{5}{|l|}{ Age (Years) } \\
\hline Mean age $( \pm S E)$ & $55.3(0.20)$ & $53.4(0.20)$ & $54.6(0.21)$ & $54.5(0.12)$ \\
\hline \multicolumn{5}{|l|}{ Gender } \\
\hline Male & $1,614(44.9)$ & $1,491(46.2)$ & $1,321(45.4)$ & $4,426(45.5)$ \\
\hline Female & $1,981(55.1)$ & $1,740(53.9)$ & $1,588(54.6)$ & $5,309(54.5)$ \\
\hline \multicolumn{5}{|l|}{ Education n (\%) } \\
\hline Illiterate & $1,769(49.2)$ & $1,306(40.4)$ & $1,924(66.2)$ & $5,000(51.4)$ \\
\hline Studied up to primary & $532(14.8)$ & $779(24.1)$ & $487(16.7)$ & $1,798(18.5)$ \\
\hline Middle School (class 6-8) & $471(13.1)$ & $294(9.1)$ & $169(5.8)$ & $934(9.6)$ \\
\hline High School (class 9-12) & $721(20.1)$ & $742(23.0)$ & $262(9.0)$ & $1,725(17.7)$ \\
\hline Graduation & $102(2.8)$ & $101(3.1)$ & $65(2.2)$ & $268(2.8)$ \\
\hline \multicolumn{5}{|l|}{ Occupation (\%) } \\
\hline Primarily Indoor & 569 (15.9) & $102(3.2)$ & $1,062(36.5)$ & $1,733(17.8)$ \\
\hline Primarily Outdoor & $3,021(84.2)$ & $3,121(96.8)$ & $1,847(63.5)$ & $7,989(82.2)$ \\
\hline Diabetes Mellitus (\%) & $206(5.8)$ & $166(5.3)$ & $460(16.2)$ & $832(8.7)$ \\
\hline Hypertension (\%) & $1,309(36.7)$ & $1,140(35.6)$ & $1,247(43.8)$ & $3,696(38.5)$ \\
\hline \multicolumn{5}{|l|}{ Body Mass Index (\%) } \\
\hline$<25 \mathrm{~kg} / \mathrm{m}^{2}$ & $2554(71.8)$ & $2686(85.5)$ & $1743(64.3)$ & $6983(74.2)$ \\
\hline$\geq 25 \mathrm{~kg} / \mathrm{m}^{2}$ & $1002(28.1)$ & $456(14.5)$ & $967(35.7)$ & $2425(25.8)$ \\
\hline \multicolumn{5}{|c|}{ Lifetime cumulative effective sun exposure (Thousand hours) } \\
\hline Median & 114.14 & 72.76 & 109.89 & 96.067 \\
\hline Range (min.-max.) & $7.30-314.10$ & $7.30-223.76$ & $7.30-252.18$ & $7.305-314.10$ \\
\hline
\end{tabular}


Table 2: Climatic parameters at the three locations in India during the mid-point of the

747 study (2013)

\begin{tabular}{|c|c|c|c|}
\hline $\begin{array}{l}\text { Region } \\
\text { Parameters }\end{array}$ & $\begin{array}{c}\text { Delhi-NCR } \\
\text { (Northern Plains) }\end{array}$ & $\begin{array}{c}\text { Guwahati } \\
\text { (North-eastern Hilly) }\end{array}$ & $\begin{array}{c}\text { Prakasam } \\
\text { (Southern Coastal) }\end{array}$ \\
\hline UVA $($ mean $\pm S D)\left(W^{-2}\right)$ & $10.92 \pm 3.87$ & $11.23 \pm 3.33$ & $13.05 \pm 3.48$ \\
\hline UVB $($ mean $\pm S D)\left(W^{-2}\right)$ & $0.25 \pm 0.11$ & $0.28 \pm 0.11$ & $0.35 \pm 0.10$ \\
\hline AOD (mean \pm SD) & $0.64 \pm 0.38$ & $0.49 \pm 0.36$ & $0.46+0.19$ \\
\hline AQI & 179 & 127 & 68 \\
\hline Humidity (mean \pm SD) (\%) & $65.24 \pm 21.70$ & $80.57 \pm 9.09$ & $73.94 \pm 4.86$ \\
\hline Precipitation (mm) & 1085.4 & 1650.5 & 1219.2 \\
\hline $\begin{array}{l}\text { Temperature }\left({ }^{\circ} \mathrm{C}\right) \\
\text { Mean } \pm \mathrm{SD} \\
\text { Minimum } \\
\text { Maximum }\end{array}$ & $\begin{array}{c}24.51 \pm 7.41 \\
19.0 \\
31.8\end{array}$ & $\begin{array}{c}24.91 \pm 4.77 \\
19.4 \\
31.1\end{array}$ & $\begin{array}{c}28.03 \pm 2.10 \\
24.2 \\
31.8\end{array}$ \\
\hline Average Wind Speed $(\mathrm{km} / \mathrm{hr})$ & 6.5 & 3.4 & 8.4 \\
\hline \multicolumn{4}{|l|}{ Air pollutants $\left(\mu \mathrm{g} / \mathrm{m}^{3}\right)$} \\
\hline $\begin{array}{l}\text { Mean } \\
\text { Maximum } \\
\text { Minimum }\end{array}$ & $\begin{array}{c}4.1 \\
10.5 \\
3.4\end{array}$ & $\begin{array}{c}7 \\
12 \\
3.2\end{array}$ & $\begin{array}{c}13.4 \\
56.1 \\
4\end{array}$ \\
\hline \multicolumn{4}{|l|}{ Nitrogen dioxide } \\
\hline Mean & 63.7 & 15.7 & 18 \\
\hline Maximum & 108.2 & 22.7 & 81.3 \\
\hline Minimum & 31.7 & 9.8 & 8.9 \\
\hline \multicolumn{4}{|l|}{ PM10 } \\
\hline Mean & 218.8 & 141.2 & 67.8 \\
\hline Maximum & 473.5 & 325.7 & 198.4 \\
\hline Minimum & 60.2 & 38 & 19 \\
\hline
\end{tabular}

748

\section{Footnote}

750 NCR- National capital region; UVA- Ultraviolet-A; UVB- Ultraviolet-B; AOD- Aerosol optical

751 depth; AQI- Air quality index; PM10- Particulate matter $\leq 10 \mu \mathrm{m}$. 
753 Table 3: Age-wise Prevalence (95\% Confidence Intervals, $\mathrm{Cl}$ ) of Dry Eye Disease (DED) in 754 three geographical locations of India, among population aged $\geq \mathbf{4 0}$ years

755

\begin{tabular}{|c|c|c|c|c|c|c|c|}
\hline & \multicolumn{2}{|c|}{ Overall } & \multicolumn{5}{|c|}{ Gender } \\
\hline & \multirow[b]{2}{*}{$\mathbf{n}$} & \multirow[b]{2}{*}{$\begin{array}{l}\text { DED } \\
\%(C I)\end{array}$} & \multicolumn{2}{|c|}{ Male } & \multicolumn{2}{|c|}{ Female } & \multirow[b]{2}{*}{$p t$} \\
\hline & & & $\mathbf{n}$ & $\begin{array}{l}\text { DED } \\
\%(C I)\end{array}$ & $\mathbf{n}$ & $\begin{array}{l}\text { DED } \\
\%(\mathrm{Cl})\end{array}$ & \\
\hline All participants & 9733 & $\begin{array}{c}26.2 \\
(25.3-27.1)\end{array}$ & 4,426 & $\begin{array}{c}24.0 \\
(22.7-25.2)\end{array}$ & 5,307 & $\begin{array}{c}28.0 \\
(26.8-29.2)\end{array}$ & $<0.001$ \\
\hline \multicolumn{8}{|l|}{ Age Group } \\
\hline $40-49$ years & 3,998 & $\begin{array}{c}20.7 \\
(19.5-22.0)\end{array}$ & 1727 & $\begin{array}{c}18.9 \\
(17.0-20.7)\end{array}$ & 2271 & $\begin{array}{c}22.1 \\
(20.4-23.9)\end{array}$ & 0.011 \\
\hline $50-59$ years & 2,438 & $\begin{array}{c}26.8 \\
(25.1-28.6)\end{array}$ & 1138 & $\begin{array}{c}22.8 \\
(20.4-25.3)\end{array}$ & 1300 & $\begin{array}{c}30.3 \\
(27.8-32.8)\end{array}$ & 0.000 \\
\hline $60-69$ years & 1,981 & $\begin{array}{c}29.1 \\
(27.1-31.1)\end{array}$ & 900 & $\begin{array}{c}26.8 \\
(23.9-29.7)\end{array}$ & 1081 & $\begin{array}{c}31.0 \\
(28.2-33.8)\end{array}$ & 0.040 \\
\hline$>70$ years & 1,316 & $\begin{array}{c}37.2 \\
(34.5-39.8)\end{array}$ & 661 & $\begin{array}{c}35.6 \\
(31.9-39.2)\end{array}$ & 655 & $\begin{array}{c}38.8 \\
(35-42.5)\end{array}$ & 0.226 \\
\hline$p$ value* & & $<0.001$ & & $<0.001$ & & $<0.001$ & \\
\hline
\end{tabular}

756 Footnote

757 * represents $p$-value of comparison of prevalence across age-groups, calculated using Chi758 square tests

$759+$ represents $p$-value of comparison of prevalence across males and females, calculated

760 using Chi-square tests

761 
Table 4: Site-specific prevalence of dry eye disease (DED) and its association with various

risk factors

\begin{tabular}{|c|c|c|c|c|c|c|c|c|}
\hline \multirow[t]{2}{*}{ Risk Factor } & \multicolumn{2}{|c|}{$\begin{array}{c}\text { Delhi NCR } \\
\text { (Northern Plains) } \\
\end{array}$} & \multicolumn{2}{|c|}{$\begin{array}{c}\text { Guwahati } \\
\text { (North-eastern Hilly) }\end{array}$} & \multicolumn{2}{|c|}{$\begin{array}{c}\text { Prakasam } \\
\text { (Southern Coastal) }\end{array}$} & \multicolumn{2}{|c|}{ Overall } \\
\hline & $n$ & DED * & $\mathbf{N}$ & DED * & $n$ & DED & $\mathbf{n}$ & DED* \\
\hline \multicolumn{9}{|c|}{ SOCIO-DEMOGRAPHIC FACTORS } \\
\hline \multicolumn{9}{|c|}{ Age Group } \\
\hline $40-49$ years & 1427 & $461(32.3)$ & 1454 & $279(19.2)$ & 1117 & $89(8.0)$ & 3,998 & $829(20.7)$ \\
\hline 50-59 years & 881 & $374(42.5)$ & 802 & 200 (24.9) & 755 & $80(10.6)$ & 2,438 & $654(26.8)$ \\
\hline $60-69$ years & 746 & $345(46.3)$ & 603 & $162(26.9)$ & 632 & $69(10.9)$ & 1,981 & $576(29.1)$ \\
\hline $70+$ years & 540 & $304(56.3)$ & 371 & 135 (36.4) & 405 & $50(12.4)$ & 1,316 & $489(37.2)$ \\
\hline$p$ valuet & & $<0.001$ & & $<0.001$ & & 0.036 & & $<0.001$ \\
\hline \multicolumn{9}{|l|}{ Gender } \\
\hline Male & 1614 & $645(40.0)$ & 1491 & $298(20.0)$ & 1321 & $119(9.0)$ & 4,426 & $1062(24.0)$ \\
\hline Female & 1980 & $839(42.4)$ & 1739 & $478(27.5)$ & 1588 & $169(10.6)$ & 5,307 & $1486(28.0)$ \\
\hline$p$ valuet & & 0.144 & & $<0.001$ & & 0.142 & & $<0.001$ \\
\hline \multicolumn{9}{|l|}{ Site } \\
\hline Delhi NCR/Plain & - & - & - & - & - & - & 3,594 & $1484(41.3)$ \\
\hline Guwahati/Hilly & - & - & - & - & - & - & 3,230 & $776(24.0)$ \\
\hline Prakasam/Coastal & - & - & - & - & - & - & 2,909 & $288(9.9)$ \\
\hline$p$ valuet & - & - & - & - & - & - & & $<0.001$ \\
\hline \multicolumn{9}{|l|}{ Occupation } \\
\hline Primarily Indoor & 569 & $259(45.5)$ & 101 & $37(36.6)$ & 1062 & $116(10.9)$ & 1732 & $412(23.8)$ \\
\hline Primarily Outdoor & 3020 & $1223(40.5)$ & 3121 & $737(23.6)$ & 1847 & $172(9.3)$ & 7988 & $2132(26.7)$ \\
\hline$p$ valuet & & 0.026 & & 0.003 & & 0.160 & & 0.013 \\
\hline \multicolumn{9}{|c|}{ HEALTH BEHAVIOR RISK FACTORS } \\
\hline \multicolumn{9}{|c|}{ Smoking } \\
\hline Yes & 1993 & 874 (43.9) & 723 & $153(21.2)$ & 868 & $71(8.2)$ & 3584 & 1098 (30.6) \\
\hline No & 1601 & $610(38.1)$ & 2501 & $622(24.9)$ & 2041 & $217(10.6)$ & 6143 & 1449 (23.6) \\
\hline$p$ valuet & & $<0.001$ & & 0.040 & & 0.043 & & $<0.001$ \\
\hline \multicolumn{9}{|c|}{ Indoor smoke exposure } \\
\hline Yes & 2323 & 997 (42.9) & 2958 & $748(25.3)$ & 1651 & $175(10.6)$ & 6932 & $1920(27.7)$ \\
\hline No & 1271 & $487(38.3)$ & 272 & $28(10.3)$ & 1258 & $113(9.0)$ & 2801 & $628(22.4)$ \\
\hline$p$ valuet & & 0.007 & & $<0.001$ & & 0.148 & & $<0.001$ \\
\hline \multicolumn{9}{|c|}{ Lifetime cumulative effective sun exposure } \\
\hline $1^{\text {st }}$ quintile & 468 & $166(35.5)$ & 912 & 180 (19.7) & 567 & $38(6.7)$ & 1947 & $384(19.7)$ \\
\hline $2^{\text {nd }}$ quintile & 506 & $188(37.2)$ & 1186 & $277(23.4)$ & 253 & $15(5.9)$ & 1945 & $480(24.7)$ \\
\hline $3^{\text {rd }}$ quintile & 649 & $248(38.2)$ & 682 & $179(26.3)$ & 616 & $50(8.1)$ & 1947 & $477(24.5)$ \\
\hline $4^{\text {th }}$ quintile & 840 & 334 (39.8) & 347 & $102(29.4)$ & 760 & $79(10.4)$ & 1947 & $515(26.5)$ \\
\hline $5^{\text {th }}$ quintile & 1131 & $548(48.5)$ & 100 & $37(37.0)$ & 711 & 106 (14.9) & 1942 & $691(35.6)$ \\
\hline$p$ valuet & & $<0.001$ & & $<0.001$ & & $<0.001$ & & $<0.001$ \\
\hline \multicolumn{9}{|c|}{ Protective eye gear/ head gear use } \\
\hline Yes & 3533 & 1461 (41.4) & 3015 & $728(24.2)$ & 2900 & $288(9.9)$ & 9448 & $2477(26.2)$ \\
\hline No & 61 & $23(37.7)$ & 214 & $48(22.4)$ & 8 & $0(0.0)$ & 283 & $71(25.1)$ \\
\hline$p$ valuet & & 0.566 & & 0.570 & & 0.348 & & 0.670 \\
\hline
\end{tabular}




\section{SYSTEMIC RISK FACTORS}

\section{Diabetes Mellitus}

$\begin{array}{lcccccccc}\text { Yes } & 206 & 96(46.6) & 166 & 42(25.3) & 460 & 53(11.5) & 832 & 191(23.0) \\ \text { No } & 3365 & 1379(41.0) & 2995 & 714(23.8) & 2381 & 231(9.7) & 8741 & 2324(26.6) \\ p \text { valuet } & & 0.112 & & 0.667 & & 0.234 & 0.023\end{array}$

\section{Hypertension}

Yes

130

No

$2254 \quad 849(38.0) \quad 2061$

311 (28.5)

1247

102 (8.2) 3695

1038 (28.1)

$p$ valuet

$<0.001$

459 (21.7)

1599

$183(11.4) \quad 5914$

1484 (25.1)

Body Mass Index

$<25 \mathrm{~kg} / \mathrm{m}^{2}$

$2553 \quad 1087(42.6) \quad 2686$

$<0.001$

0.004

0.001

$\geq 25 \mathrm{~kg} / \mathrm{m}^{2}$

$1002 \quad 378(37.7) \quad 456$

635 (23.6) 1743

$220(12.6)$

6974

$1942(27.8)$

$p$ value ${ }^{\dagger}$

0.008

0.597

$51(5.2)$

2423

542 (22.4)

764

765

Note: * values represent number of participants with DED and row \%; + p-value calculated using chi-square test 

of dry eye disease with various risk factors

\begin{tabular}{|c|c|c|c|c|c|c|c|c|}
\hline & \multicolumn{2}{|c|}{$\begin{array}{c}\text { Delhi-NCR } \\
\text { (Northern Plains) } \\
n=3595\end{array}$} & \multicolumn{2}{|c|}{$\begin{array}{c}\text { Guwahati } \\
\text { (North-eastern Hilly) } \\
n=3231\end{array}$} & \multicolumn{2}{|c|}{$\begin{array}{l}\text { Prakasam } \\
\text { (Southern Coastal) } \\
n=2909\end{array}$} & \multicolumn{2}{|c|}{$\begin{array}{l}\text { All Centers } \\
n=9735\end{array}$} \\
\hline & OR (95\% Cl) & $p$ value & OR (95\% Cl) & $p$ value & OR $(95 \% \mathrm{Cl})$ & $p$ value & OR $(95 \% \mathrm{Cl})$ & $p$ value \\
\hline \multicolumn{9}{|l|}{ Gender } \\
\hline Male & 1 & - & 1 & - & 1 & - & 1 & - \\
\hline Female & $1.0(0.8,1.3)$ & 0.889 & $1.4(1.1,1.7)$ & 0.001 & $0.8(0.4,1.5)$ & 0.462 & $1.2(1.0,1.4)$ & 0.017 \\
\hline \multicolumn{9}{|l|}{ Smoking } \\
\hline No & 1 & - & 1 & - & 1 & - & 1 & - \\
\hline Yes & $1.3(1.1,1.6)$ & $<0.001$ & $1.0(0.8,1.3)$ & 0.739 & $0.7(0.5,1.1)$ & 0.107 & $1.2(1.0,1.3)$ & 0.019 \\
\hline \multicolumn{9}{|l|}{ Indoor Smoke } \\
\hline No & 1 & - & 1 & - & 1 & - & 1 & - \\
\hline Yes & $1.4(1.1,1.7)$ & 0.014 & $2.7(1.8,4.2)$ & $<0.001$ & $1.6(0.8,3.1)$ & 0.144 & $1.3(1.1,1.5)$ & 0.006 \\
\hline \multicolumn{9}{|c|}{ Lifetime Cumulative Effective Sun Exposure } \\
\hline $1^{\text {st }}$ quintile & 1 & - & 1 & - & 1 & - & 1 & - \\
\hline $2^{\text {nd }}$ quintile & $1.1(0.8,1.4)$ & 0.640 & $1.3(1.0,1.6)$ & 0.043 & $0.8(0.4,1.6)$ & 0.603 & $1.2(1.0,1.4)$ & 0.056 \\
\hline $3^{\text {rd }}$ quintile & $1.1(0.9,1.4)$ & 0.459 & $1.5(1.1,1.9)$ & 0.002 & $1.0(0.7,1.7)$ & 0.861 & $1.3(1.1,1.5)$ & 0.005 \\
\hline $4^{\text {th }}$ quintile & $1.1(0.9,1.4)$ & 0.382 & $1.8(1.3,2.4)$ & $<0.001$ & $1.5(1.0,2.3)$ & 0.072 & $1.4(1.2,1.6)$ & $<0.001$ \\
\hline $5^{\text {th }}$ quintile & $1.5(1.2,1.9)$ & 0.001 & $2.8(1.7,4.5)$ & $<0.001$ & $2.1(1.3,3.2)$ & 0.001 & $1.8(1.5,2.2)$ & $<0.001$ \\
\hline \multicolumn{9}{|l|}{ Diabetes Mellitus } \\
\hline No & 1 & - & 1 & - & 1 & - & 1 & - \\
\hline Yes & $1.2(0.9,1.6)$ & 0.205 & $1.0(0.7,1.5)$ & 0.980 & $1.8(1.3,2.6)$ & 0.001 & $1.2(1.0,1.5)$ & 0.031 \\
\hline \multicolumn{9}{|l|}{ Hypertension } \\
\hline No & 1 & - & 1 & - & 1 & - & 1 & - \\
\hline Yes & $1.5(1.3,1.7)$ & $<0.001$ & $1.3(1.1,1.5)$ & 0.009 & $0.7(0.5,0.9)$ & 0.003 & $1.3(1.2,1.4)$ & $<0.001$ \\
\hline \multicolumn{9}{|l|}{ BMI } \\
\hline$<25 \mathrm{~kg} / \mathrm{m}^{2}$ & 1 & & 1 & & 1 & & 1 & \\
\hline$\geq 25 \mathrm{~kg} / \mathrm{m}^{2}$ & $0.8(0.7,0.9)$ & 0.009 & $1.0(0.8,1.3)$ & 0.923 & $0.4(0.3,0.6)$ & $<0.001$ & $0.8(0.7,0.9)$ & $<0.001$ \\
\hline \multicolumn{9}{|l|}{ Site } \\
\hline Delhi NCR/Plain & - & & - & & - & & 1 & - \\
\hline Guwahati/Hilly & - & & - & & - & & $0.5(0.4,0.6)$ & $<0.001$ \\
\hline Prakasam/Coastal & - & & - & & - & & $0.2(0.1,0.2)$ & $<0.001$ \\
\hline \multicolumn{9}{|c|}{ Footnotes } \\
\hline \multicolumn{9}{|c|}{$\begin{array}{l}\text { Note: Only participants with dry eye disease on clinical evaluation were assessed and participants } \\
\text { with no dry eye disease were included as controls. OR=Odd Ratio; Cl=Confidence Interval; NCR- } \\
\text { National capital region. }\end{array}$} \\
\hline
\end{tabular}


778 Table 6: Review of literature of studies evaluating environmental risk factors for Dry Eye Disease (DED)

\begin{tabular}{|c|c|c|c|c|c|c|c|c|c|c|}
\hline Author & $\begin{array}{l}\text { Type of } \\
\text { Study }\end{array}$ & $\begin{array}{l}\text { Sample } \\
\text { Size }\end{array}$ & $\begin{array}{l}\text { Site of } \\
\text { Study }\end{array}$ & Study population & $\begin{array}{l}\text { Age } \\
\text { (mean) }\end{array}$ & $\begin{array}{l}\text { Gender } \\
\text { (M/F) }\end{array}$ & $\begin{array}{l}\text { Diagnostic } \\
\text { criteria }\end{array}$ & Prevalence & Risk Factors Assessed & Results \\
\hline $\begin{array}{l}\text { Um et } \\
\text { al.[6], } \\
2014\end{array}$ & $\begin{array}{l}\text { Population } \\
\text { based } \\
\text { Cross- } \\
\text { sectional } \\
\text { study }\end{array}$ & 16,431 & $\begin{array}{l}\text { South } \\
\text { Korea }\end{array}$ & $\begin{array}{l}>30 \text { years age of } \\
\text { the } 5 \text { th KNHANES }\end{array}$ & NA & $43: 57$ & $\begin{array}{l}\text { Previously } \\
\text { diagnosed } \\
\text { by } \\
\text { ophthalmo } \\
\text { logist with } \\
\text { presence } \\
\text { of } \\
\text { symptoms }\end{array}$ & $\begin{array}{l}10.4 \% \\
\text { (Diagnosed } \\
\text { cases) } \\
17.7 \% \\
\text { (Symptom } \\
\text { s only) }\end{array}$ & $\begin{array}{l}\text { Age, gender, sunshine } \\
\text { exposure, region } \\
\text { (urban/rural), city size, } \\
\text { temperature, wind } \\
\text { speed, humidity, } \\
\text { sunshine duration, } \\
\text { precipitation, air } \\
\text { pollutants ( } \mathrm{SO}_{2}, \mathrm{NO}_{2} \text {, } \\
\mathrm{CO}, \text { Ozone, } \mathrm{PM} 10 \text { ) }\end{array}$ & $\begin{array}{l}\text { Positive association } \\
\text { Age } \\
\text { Female gender } \\
\text { Urban area } \\
\text { Higher temperature } \\
\text { Longer sunshine } \\
\text { Air pollutant- } \mathrm{SO}_{2} \\
\text { Negative association } \\
\text { Humidity }\end{array}$ \\
\hline $\begin{array}{l}\text { Galor } \\
\text { et } \\
\text { al.[48], } \\
2014\end{array}$ & $\begin{array}{l}\text { Retrospect } \\
\text { ive study }\end{array}$ & $3,410,000$ & USA & $\begin{array}{l}\text { Patients with ICD- } \\
9 \text { code for DED in } \\
\text { Veterans } \\
\text { Administration } \\
\text { eye between } \\
2006-2011\end{array}$ & NA & NA & NA & $19.6 \%$ & $\begin{array}{l}\text { AOD, } \\
\text { Atmospheric pressure, } \\
\text { Humidity, } \\
\text { temperature }\end{array}$ & $\begin{array}{l}\text { Positive association } \\
\text { Air pollution } \\
\text { Air pressure } \\
\text { Longitude } \\
\text { Latitude } \\
\text { Negative association } \\
\text { Wind speed } \\
\text { Humidity }\end{array}$ \\
\hline $\begin{array}{l}\text { Zhong } \\
\text { et } \\
\text { al.[49], } \\
2018\end{array}$ & $\begin{array}{l}\text { Retrospect } \\
\text { ive study }\end{array}$ & 25,818 & Taiwan & $\begin{array}{l}\text { Patients with ICD- } \\
9 \text { code for DED at } \\
\text { National Health } \\
\text { Insurance of } \\
\text { Taiwan from } 2004 \\
\text { to } 2013\end{array}$ & $\begin{array}{l}51.1 \pm 17.7 \\
\text { years }\end{array}$ & $31: 69$ & NA & - & $\begin{array}{l}\text { Air pollutants - } \mathrm{CO} \text {, } \\
\mathrm{NO}_{2}, \text { Ozone, } \mathrm{PM} 2.5, \\
\mathrm{PM}_{10} \text {, and } \mathrm{SO}_{2} \text {, and } \\
\text { meteorological data, } \\
\text { Relative humidity and } \\
\text { temperature }\end{array}$ & $\begin{array}{l}\text { Positive association } \\
\text { Age } \\
\text { Female gender } \\
\text { Air pollution - } \mathrm{CO}, \mathrm{NO}_{2} \\
\text { Temperature } \\
\text { Negative association } \\
\text { Relative humidity }\end{array}$ \\
\hline $\begin{array}{l}\text { Yu et } \\
\text { al.[50] } \\
\text { A, 2019 }\end{array}$ & $\begin{array}{l}\text { Hospital } \\
\text { based } \\
\text { cross } \\
\text { sectional } \\
\text { study }\end{array}$ & 23,922 & China & $\begin{array}{l}\text { Cases presenting } \\
\text { to ophthalmology } \\
\text { clinics in China } \\
\text { between July to } \\
\text { December } 2013\end{array}$ & NA & $49: 51$ & $\begin{array}{l}\text { Chinese } \\
\text { dry-eye } \\
\text { diagnostic } \\
\text { criteria* }\end{array}$ & $61.6 \%$ & $\begin{array}{l}\text { Age, gender, history of } \\
\text { kerato-refractive } \\
\text { surgery, history of } \\
\text { diseases (DM, arthritis } \\
\text { and thyroid diseases), } \\
\text { medication history, air }\end{array}$ & $\begin{array}{l}\text { Positive association } \\
\text { Age } \\
\text { Female gender } \\
\text { History of kerato- } \\
\text { refractive surgery } \\
\text { Arthritis, thyroid disease }\end{array}$ \\
\hline
\end{tabular}




\begin{tabular}{|c|c|c|c|c|c|c|c|c|c|c|}
\hline & & & & & & & & & $\begin{array}{l}\text { pollutant data (CO, } \\
\mathrm{NO}_{2}, \text { Ozone, } \mathrm{PM} 10 \text {, } \\
\left.\mathrm{PM}_{2.5}, \mathrm{SO}_{2}\right) \text {, relative } \\
\text { humidity, mean air } \\
\text { pressure, and air } \\
\text { temperature }\end{array}$ & 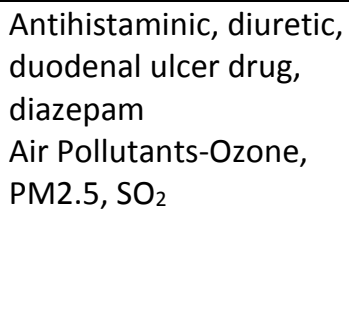 \\
\hline $\begin{array}{l}\text { Current } \\
\text { study }\end{array}$ & $\begin{array}{l}\text { Population } \\
\text { based } \\
\text { Cross- } \\
\text { sectional } \\
\text { study (part } \\
\text { of ICMR- } \\
\text { EYE SEE } \\
\text { Study) }\end{array}$ & 9,735 & $\begin{array}{l}\text { India- } \\
\text { Plain/ } \\
\text { Delhi } \\
\text { NCR, } \\
\text { Hilly/G } \\
\text { uwaha } \\
\text { ti, } \\
\text { Coastal } \\
\text { /Praka } \\
\text { sam }\end{array}$ & $\begin{array}{l}\text { Population with } \\
\text { age } \geq 40 \text { years }\end{array}$ & $\begin{array}{l}54.5 \pm 0.1 \\
\text { years }\end{array}$ & $46: 54$ & $\begin{array}{l}\text { TFOS- } \\
\text { DEWS II } \\
\text { diagnostic } \\
\text { criteria } \\
\text { (OSDI } \geq 13 \\
\text { and } \\
\text { TBUT<10 } \\
\text { or ocular } \\
\text { surface } \\
\text { staining> } 5 \\
\text { corneal } \\
\text { spots/>9 } \\
\text { conjunctiv } \\
\text { al spots) }\end{array}$ & $\begin{array}{l}26.2 \% \\
\text { (TBUT <10- } \\
34.5 \% ; \\
\text { Schirmer I } \\
<5-27.5 \% \text {; } \\
\text { Ocular } \\
\text { surface } \\
\text { staining - } \\
1.7 \% ; \\
\text { OSDI } \geq 13 \text { - } \\
65.4 \% \text { ) }\end{array}$ & $\begin{array}{l}\text { Age, Gender, } \\
\text { Occupation, DM, HTN, } \\
\text { life-time cumulative } \\
\text { effective sun-exposure, } \\
\text { smoking, indoor } \\
\text { smoke, ultra-violet } \\
\text { radiation, humidity, } \\
\text { temperature, air } \\
\text { pollution }(\mathrm{AOD}, \mathrm{AQ} \text {, } \\
\left.\mathrm{PM} 10, \mathrm{SO}_{2}, \mathrm{NO}_{2}\right) \text {, }\end{array}$ & $\begin{array}{l}\text { Positive association } \\
\text { Age } \\
\text { Female gender } \\
\text { HTN } \\
\text { Lifetime cumulative } \\
\text { effective sun-exposure } \\
\text { Smoking } \\
\text { Indoor smoke } \\
\text { Negative association } \\
\text { Site of residence (hills \& } \\
\text { coastal region) } \\
\text { Possible positive } \\
\text { association } \\
\text { Air pollution - NO }{ }_{2} \text {, } \\
\text { PM10, AQI, AOD } \\
\text { Possible negative } \\
\text { association } \\
\text { Humidity } \\
\text { Temperature } \\
\text { Wind speed }\end{array}$ \\
\hline
\end{tabular}

* (1) presence of at least one of the six symptoms: dry sensation, foreign body sensation, burning sensation, eyesight fatigue, discomfort and vision fluctuation; (2) TBUT $\leq 5 \mathrm{~s}$ or $\mathrm{Schirmer}$ I test $\leq 5 \mathrm{~mm} / 5 \mathrm{~min}$; (3) a positive diagnosis of fluorescein staining accompanied by one of the results: $5 \mathrm{~s}<\mathrm{TBUT} \leq 10 \mathrm{~s}$ or $5 \mathrm{~mm} / 5 \mathrm{~min}<\mathrm{Schirmer}$ I test $\leq 10 \mathrm{~mm} / 5 \mathrm{~min}$. The presence of (1) was essential for disease diagnosis. Subjects showing the presence of a combination of (1) and (2), or (1) and (3) were diagnosed with DED.

Footnotes: KNHANES - Korea National Health and Nutrition Examination Survey; $\mathrm{SO}_{2}$ - Sulphur dioxide; $\mathrm{NO}_{2}$ - Nitrogen dioxide; $\mathrm{CO}$ - Carbon mono-oxide; PM10 - Particulate matter 10 um; ICD - International classification of disease; DED - Dry eye disease; AOD- aerosol optical depth; PM2.5 - Particulate matter $2.5 \mu$ m; NCR- National capital region; DM - Diabetes mellitus; OSDIOcular Surface Disease Index; TBUT- Tear break up time; HTN -Hypertension; AQI-Air quality index. 
Supplementary Table 1: Demographic profile of the participant and non-participant population of the study

789

\begin{tabular}{lccc}
\hline & $\begin{array}{c}\text { Non-Participant } \\
\mathbf{n}(\%)\end{array}$ & $\begin{array}{c}\text { Participant } \\
\mathbf{n}(\%)\end{array}$ & $\begin{array}{c}\text { Overall } \\
\mathbf{n}(\%)\end{array}$ \\
\hline Age group & & & \\
$40-49$ & $1,169(22.6)$ & $3,998(77.4)$ & $5,167(100)$ \\
$50-59$ & $610(20)$ & $2,437(80)$ & $3,047(100)$ \\
$60-69$ & $320(13.9)$ & $1,981(86.1)$ & $2,301(100)$ \\
$\geq 70$ & $189(12.5)$ & $1,317(87.5)$ & $1,506(100)$ \\
Gender & & & \\
Male & $1614(26.7)$ & $4426(73.3)$ & $6040(100)$ \\
Female & $674(11.3)$ & $5307(88.7)$ & $5981(100)$ \\
& & & \\
Study Site & & & \\
Delhi & $758(17.4)$ & $3595(84.6)$ & $4353(100)$ \\
Guwahati & $911(22)$ & $3229(78)$ & $4140(100)$ \\
Prakasam & $619(17.5)$ & $2909(82.5)$ & $3528(100)$ \\
\hline
\end{tabular}


Supplementary Table 2: A gender wise multi-logistic regression analysis showing association of DED with various risk factors

795

\begin{tabular}{|c|c|c|c|c|}
\hline & \multicolumn{2}{|c|}{$\begin{array}{c}\text { Male } \\
n=4314\end{array}$} & \multicolumn{2}{|c|}{$\begin{array}{l}\text { Female } \\
n=5143\end{array}$} \\
\hline & OR $(95 \% \mathrm{Cl})$ & p value & OR $(95 \% \mathrm{Cl})$ & p value \\
\hline \multicolumn{5}{|l|}{ Smoking } \\
\hline No & 1 & - & 1 & - \\
\hline Yes & $1.2(1.0,1.4)$ & 0.112 & $1.1(0.9,1.4)$ & 0.16 \\
\hline \multicolumn{5}{|l|}{ Indoor Smoke } \\
\hline No & 1 & & 1 & \\
\hline Yes & $1.7(1.4,2.0)$ & $<0.001$ & $1.1(0.3,1.4)$ & 0.294 \\
\hline \multicolumn{5}{|c|}{ Lifetime Cumulative Effective Sun Exposure } \\
\hline $1^{\text {st }}$ quintile & 1 & - & 1 & - \\
\hline $2^{\text {nd }}$ quintile & $1.2(0.9,1.5)$ & 0.172 & $1.2(0.9,1.4)$ & 0.168 \\
\hline $3^{\text {rd }}$ quintile & $1.6(1.3,2.1)$ & $<0.001$ & $1.1(0.9,1.4)$ & 0.420 \\
\hline $4^{\text {th }}$ quintile & $1.6(1.3,2.0)$ & $<0.001$ & $1.3(1.1,1.7)$ & 0.013 \\
\hline $5^{\text {th }}$ quintile & $2.1(1.3,268)$ & $<0.001$ & $1.8(1.4,2.3)$ & $<0.001$ \\
\hline \multicolumn{5}{|l|}{ Diabetes Mellitus } \\
\hline No & 1 & - & 1 & - \\
\hline Yes & $1.2(0.9,1.6)$ & 0.226 & $1.3(1.0,1.6)$ & 0.06 \\
\hline \multicolumn{5}{|l|}{ Hypertension } \\
\hline No & 1 & - & 1 & - \\
\hline Yes & $1.3(1.1,1.6)$ & 0.001 & $1.2(1.1,1.4)$ & 0.002 \\
\hline \multicolumn{5}{|l|}{ BMI } \\
\hline$<25$ & 1 & - & 1 & - \\
\hline$>=25$ & $.7(0.5-0.8)$ & $<0.001$ & $0.8(0.7-0.97)$ & 0.021 \\
\hline \multicolumn{5}{|l|}{ Site } \\
\hline Delhi NCR/Plain & 1 & - & 1 & - \\
\hline Guwahati/Hilly & $0.3(0.3,0.4)$ & $<0.001$ & $0.6(0.5,0.7)$ & $<0.001$ \\
\hline Prakasam/Coastal & $0.2(0.1,0.2)$ & $<0.001$ & $0.2(0.1,0.2)$ & $<0.001$ \\
\hline
\end{tabular}


Supplementary Table 3: Multivariate regression analysis showing association of dry eye disease with various risk factors including systolic and diastolic hypertension

801

\begin{tabular}{|c|c|c|c|c|c|c|c|c|}
\hline & $\begin{array}{l}\text { Delh } \\
\mathrm{n}=353\end{array}$ & & $\begin{array}{r}\text { Guwah } \\
n=30\end{array}$ & & $\begin{array}{r}\text { Prakasa } \\
n=262\end{array}$ & & $\begin{array}{r}\text { Overall Pop } \\
n=921\end{array}$ & lation \\
\hline & OR $(95 \% \mathrm{Cl})$ & $p$ value & OR $(95 \% \mathrm{CI})$ & $p$ value & OR $(95 \% \mathrm{CI})$ & $p$ value & OR $(95 \% \mathrm{CI})$ & $p$ value \\
\hline Gender & & & & & & & & \\
\hline Male & 1 & & 1 & & 1 & & 1 & \\
\hline Female & $1.0(0.8,1.3)$ & 0.860 & $1.4(1.1,1.7)$ & 0.001 & $0.8(0.4,1.5)$ & 0.446 & $1.2(1.0,1.4)$ & 0.014 \\
\hline Smokin & & & & & & & & \\
\hline No & 1 & & 1 & & 1 & & 1 & \\
\hline Yes & $1.3(1.1,1.6)$ & $<0.001$ & $1.0(0.8,1.3)$ & 0.811 & $0.7(0.5,1.1)$ & 0.092 & $1.2(1.0,1.3)$ & 0.022 \\
\hline Indoor & & & & & & & & \\
\hline No & 1 & & 1 & & 1 & & 1 & \\
\hline Yes & $1.4(1.1,1.7)$ & 0.012 & $2.7(1.8,4.2)$ & $<0.001$ & $1.6(0.9,3.1)$ & 0.141 & $1.3(1.1,1.5)$ & 0.004 \\
\hline
\end{tabular}

Lifetime Cumulative Effective Sun Exposure

$1^{\text {st }}$ quintile 1

1

$2^{\text {nd }}$ quintile

$3^{\text {rd }}$ quintile

$4^{\text {th }}$ quintile

$5^{\text {th }}$ quintile

Diabetes Mellitus

No

Yes

1

$1.2(0.9,1.7)$

$1.1(0.8,1.4)$

0.524

0.368

$1.2(1.0,1.6)$

$1.5(1.1,1.9)$

$1.8(1.4,2.5)$

$2.9(1.8,4.6)$

1

$0.161 \quad 1.0(0.7,1.5)$

1

No

1

$1.4(1.2,1.6)$

Yes

1

$1.1(0.9,1.4)$

1

$0.8(0.7,0.9)$

$<0.001$

$1.1(0.9,1.4)$

1

0.305

$1.2(0.9,1.6)$

0.290

1

$<25 \mathrm{~kg} / \mathrm{m}^{2}$

$\geq 25 \mathrm{~kg} / \mathrm{m}^{2}$

Site

Delhi NCR/Plain

Guwahati/Hilly

802

Prakasam/Coastal
$0.5(0.5,0.6) \quad<0.001$

$0.2(0.1,0.2)<0.001$ 